\title{
Bile Formation and Secretion
}

\author{
James L. Boyer ${ }^{*}, 1$ \\ ${ }^{1}$ Department of Medicine and Liver Center, Yale University School of Medicine, New Haven, \\ Connecticut
}

\section{Abstract}

Bile is a unique and vital aqueous secretion of the liver that is formed by the hepatocyte and modified down stream by absorptive and secretory properties of the bile duct epithelium. Approximately $5 \%$ of bile consists of organic and inorganic solutes of considerable complexity. The bile-secretory unit consists of a canalicular network which is formed by the apical membrane of adjacent hepatocytes and sealed by tight junctions. The bile canaliculi ( $1 \mu \mathrm{m}$ in diameter) conduct the flow of bile countercurrent to the direction of portal blood flow and connect with the canal of Hering and bile ducts which progressively increase in diameter and complexity prior to the entry of bile into the gallbladder, common bile duct, and intestine. Canalicular bile secretion is determined by both bile salt-dependent and independent transport systems which are localized at the apical membrane of the hepatocyte and largely consist of a series of adenosine triphosphatebinding cassette transport proteins that function as export pumps for bile salts and other organic solutes. These transporters create osmotic gradients within the bile canalicular lumen that provide the driving force for movement of fluid into the lumen via aquaporins. Species vary with respect to the relative amounts of bile salt-dependent and independent canalicular flow and cholangiocyte secretion which is highly regulated by hormones, second messengers, and signal transduction pathways. Most determinants of bile secretion are now characterized at the molecular level in animal models and in man. Genetic mutations serve to illuminate many of their functions.

\section{Introduction}

Bile formation is a unique function of the liver which is vital to survival of the organism. Knowledge of the mechanism of bile formation has progressed rapidly in recent years and has provided the basis for further diagnosis and treatment of cholestatic disorders. Here, we review historical milestones in these developments and summarize current knowledge in this field.

Bile is a complex aqueous secretion that originates from hepatocytes and is modified distally by absorptive and secretory transport systems in the bile duct epithelium. Bile then enters the gallbladder where it is concentrated or is delivered directly to the intestinal lumen. Bile consists of $\sim 95 \%$ water in which are dissolved a number of endogenous solid constituents including bile salts, bilirubin phospholipid, cholesterol, amino acids, steroids, enzymes,

(C) 2013 American Physiological Society

'Correspondence to james.boyer@yale.edu. 
porphyrins, vitamins, and heavy metals, as well as exogenous drugs, xenobiotics and environmental toxins (76). Bile serves a number of important functions. (i) Bile is the major excretory route for potentially harmful exogenous lipophilic substances, noted above, as well as other endogenous substrates such as bilirubin and bile salts whose molecular weights are $>300$ to 500 daltons and not readily filtered or excreted by the kidney. (ii) Bile salts are the major organic solutes in bile and normally function to emulsify dietary fats and facilitate their intestinal absorption. (iii) Bile is the major route for elimination of cholesterol. (iv) Bile protects the organism from enteric infections by excreting immune globulin $\mathrm{A}(\operatorname{Ig} \mathrm{A})$, inflammatory cytokines, and stimulating the innate immune system in the intestine. (v) Bile is an essential component of the cholehepatic and enterohepatic circulation, and finally, (vi) many hormones and pheromones are excreted in bile, and contribute to growth and development of the intestine in some species and provide attractants for the weaning of nonhuman vertebrates.

The importance of bile secretion to the health of the organism becomes most evident when this secretion is impaired by developmental, genetic or acquired cholestatic diseases. This is most dramatically demonstrated by children born with biliary atresia who develop progressive cholestatic liver injury, biliary cirrhosis, and ultimately liver failure and death.

\section{Historical Aspects}

Although the importance of bile has been recognized since antiquity (60) little was known about the fundamental mechanisms that produced this vital secretion until the middle of the 20th century. Knowledge lagged far behind the understanding of other body fluids such as urine. Indeed because bile is a "hidden" secretion, sampling required a surgical laparotomy and cannulation of the common bile duct. Yet the primary secretion is formed by hepatocytes at the level of the bile canaliculus whose $\sim 1 \mu \mathrm{m}$ microscopic dimensions are only clearly visualized by electron microscopy. Thus for many years the scientific literature was largely limited to reports of the chemical composition of bile (508). Since there was no ability to sample or assess the primary source of bile, these analyses were the combined result of hepatocyte bile that was modified further by secretory and absorptive properties of the bile duct epithelium (74).

A mechanistic understanding of biliary secretion in the modern era began with earnest with the work of Ralph Brauer and Ivar Sperber. Brauer was a physiologist who worked for the US Navy. Using the isolated perfused rat liver, he demonstrated that bile was secreted against pressures that exceeded the vascular perfusion pressure (90). Thus bile was not formed by hydrostatic filtration as was urine. This landmark study clearly demonstrated that the formation of bile was an energy dependent process, findings that were later confirmed using metabolic poisons that resulted in inhibition of bile production $(65,70)$.

Sperber was the first to articulate the "osmotic theory of bile formation" in a classic review entitled "Secretion of organic anions in the formation of urine and bile," published in Pharmacological Reviews in 1959 (513). Sperber was a Swedish physiologist who worked at the Royal College of Agriculture in Uppsala. His report was heavily influenced by prior work of many different investigators, particularly early renal physiologists but included his 
own studies of the secretion of phenol red in urine and bile in the anesthetized chicken. Sperber observed that when organic solutes, bile acids and other "cholephiles" were injected intravenously, they were concentrated in bile and stimulated bile flow. A few years earlier, in 1953, Pappenheimer had proposed that water could flow across a semipermeable membrane as a result of the creation of osmotic gradients (429). It is reasonable to assume that Sperber was influenced by this publication and concluded that the concentrative transport of solutes in bile created osmotic gradients that then stimulated the passive diffusion of water (and electrolytes) across the semipermeable canalicular membrane into bile (77). This "Milestone" publication, albeit primarily a review of the work of others, established the following paradigm for the emerging field of biliary secretion upon which all further studies have been based.

"It appears quite possible to assume osmotic filtration as a factor in bile formation. The primary event of bile formation would be the active transfer (from cells or through cells of bile acids and possibly other, though quantitatively less important compounds) into the bile capillaries."

Subsequent investigators began to define the basic mechanisms that generated this secretion. Henry Wheeler and his colleagues (585) were the first to measure the biliary clearance of radiolabled inert solutes such as erythritol or mannitol. These small molecules were believed to enter bile at the level of the bile canaliculus, either across the tight junction barrier or through rapid transcellular pathways in the hepatocytes. Using these techniques of solute clearances, which were originally adopted from studies of renal clearances, Wheeler and subsequent investigators were able to characterize canalicular bile production and distinguish it from fluid secretion formed more distally by the bile duct epithelium (586). These studies led to the recognition that there were both "bile salt-dependent" [bile saltdependent bile flow (BSDF)] and "bile salt-independent" [bile salt-independent bile flow (BSIF)] components of hepatocellular canalicular bile formation, and that there were considerable species differences with respect to the relative contribution of fluid secretion from the bile duct epithelium (76). Initially, these solute clearances were performed in dogs and rats with biliary fistulae, but were subsequently used to quantify the components of bile in patients with in-dwelling t-tubes following routine cholecystectomy (80). These studies estimated that man produced $\sim 750 \mathrm{~mL}$ of bile daily and that $\sim 75 \%$ was formed at the level of the bile canaliculus in the adult. Approximately $50 \%$ of canalicular bile in man was found to be bile salt-dependent while a variable fraction $(25 \%)$ of the daily total production of bile came from the bile ducts in response to the release of secretin induced by meals (80).

At this point, attention was focused on the mechanism of the bile salt-independent component of canalicular bile. There was considerable interest in the role of sodium transport and many biliary physiologists believed that BSIF might be generated by active extrusion of sodium ions into the canalicular lumen. This concept was disproven when histochemical techniques demonstrated that the sodium pump $\left(\mathrm{Na}^{+}, \mathrm{K}^{+}\right.$-ATPase $)$was localized at the basolateral membrane of the hepatocyte $(66,318,541)$ similar to other classical epithelia. This milestone discovery indicated that the liver was physiologically similar to other polarized epithelia with respect to the location of specific transport proteins, despite the unique localization of the apical canalicular membrane encircling the hepatocyte 
like a belt (71). This finding led to the realization that the inwardly directed sodium gradient, generated by the sodium pump, could be utilized as a secondary driving force when coupled to other solutes and provided a mechanistic explanation for the previously demonstrated dependence of hepatic uptake of conjugated bile salts on the presence of sodium ions (29, 567). Thus, as in other cells, the sodium gradient was coupled to move solutes "up-hill" energetically from plasma to the cell interior.

The ability to separate hepatocyte secretory events from those at the level of the cholangiocyte was greatly enhanced by the recognition in 1981 that some hepatocytes, when isolated from the liver by collagenase perfusion, remained attached and formed couplets or triplets which retained apical polarity between the adjacent cells (423). These canalicular lumens expanded with time in culture and provided a novel in vitro model that enabled studies of bile secretion to be made without the confounding effects of blood flow and pressure or the contribution of the bile ducts $(177,178,196)$. Electrophysiological studies, including measurements of the transcanalicular membrane electric potential, confirmed that the sodium pump was electrogenic (197) and that together with potassium channels in the basolateral membrane, generated both chemical and electrical driving forces that could be used for transmembrane transport of organic solutes.

At the same time, the localization of $\mathrm{Na}^{+}, \mathrm{K}^{+}$-ATPase to the basolateral membrane of the hepatocyte led to its use as a biochemical marker of this membrane domain that facilitated the purification of canalicular membrane subfractions from rat liver $(365,369)$. It was a significant advance to be able to isolate purified canalicular membrane subfractions that were relatively uncontaminated by the basolateral membrane because the apical canalicular membrane represents only $\sim 10 \%$ to $15 \%$ of the surface membrane of the hepatocyte. This technical advance then enabled transport functions to be characterized in canalicular membrane vesicles (82), an approach that ultimately led to another major milestone, the recognition that bile salts and other solutes were transported into bile largely by adenosine triphosphate (ATP)-dependent transport mechanisms $(3,393,411,524)$ rather than driven by the cellular electrical potential as originally believed $(367,583)$.

Cell isolation techniques also led to the isolation of purified populations of cholangiocytes $(12,502,533,605)$ and resulted in the finding that they could form spheroids with enclosed lumens when placed in culture (372). These isolated bile duct units (IBDUs) enabled physiologic studies to be performed that characterized the role of hormones such as secretin, bombesin, vasoactive peptide (VIP), and others, as well as the function of ion transporters, in the generation of bicarbonate secretion from this epithelia $(16,74,116,117)$.

Since the 1990s molecular cloning techniques and cellular expression systems revolutionized our understanding of the mechanisms of bile formation and the molecular causes of cholestasis (554). Today most of the major membrane transport proteins that determine both the hepatic uptake of organic solutes as well as bile salt-dependent and bile salt-independent canalicular and cholangiocyte excretion are now characterized at the molecular level. What follows is a summary of the current state of knowledge in this field based largely on these historical milestones. 


\section{Anatomical Determinants of Bile Secretion}

The hepatocyte is a highly polarized cell, whose apical excretory domain represents about $10 \%$ to $15 \%$ of the cell surface area (Fig. 1A). The remaining major portions of the cell membrane consist of the basal membrane that faces the blood sinusoids and contains many microvilli, and the smooth lateral membrane that lines the intercellular space (Fig. 1B). The bile lumen (canaliculus) is very small $(\sim 1 \mu \mathrm{m})$ and is formed between two adjacent hepatocytes whose adjoining apical membranes are sealed by tight junctions (zonula occludens) (26) (Fig. 2A). This is the only physical barrier between the blood and the canalicular lumen (Fig. 1B) and as such determines "paracellular permeabilty" between blood and bile (26). The structure of the tight junction is best visualized in freeze fracture replicas, which reveal a series of four to five cross-linked parallel strands (Fig. 3). These strands are primarily composed of globular proteins known as occludins and claudins (363, 386) (Fig. 2B). Tight junctions hold the hepatocytes together, as well as provide a barrier that prevents bile acids and other large solutes from diffusing from bile, while at the same time allowing the passage of small ions. $\mathrm{Ca}^{2+}$ is needed to maintain this seal. Claudins and occludins are connected to cytoskeletal proteins (ZO-1 and ZO-2) on the cytoplasmic side of the membrane as part of the tight junction complex. This intercellular barrier is negatively charged which facilitates the passage of small ions, particularly sodium, but is impermeant to molecules the size of proteins. During cholestatic liver injury, the tight junction may be disrupted, resulting in regurgitation of bile contents into the intercellular space and dissipation of the intracanalicular osmotic gradients upon which the secretion of bile depends (72).

The apical canalicular membrane surface area is amplified by many microvilli where a number of transport proteins function to export various constituents from the hepatocyte into bile. Many of these export pumps are ATP dependent and members of the ATP-binding cassette $(\mathrm{ABC})$ super family $(407,554)$. Unlike a classical epithelial cell, the apical bile canalicular membrane and bile canaliculus encircle each hepatocyte in belt-like fashion, whose interconnections with other cells can be visualized in three dimensions as a "chickenwire"-like mesh (Fig. 1). Encircling the bile canaliculus on the cytoplasmic submembranous surface are an electron dense array of actin-based microfilaments that are structurally linked to the zonula adherens in the lateral cell membrane and the canalicular microvilli $(440,442)$. Together with myosin- $\mathrm{V}$ these actin filaments function both to stabilize the apical pole of the hepatocytes as well as to enable periodic contractions (canalicular peristalsis) (441). Microtubule arrays extend from apically localized organizing centers to submembranous regions of both basolateral and apical plasma membrane domains. Vesicles (10-20 nm) are prominent in subapical regions of the hepatocyte and move acoss the cell between early (Rab4) and late (Rab11) recycling endosomal compartments attached to microtubules. The myosin-like motor dynein facilitates movement of vesicles toward the minus ends of microtubules at the apical pole, whereas kinesin motors move vesicles toward the positive ends near the basolateral domain (357). Members of the ABC family that reside on the canalicular domain such as the bile salt export pump appear to move from the endoplasmic reticulum (ER) through the Golgi by a direct pathway $(248,279)$, whereas proteins having glycosylphosphatidylinositol anchors or single transmembrane domains initially target to the 
sinusoidal plasma membrane from where they proceed by transcytosis on microtubules to the canalicular domain $(240,481)$.

Hepatocytes are located within a functional unit of the hepatic lobule where bile is formed countercurrent to the direction of blood flow. Hepatocytes that are present in periportal zones of the lobule are exposed to the highest concentrations of bile salts and so are the primary cells involved in bile salt-dependent bile formation. In contrast, more distal cells in the lobule secrete bile that is comparatively bile salt independent. This results in smaller diameters of the canalicular lumen in central zones of the lobule, which increase in size as they approach the portal tracts (320). There they connect with the initial branches of the biliary tree, the canals of Hering. Once secreted into the biliary tree, biliary solutes are exposed to cholangiocytes that form the lining of the bile duct epithelium in the biliary tree. Cholangiocytes are classic epithelial cells but are highly heterogeneous both in structure and function $(12,54)$. Cells in the most proximal ducts are small and cuboidal, while their cytoplasmic/nuclear ratios and size increase in more distal bile ducts. The biliary tree contains $\sim 12$ branches from the common bile duct to form the right and left hepatic ducts, which branch to form the segmental and area ducts and, finally, the small septal ducts $(>100$ $\mu \mathrm{mol} / \mathrm{L}$ diameter $)$, the smaller interlobular ducts $(15-100 \mu \mathrm{mol} / \mathrm{L})$, the ductules $(<15$ $\mu \mathrm{mol} / \mathrm{L}$ ), and the Canals of Hering that drain the bile from the bile canaliculi (54) (see Fig. 9). Transport proteins at the luminal apical membrane of cholangiocytes function to both secrete a bicarbonate-enriched fluid as well as to reabsorb fluid and other solutes from the primary secretion of hepatocytes $(74,261,535)$. The final secretory product flows to the gallbladder and intestine. Considerable species differences exist with respect to the function of cholangiocytes in modifying hepatocyte bile $(74,262)$.

The hepatic artery is the primary blood supply to the bile duct epithelium and surrounds the biliary branches with an anastomosing plexus. While there are variations in cholangiocyte arterial anatomy between species, blood flow in this plexus appears to be directed from small to larger bile duct segments with occasional anastomotic connections with the portal vein vasculature. In contrast, the portal vein provides the primary source of blood for the hepatic parenchymal cells via the hepatic sinusoids. This structural arrangement is thought to provide for a "cholehepatic" circulation, which may allow solutes that are removed from bile by the biliary epithelium to return to the portal circulation for reuptake by the hepatocyte for metabolic use or reexcretion into bile (149). The hypercholeretic properties of Nor-ursodeoxycholic acid are thought to depend on this cholehepatic circulation (599).

Ekataksin has described the hepatic microcirculatory subunit as a cone-like structure where there are fewer sinusoids and parenchymal cells in the distal pericentral zones of the lobule than in the more proximal periportal regions (149). The functional consequence of this anatomical arrangement would restrict the hepatic distribution of solutes that reach this distal pericentral region of the lobule, so that they are more likely to pass through to the systemic circulation. This arrangement may explain in part why canalicular bile stasis is observed predominantly in pericentral regions of the lobule in cholestatic liver injury (149). 


\section{Components of Bile}

A general assessment of the major constituents of bile are listed in Table 1, recognizing that considerable species variations exist. Bile is a highly complex secretion which is aqueous in nature and contains less than 5\% solid contents in most species (86). Bile cannot be sampled at its origin for obvious anatomical reasons but is isoosmotic with respect to plasma when collected from the bile ducts. Bile consists of a variety of organic and inorganic solutes. The latter consist primarily of passively secreted ions whose concentrations in bile are similar for the most part to those in plasma. $\mathrm{HCO}_{3}{ }^{-}$concentrations may be greater in bile than plasma in certain species such as the guinea pig or postprandially as a result of enteric hormones like secretin that stimulate $\mathrm{HCO}_{3}{ }^{-}$and fluid secretion from the bile duct epithelium.

In contrast, organic anions and cations are highly concentrated in bile by active transport mechanisms at the canalicular membrane. The most prevalent organic solutes in bile in all vertebrates are bile salts. The chemistry of bile salts varies greatly among species. Bile salts are 24 carbon water soluble products of cholesterol metabolism. Two primary bile salts are synthesized in mammalian liver: cholic acid, a trihydroxylated bile salt, and chenodeoxycholic acid (CDCA), a dihydroxy bile salt. Each can be conjugated at the side chain with either taurine or glycine. Conjugation metabolizes bile salts into stronger acids which limits their passive reabsorption as they pass down the bilary tree. Intestinal bacteria then produce "secondary bile acids" by converting cholic acid to deoxycholic acid (two hydroxyl groups), while CDCA is metabolized to lithocholic acid, a monohydroxy bile salt. Most of these conjugated bile salts as well as bile salts that are deconjugated by intestinal bacteria are reabsorbed in the distal intestine and undergo an enterohepatic circulation that maintains the bile acid pool. Thus, at least 12 major conjugated primary and secondary bile salt species are contained in human bile, although primary bile salts are usually predominant (468). Secondary bile salts are characteristic of the bile of rabbits. Murine bile contains significant amounts of the more hydrophilic muricholic acid. See Ref. (233) for more details regarding bile acid metabolism. Some lower vertebrates contain 27 carbon bile alcohols where the side chain is hydroxylated and subsequently sulfated. A more detailed discussion of the evolutionary development of bile acids can be found in Refs. $(213-215,234)$.

The transport of bile salts from the liver into the bile canaliculus provides the major osmotic driving force for BSDF. Once excreted into the canaliculus they are rapidly incorporated into mixed micelles consisting of bile salts, phospholipid and cholesterol.

Phosphatidylcholine (PC) is the major phospholipid in bile while cholesterol is the predominant sterol. Very little neutral lipids (diglycerides, triglycerides), or acidic lipids (fatty acids) are found in bile. Bile is the major route for elimination of cholesterol from the body. The formation of micelles acts to maintain cholesterol in solution while at the same time lowering the free (intermicelle) bile salt concentrations. The ability to form micelles greatly reduces the toxic detergent effects of bile salts on the biliary epithelium. This property is best demonstrated in cases where the liver is injured when PC is absent, as in patients with MDR3 mutations (131) and in Mdr2 knockout mice (150). In the intestine, the detergent properties of bile salts facilitate lipid absorption. 
Glutathione (GSH) and oxidized GSH (GSSG), as well as GSH conjugates are other prominent organic solutes in bile $(43,49)$. They are transported into bile by the multidrug resistance protein 2 (MRP2) and are largely responsible for the secretion of canalicular BSIF in most species (47). Bile is the major route of excretion of bilirubin. Bilirubin must first be conjugated with glucuronic acid by uridine glucuronyl transferase in the liver microsomes to form bilirubin mono and diglucuronide conjugates before it can be excreted into the bile by MRP2. Only trace amounts of the highly water insoluble unconjugated bilirubin are present in bile, probably as a result of nonenzymatic hydrolysis of bilirubin monoglucuronide or the result of bacterial glucuronidase enzymes.

Organic cations are also excreted into bile, mostly by the multidrug resistance protein 1 (MDR1) or P-glycoprotein. Many organic cations are drugs and xenobiotics $(371,394)$. Bile is also the major route of excretion of trace metals, particularly arsenic, copper, manganese, lead, mercury, selenium, silver, and zinc $(38,138,283)$. However, for the most part, the mechanisms by which these metals are excreted into bile remain unclear as discussed later (38).

Many proteins are present in bile, but the very high concentrations of interfering substances, particularly lipids and bile salts, and bile's inaccessibility has made proteomic analysis very difficult. This has limited the number of studies and exploration of the bile proteome is still in its infancy. Recent studies have identified over 2500 individual proteins in normal human bile $(50,295)$. Primary interest in proteomics is related to clinically relevant biomarkers, particularly those important in hepatobiliary cancers (154). Most proteins in the bile appear to come from plasma as emphasized by the relative paucity of proteins in bile of the perfused rat liver. Blood to bile transfer occurs by simple diffusion across the semipermeable tight junction paracellular pathway. The inverse ratio between molecular size of proteins found in bile and their bile-plasma ratio supports these conclusions $(316,451)$.

Four proteins, namely secretory $\operatorname{IgA}, \operatorname{IgM}$, hemoglobin, and ceruloplasmin, deviate from this predicted relationship and presumably enter bile as content of intracellular vesicles that fuse with the canalicular membrane. Proteins that are relatively abundant in bile include albumin, hemoglobin/haptoglobin complexes, and apotransferrin. These enter bile via exocytosis of vesicles at the canalicular membrane. IgA is another major protein in bile and contributes to immunological surveillance within the biliary system. Fibroblast growth factor 19 (FGF19), a major inhibitor of bile acid synthesis, is another protein that is present in bile in high concentration compared to plasma. Human gallbladder bile contains $~ 100$-fold higher concentrations of FGF19 than plasma and gallbladder epithelia (613). Explants of gallbladder secrete 500× higher amounts of FGF19 compared to ileal explants (613). FGF19 is also synthesized in human liver where it regulates bile salt synthesis. However, the reason for such high concentrations of FGF19 in bile is not clear (613). Many enzymes are also detectable in bile and originate primarily from lysosomes and the canalicular membrane. Lysosomal enzymes enter bile via exocytosis. Canalicular membrane ectoenzymes are also found in bile, presumably related to the detergent effects of bile salts, and represent $2 \%$ to $3 \%$ of their total content in rat liver (187). Other intracellular enzymes are only detected in bile in trace amounts. 
Peptides and amino acids are also found in bile (316). Glycine, cysteine, and glutamic acid are formed in bile from enzymatic breakdown of the tripeptide GSH by $\gamma$-glutamyl transpeptidase and dipeptidases located on the luminal membranes of the bile canaliculus and bile duct epithelia $(43,44)$. These individual amino acids are partially reclaimed from the bile by specific amino acid transporters that also line the luminal membrane of the bile duct epithelium $(46,388)$. Leukotrienes and their metabolites and other inflammatory cytokines, including tumor necrosis factor (TNF)-a (which is also synthesized in bile duct epithelial cells), appear in bile $(398,453,464)$.

Bile also delivers vitamins to the intestine. The vitamin D metabolite, 25-hydroxyvitamin D, is first formed in the hepatocytes by CYP2R1 $(112,113)$. These metabolites may function in intestinal growth and development in the newborn and in calcium homeostasis in the adult. Folic acid, pyridoxine, and transcobalamin also enter the intestine via the bile. Steroid hormones, estrogens, prolactin, and insulin are other important substances excreted in bile. Bile is also the pathway for excretion of pheromones which play an important role as sexual attractants and suckling in non-human mammals and lower vertebrates, particularly teliost fish and lamprey where bile acid metabolites are thought to account for this function (182, 336). Bile is also the route of excretion of water-insoluble porphyrins, particularly protoporphyrin and coproporphyrin $(67,340)$. For some solutes, such as glucose and phosphate, efficient transport systems on the bile duct epithelium function to reabsorb these bile components prior to delivery to the intestine. These solutes can be detected in bile when the transport systems are impaired during bile duct injury or when supraphysiologic amounts of the substrate are infused $(205,421)$.

\section{Mechanisms of Bile Formation}

Bile is formed by filtration in response to osmotic gradients created by the transport of osmotically active solutes into the bile canalicular lumen. Water and small solutes enter the biliary space passively via solvent drag (514). This process requires energy in the form of ATP, and is not affected by the hydrostatic pressure that comes from blood perfusing the hepatic sinusoids (90).

\section{Determination of BSDF and BSIF}

Figure 4 illustrates the graphic expression of the three major sources of bile. As bile salt excretion increases, bile flow is stimulated. In these types of experiments, BSDF is estimated by extrapolating the linear relationship of bile salt excretion and bile flow to the ordinate since it is not possible to completely deplete bile of bile salts. The magnitude of BSIF is defined where this line intercepts the ordinate while the slope of this line reflects the choleretic potential of the bile salt(s). Canalicular BSIF is estimated by plotting the relationship between bile salt excretion and the clearance of radiolabeled erythritol or mannitol. The linear relationship between bile flow or solute clearance and bile salts will be considerably distorted when choleretics are infused and bile flow rates are rapidly changing, This is because the collected samples may each have different delays in transit time in the biliary dead space between the bile canaliculus and the end of the biliary cannula where bile salts and the radiolabled solute are collected. Corrections that estimate the mean transit 
times for a given sample of bile are required for these relationships to be more accurately expressed [see Ref. (80) for a more detailed treatment of this issue].

\section{Pathway for water entry to bile}

Water can enter the bile canaliculus through transcellular or paracellular pathways (351). Although it has been difficult to accurately quantitate the contributions of these two sources of biliary fluid, it is likely that the majority of water enters bile across the cells. Both the sinusoidal and canalicular plasma membranes of the hepatocyte are permeable to water presumably through aquaporin (AQP) water channels (4). AQP8, a $\sim 34 \mathrm{kDa}$ protein, has been identified on the canalicular membrane in rat, mouse, and human hepatocytes, while $\mathrm{AQP} 9, \mathrm{a} \sim 32 \mathrm{kDa}$ protein is located at the hepatocyte sinusoidal membrane in rat, mouse, pig, and human $(174,351)$. While direct evidence for the role of these water channels in the formation of bile remains unclear, AQPs clearly alter water permeabilty in in vitro studies in the liver (174) and are down regulated in animal models of cholestasis (327). Whether they play a role in human cholestatic disorders is not known $(174,475)$. Although the tight junctions between hepatocytes are classified as "leaky," their surface area is limited compared to the canalicular membrane. The paracellular pathway is negatively charged and serves primarily for the entry of $\mathrm{Na}^{+}$ions and small cations to maintain electroneutrality (89).

A third and highly variable component of bile comes from the bile duct epithelium. In rodents, it comprises less than $10 \%$ of total bile production whereas in humans, it may account for as much as a third of daily bile production. Secretion from cholangiocytes is stimulated by hormones released in the small intestine in responses to meals.

\section{Determination of canalicular bile flow}

To determine the fraction of bile that is derived from the hepatocytes, the concept of solute clearance was adopted from renal physiologists whereby biliary clearances could be calculated using nontransported, nonmetabolizable radiolabeled solutes such as erythritol or mannitol (586). This technique assumes that these small molecules gain entrance to bile primarily, if not entirely, at the level of the bile canaliculus. This assumption must be validated by demonstrating that the biliary clearance of a given solute remains unchanged when cholangiocyte bile is stimulated by hormones such as secretin $(80,584,585)$. With acceptance of this caveat, estimates of the three components of bile can be made (Table 2).

\section{Species variations in bile secretion}

The total amounts and relative contributions of canalicular BSDF and BSIF and cholangiocyte secretions vary considerably among species $(151,586)$ (Table 3 and Figure 5). Rats produce $\sim 100 \mu \mathrm{L} /$ gliver/h almost entirely from hepatocytes. Humans produce an average of $\sim 17 \mu \mathrm{L} / \mathrm{g}$ liver/h of bile each day. In contrast, bile flow in marine elasmobranchs, primitive vertebrates, is $100 \times$ slower than in rodents when expressed per $\mathrm{g}$ of liver $(84,85)$. The choleretic potential of a bile acid is represented by the slope of the BSDF rate in Figures 4 and 5 as microliters of bile produced per $\mu$ mole of excreted bile salt (438). As illustrated in Table 3 , in the rat taurocholate has a choleretic potential of 8 to $15 \mu \mathrm{L}$ bile/ $\mu$ mole bile salt compared with 30 to $40 \mu \mathrm{L} /$ micromole for taurodehydrocholate (81) and more than $40 \mu \mathrm{L} /$ 
$\mu$ mole for ursodeoxycholic acid (148). Taurodehydrocholate does not form micelles and therefore has a greater osmotic activity per $\mu$ mole of excreted bile salt than taurocholate, whose critical micellar concentration is about $6 \mathrm{mmol} / \mathrm{L}$. However Nor-ursodeoxycholic acid, a C-23 bile acid has the highest recorded choleretic activity based on its ability to undergo cholehepatic recycling (599).

Studies of the source of bile flow in humans are derived from patients in whom indwelling biliary cannulas have permitted estimates $(80,447)$. These studies suggest that canalicular bile production is divided evenly between BSDF $(\sim 250 \mathrm{~mL} / 24 \mathrm{~h})$ and BSIF $(\sim 250 \mathrm{~mL} / 24$ h), whereas another third ( $250 \mathrm{~mL} / 24 \mathrm{~h}$ ) comes from the bile duct epithelium (80). In general, species that are intermittent feeders have a larger fraction of bile secreted from the biliary epithelium than those that feed continuously.

\section{Nonosmotic choleretic effects of bile acids}

In addition to their osmotic properties, which are related to the chemical structure of the particular bile salt that determines its critical micellar concentration $(204,599)$, bile salts also have other biologic effects that can affect BSDF and BSIF: (i) bile salts may affect permeability properties of the canalicular membrane or tight junctions. Experiments in the rat and rhesus monkey show that bile salts can modify the canalicular fraction of BSIF (36). In the partially bile duct ligated rat, the increased flux of bile salts through the unobstructed lobes significantly increases the magnitude of BSIF. In the rhesus monkey, changes in the relative order of different rates of taurocholate infusions affect the magnitude of canalicular BSIF such that high rates of infusion followed by low rates result in a larger BSIF than when the order is reversed. Increases in ${ }^{14} \mathrm{C}$-Inulin clearances suggest that permeability in the bile canalicular membrane or paracellular pathway may account for these changes $(36,75)$. (ii) Acute exposure of rats to taurochenodeoxycholic acid, a dihydroxy, more hydrophobic bile acid, increased recovery of ${ }^{3} \mathrm{H}$-methoxyinulin and the ectoenzymes $5^{\prime}$-nucleotidase and phosphodiesterase in subcellular vesicles from liver tissue and bile, consistent with stimulating the rates of vesicle transport into bile (341). (iii) Bile salts can stimulate the targeting of vesicles and transporters to the canalicular domain $(278,280)$ and increase the permeabilty of the tight junction barrier. As the flux of bile salts increases postprandially or with exogenous infusions, hepatocytes are recruited for secretion in more distal regions of the hepatic lobule (320). (iv) Structural changes in the bile canaliculus consisting of increases in canalicular side branching and redundancy of canalicular microvilli have also been observed with freeze fracture replicas after chronic infusion of taurocholate in rats (320). Tubulovesicular transformation can be induced by bile salts in the pericanalicular area. These changes may also provide a partial explanation for bile salt induced changes in the transport maximum for other organic anions including BSP and bilirubin (477). (v) Finally, signal transduction pathways involving calcium signaling induced by bile salts including tauroursodeoxycholate (TUDCA), taurochenodeoxycholate (TCDCA), and taurolithocholate (TLC) can mobilize intracellular calcium stores and induce calcium oscillations (62). TUDCA induces hepatocellular exocytosis, an effect dependent on calcium (63). Pericanalicular calcium signaling mediated by InsP3R2 plays an important role in maintaining bile salt secretion through posttranslational regulation of the bile salt transporter, Bsep, as observed in rat hepatocyte sandwich cultures (296). 
Ursodeoxycholic acid is also "hypercholeretic" compared with the more dominant endogenous rat bile salt, taurocholate, presumably because it is a weak acid with a higher $\mathrm{pK}$ of about 5 (458). At this pK, ursodeoxycholic acid will be protonated in bile, allowing for back diffusion into the bile duct epithelium (534). That physical property may allow this bile salt to undergo a "cholehepatic" circulation so that a certain fraction recycles to the hepatocyte (599). This effect results in a higher apparent choleretic activity than a bile salt such as taurocholate, whose $\mathrm{pK}$ is about 2 . Very little taurocholate is likely to be protonated at the alkaline $\mathrm{pH}$ of bile, minimizing its back diffusion so that the majority of this bile salt is excreted directly. Bile salt uptake and efflux transporters, Asbt and Osta-Ost $\beta$, are also expressed on the luminal and basolateral membranes, respectively, in cholangiocytes and gallbladder epithelium so that transporter-mediated shunting may also occur $(132,590)$. Table 3 compares the choleretic potential of several different bile salts in different species.

\section{Cellular and Molecular Determinants of Bile Formation}

In the last two decades, developments in the fields of cell and molecular biology have resulted in major advances in the understanding of the determinants of bile formation. This section discusses the major properties and functional role of each of these transport proteins and enzymes that contribute to this secretion beginning with mechanisms of hepatic uptake (phase 0 ), followed by a brief description of intracellular events including phase I and phase II metabolism and then focusing on export pumps (phase III) at the canalicular as well as basolateral domain of the hepatocyte.

\section{The hepatocyte}

The major transport systems and enzymes that are expressed in the hepatocyte and contribute to the formation of canalicular bile are listed in Table 4. The location of the membrane transporters is illustrated in Figure 6. Most of these proteins have been characterized at the molecular level from human liver and their functional properties determined in both in vitro and in vivo preparations $(76,152,553,554)$. These transport proteins and enzymes are commonly divided into four main functional groups or "phases," designated as Phase 0 , I, II, and III (78) (Fig. 7). Phase 0 consists of hepatic uptake mechanisms located on the basolateral membrane of the hepatocyte that determine how organic solutes enter the liver. Phase I functions are carried out primarily by intracellular cytochrome $\mathrm{P}_{450}$ enzymes that metabolize (hydroxylate) lipid soluble substrates to facilitate phase II reactions. Phase II reactions consist of enzymes that conjugate many organic compounds with sulfate, glucuronides, GSH or acetyl groups to increase their aqueous solubility and enable these substances to be substrates for phase III transporters. Phase III transporters are export pumps that function to extrude these solutes out of the hepatocytes into bile or back into the systemic circulation. For the purpose of this review on bile formation, the focus will be primarily on Phase 0 and Phase III transporters.

\section{Phase 0 organic solute uptake by basolateral membrane transporters}

Transport systems at the basolateral, sinusoidal domain of the hepatocyte facilitate the selective uptake of various albumin-bound organic anions, cations, and neutral compounds that are excreted into bile. 
Sodium-taurocholate cotransporting polypeptide (SLC10A/SIc10a)-The sodium-taurocholate cotransporting polypeptide is the primary mechanism for the hepatic uptake of conjugated bile salts from sinusoidal blood. Sodium-taurocholate cotransporting polypeptide (NTCP/Ntcp) was the first member of the SLC10 family to be identified at the molecular level using expression cloning technologies with Xenopus oocytes $(207,212)$. NTCP is a sodium coupled transporter that derives its energy from the sodium gradient maintained by the ATP-dependent sodium pump, $\mathrm{Na}^{+} / \mathrm{K}^{+}$-ATPase. The sodium pump is also localized to the basolateral membrane and is expressed throughout the hepatic lobule (66, $318,541)$. The sodium pump establishes two important driving forces for hepatic uptake transport mechanisms: (1) an inwardly directed chemical gradient for $\mathrm{Na}^{+}$, where $3 \mathrm{Na}^{+}$ions are exchanged for $2 \mathrm{~K}^{+}$ions, resulting in intracellular concentrations of these cations of about 15 and $130 \mathrm{mEq}$ per liter, respectively, as well as (2) an intracellular negative electrical gradient of about -35 to $-40 \mathrm{meV}$ (197). The outward conductance of $\mathrm{K}^{+}$via $\mathrm{K}^{+}$ channels in the basolateral membrane further contributes to the regulation of this negative membrane potential. Together, the chemical and electrical gradients produced by the sodium pump are able to move solutes into the hepatocyte against their concentration gradients, a process known as secondary active transport.

NTCP is a prototypical secondary active transporter. During fasting, the concentrations of bile salts in sinusoidal blood are approximately 10 to $20 \mu \mathrm{mol} / \mathrm{L}$, but rise significantly in response to stimulation of the enterohepatic circulation of bile salts by feeding. This transporter has a high affinity for bile salts: the $K_{\mathrm{m}}$ for human and rat isoforms are $\sim 6$ and 25 $\mu \mathrm{mol} / \mathrm{L}$, respectively, as originally expressed in oocytes (212) but vary considerably in subsequent published reports (521). Bile acid uptake by NTCP results in a high first-pass clearance so that little passes into the systemic circulation. However during feeding, the flux of bile salts from the intestine increases in the portal and sinusoidal circulation resulting in recruitment of hepatocytes for bile acid uptake in pericentral as well as periportal zones of the liver lobule and resulting in increases in the concentration of bile salts spilling over into the systemic circulation (101). NTCP/Ntcps belong to the SLC10 family of $\mathrm{Na}^{+}$-solute symporters, which also include sodium-dependent bile salt transporters in the ileum (124, 589), renal proximal convoluted tubule (124), and apical membrane of bile duct epithelial cells (321). The human liver NTCP is a 349-amino-acid, 50-kD glycoprotein with seven transmembrane spanning domains, while rat liver Ntcp is a 362-amino-acid, 51-kD glycoprotein. Ntcps are expressed only in mammalian hepatocytes and is first detected in developing rat liver immediately prior to birth (83). Small amounts of mRNA have been detected in rodent kidney, pancreatic acinar cells, and placenta but their functional significance is not clear. Substrate specificity is primarily limited to bile salts, particularly conjugated bile salts, but can accommodate some drugs like the statin, rosuvastatin, as well as estrone-3- $\mathrm{SO}_{4}$ and bromosulfophathalein (521). Ntcps account for most if not all of the sodium-dependent hepatic uptake of conjugated bile salts. Although microsomal epoxide hydrolase has been proposed as an alternative sodium dependent bile acid uptake transporter (570) the elimination of uptake of bile salts in liver mRNA injected Xenopus oocytes by antisense oligonucleotides to Ntcp suggests otherwise (211). 
NTCP expression is regulated in several physiologic conditions including pregnancy (33) and cholestasis (175). Retinoids stimulate expression by binding to retinoid- $X$ nuclear receptor/retinoic acid receptor (RXR/RAR) in the promoter region of the rodent liver Ntcp gene that also contains a TATA element, a hepatocyte nuclear factor-binding site (HNF1), and a response element for cytokines (264). Bile salts regulate the expression of Ntcp indirectly via the nuclear receptor farnesoid X-receptor (Fxr) which in turn stimulates expression of the short heterodimer protein, Shp, which in turn blocks the effects of RXR/RAR binding to the Ntcp promoter (137). Bile salts may also affect the function of HNF1 (255). Ntcp expression can be rapidly upregulated posttranscriptionally by cyclic adenosine monophosphate (cAMP) (392) which stimulates insertion of vesicles containing Ntcp into the plasma membrane $(27,28)$. Ntcp is also downregulated by a number of other conditions including estrogens (499), bile duct ligation (175), endotoxin (200, 389, 587), and pregnancy $(1,33)$. Prolactin, by contrast, upregulates Ntcp transcription by a Stat-5dependent tyrosine phosphorylation signal transduction pathway $(172,173)$, despite its downregulation during pregnancy. Endotoxin downregulates transcription by activating cytokine production which diminishes the activity of several other transcription factors including HNF1 and the RXR and its heterodimeric partner, RAR (136). For more details on transcriptional and posttranscriptional regulation of NTCP see Ref. (13).

\section{Organic anion transporting polypeptides (superfamily SLCO) (formerly} SLC21A, the OATP/Oatps)-Unlike conjugated bile salts, unconjugated bile salts are taken up by the liver at the hepatocyte basolateral sinusoidal membrane by sodiumindependent mechanisms on carriers from the SLCO superfamily, originally known as organic anion transporting polypeptides or organic anion transporting polypeptides (OATPs) $(418,469)$. OATP/Oatps have broad substrate specificity and facilitate sodium-independent hepatic uptake of many different organic amphipathic compounds without respect to structure or electrical charge that are primarily large hydrophilic organic anions $(206,208$, 209). The OATP/Oatps are predicted to have 12 transmembrane domains with intracellular amino and carboxy termini. OATP/Oatps function as electroneutral anion exchangers and are thought to transport bile salts and other solutes in exchange for intracellular anions such as $\operatorname{GSH}(333,334)$ and bicarbonate $(479)$, although more study is needed to confirm these data. There are eleven human OATPs that are divided into six families (OATP1-OATP6). Four OATPs have been functionally identified in human liver and many are also expressed in other tissues. The four OATPS that have been functionally identified in human liver include OATP1A2, formerly OATPA, gene symbol SLCO1A2; OATP1B1, formerly OATPC, gene symbol SLCO1B1; OATP1B3, formerly OATP8, gene symbol SLCO1B3; and OATP2B1, formerly OATPB, gene symbol $S L C O 2 B 1$. OATP1B1 and 1B3 are hepatocyte specific and functionally the most important $(210,300,418)$. OATP1B1 is expressed on the basolateral membrane throughout the hepatic lobule in human liver while OATP1B3 is most strongly expressed in pericentral regions of the hepatic lobule. In addition to endogenous substrates (examples include bile salts, thyroid hormones, conjugated steroid hormones, prostaglandins, and bilirubin, as well as cyclic and linear peptides) the OATP/Oatps transport a wide variety of xenobiotics and environmental toxins. Most OATP/Oatp substrates are organic anions with molecular weights greater than 300, but OATP/Oatps also transport cations and neutral compounds. Polymorphisms in OATP1B1 account for 
differences in clearance of drugs, and mutations in this OATP have been described in patients with pravastatin induced rhabdomyolysis $(347,377)$. Polymorphisms in OATP1A2 have been associated with severe reactions to methotrexate (35) while common polymorphisms of OATP1B1 can affect the disposition of irinotecan metabolites resulting in adverse gastrointestinal effects of this drug (415).

In human liver, OATP1A2 is expressed only in cholangiocytes. Its membrane localization remains unclear but it is thought to function in the reabsorption of xenobiotics excreted into bile (326). Table 5 lists some of the more common substrates transported by these OATPS (418). Also see several recent reviews for a more comprehensive discussion of OATP1B1 $(418,540)$.

OATP1B3 transports unconjugated bilirubin from the blood to the liver and variants have been described in patients with neonatal jaundice (242). Conjugated bilirubin is extruded into bile but also back into the sinusoids by MRP3 (564).

OATP/Oatps can be regulated by transcription factors and their expression in rodents is reduced in HNF1a and HNF4a knockout mice $(226,493)$. Human OATP1B1 is also transactivated by HNF1 (254) while OATP1B3 is downregulated by HNF3 $\beta$ (569) and positively regulated by FXR which binds to its promoter (256). OATPs are differentially regulated in human cholestasis: OATP1B1 is down regulated in Sclerosing cholangitis (424). OATP1B 3 is upregulated by bile salts $(210,256)$, while $O A T P 1 A 2$ is unchanged (424). [see Ref. (540) for more details on regulation of OATP/Oatps].

Organic anion transporters OAT/Oat (SLC22 superfamily)-In contrast to the OATPs, OATs (SLC22A) transport smaller and usually hydrophilic organic anions. Like OATPs, OATs are 12 membrane spanning domain proteins that are widely expressed. Oat 2 is most highly expressed in liver based on rodent data (469). OAT2 is exclusively expressed in the liver on the basolateral membrane where it exchanges short chain fatty acids for sulfated conjugates (495). Human OAT2 transcription is dependent on HNF-4a and is downregulated by bile salts via the FXR, short heterodimer partner (SHP) inhibitory pathway (445).

\section{Organic cation transporters OCT1/Oct1; (SLC22A1/SIc22a1) and OCT3/Oct3} (SLC22A3/SIc22a3)—The OCTs are 12 membrane spanning domain electrogenic cation transporters that transport a wide variety of endogenous and exogenous structurally unrelated small organic cations by bidirectional passive facilitated diffusion via their electrochemical gradients $(288,469)$. OCT1 and OCT3 are expressed in human liver on the hepatocyte basolateral membrane. OCT1 was originally cloned from rat kidney, but was found to be expressed primarily in hepatocytes $(100,202)$. OCT1 is a 556-amino-acid, 95$\mathrm{kD}$ protein that facilitates the hepatic uptake of small (type I) organic cations including tetraethylammonium, choline, $N$-methyl-4,5-phenylpyridine and a number of cationic drugs, including antiviral drugs and metformin [see Ref. for a list of substrates (409)]. The expression of OCT1 and 3 are highly variable. Human OCT1 expression is $~ 15$-fold greater than the expression of OCT3 (410). Their substrates largely ovelap although endogenous substrates that are specific for OCT3 include adrenalin, noradrenalin and histamine. OCT1 
transcription is activated by HNF-4a and can be inhibited by SHP (476). OCT proteins contain phosphorylation sites for protein kinase $\mathrm{A}$ (PKA) and protein kinase $\mathrm{C}$ (PKC) but how this affects expression in the liver is not known. Genetic variants of OCT1 (R61C, G401S, 420del, or G465R)) delay the uptake of metformin (498). Variants of OCT3 influence oxaliplatin and lamivudine clearance $(257,381)$. Cholestasis markedly down regulates both human and rodent Oct1 and 3 expression $(135,410)$.

\section{Transcellular bile acid and organic solute transport and metabolism}

Following uptake into the hepatocyte, organic solutes that ultimately are excreted into bile must move across the cell to the apical membrane. This can occur by rapid diffusion in association with cytosolic proteins or in association with intracellular membranes (particularly the ER) or by transcytosis in membrane vesicles associated with microtubules. The hydrophobicity of the compound influences which pathway the solute will take. The more hydrophobic the solute the more it will associate with intracellular membranes rather than the cytosolic proteins $(30,225)$.

After transport into the hepatocyte, bile salts and other hydrophilic anionic substances bind to cytosolic proteins, such as 3a-hydroxylsteroid dehydrogenase (3a-HSD) $(525,526)$, GSH $S$-transferase (539), and liver fatty acid binding protein (L-FABP) (358) and then rapidly diffuse to the canalicular membrane for excretion. 3a-HSD is the most important cytosolic binding protein for bile salts. Indomethacin competes with bile salts for binding to HSD causing bile salts to efflux from hepatocytes (526). In contrast, more lipophilic substrates may associate with intracellular membranes and undergo phase II metabolism before excretion, while organic cations can become sequestered within negatively charged lysosomal structures thus delaying their excretion into bile (225). HNF1 regulates both 3aHSD and L-FABP expression (493) and both of these proteins are induced by bile salts via FXR (500).

Unconjugated bile salts such as cholic acid first shuttle through peroxisomes where conjugation takes place with the amino acids taurine and glcyine (450). A second, more difficult to establish mechanism is diffusion within the lipid bilayer of intracellular membranes and/or vesicles. This presumably occurs primarily in the ER or endosomal membrane compartments. Highly hydrophobic solutes, such as bilirubin, likely follow this pathway prior to conjugation with glucuronic acid which occurs enzymatically within the cisterna of the ER $(611,612)$. A third mechanism is microtubule-dependent vesicular transcytosis $(126,127)$ which is how bulky organic solutes (e.g., class II cations) and proteins such as transferrin, asialoglycoproteins, and polymeric immune globulin A (pIgA) move across the cell to the apical membrane (512). The role of intracellular vesicle transport of bile salts remains controversial, as does a $35 \mathrm{kD}$ bile salt-binding protein identified from human liver $(368,525)$.

$\operatorname{IgA}$ is a well-studied example of a protein that crosses the cell (hepatocytes in the rat and bile duct epithelia in the human) via microtubular-dependent vesicular transcytosis (236, 543). In rodents, pIgA binds to its receptor, secretory component, and is taken up by endocytosis at the basolateral domain of the hepatocyte. Vesicles containing the receptor and the bound ligand then fuse with the early endosomal compartment before budding off in 
transcytotic vesicles attached to the positive ends of microtubules in association with the molecular motor, dynein, a myosin-like ATPase. The IgA containing vesicle then moves toward the negative end of the microtubules to the subapical region of the hepatocyte where it fuses with the subapical endosomal compartment. Here the vesicle is associated with a small guanosine-5'-triphosphate (GTP)-binding protein, Rab3D, that regulates specific steps in intracellular trafficking $(315,349)$. pIgA is then sorted to the canalicular membrane where a protease cleaves secretory component into two smaller fragments (509). The larger 80-kd fragment enters bile together with pIgA. The process of vesicular transcytosis, fusion, and exocytosis is highly regulated by second messengers and by a family of small molecular weight, Ras-like GTP-binding proteins and other members of the soluble N-ethylmaleimidesensitive factor attachment protein receptor (SNARE) protein complex that determine the specificity of vesicle budding and sorting in cells $(470,537)$. The molecular details of these processes still remain unclear in hepatocytes but are likely to be similar to those in yeast and nerve synaptic terminals $(243,401)$.

Canalicular membrane proteins that are glycosylphosphatidylinositol (GPI)-anchored proteins (GPI linkages) are also targeted to the canalicular domain by transcytotic vesicle transport mechanisms $(51,240,559)$. These proteins are sorted in vesicles via an indirect route to the basolateral domain following synthesis in the ER; they are then resorted to the canalicular membrane via the microtubule-dependent transcytotic pathway, which is regulated by various protein kinases and phosphatases $(558,559)$. During cholestatic liver injury, vesicles containing canalicular transport proteins accumulate within the pericanalicular cytoplasm, reflecting the diminished bile excretory capacity $(51,314)$. In contrast, $\mathrm{ABC}$ bile export pumps traffic to the canalicular membrane from the Golgi through direct pathways via an apical submembranous, late endosomal compartment associated with Rablla (573).

\section{Intracellular metabolism of bile salts and other organic anions}

As illustrated in Figure 7, bile salts, particulary hydrophobic potentially toxic secondary bile salts (lithocholate and deoxycholate), and other lipid soluble organic anions like bilirubin and drugs may undergo phase I (Cytochrome P450 3A1) and or phase II (Uridine glucuronyl transferase and sulfatase) metabolism to form water soluble glucuronide and sulfate conjugates. These important metabolic processes enable these compounds to be more readily transported out of the hepatocyte by phase III (MRP2, 3, and 4) export pumps.

Unconjugated bile salts are processed in peroxisomes where they are conjugated with taurine or glycine through the action of the enzyme, bile acid acyl co-A tranferase. See reference (160) for details of the role of peroxisomes in bile salt metabolism. For a detailed account of the enzymes, regulation, and genetics of bile acid synthesis, see reference (473).

\section{Canalicular membrane transporters}

The major determinants of bile flow and bile composition are the transport proteins localized at the apical canalicular domain of hepatocytes (Fig. 6). Most of these canalicular membrane transporters belong to the $\mathrm{ABC}$ superfamily (31) and excrete organic solutes into bile against large concentration gradients of $\sim 1: 100$ to 1:1000 compared with their concentration in 
plasma, a process requiring the expenditure of ATP (407). They consist of MDR1 (ABCB1), also known as P-glycoprotein $(20,189)$, which transports organic cations; MDR3 (ABCB4), a floppase that translocates PC to the outer domain of the canalicular membrane (506); the MRP2 [multispecific organic anion transporter $(A B C C 2)$ ] that transports a variety of drug and other organic conjugates including bilirubin digucuronide $(275,289)$; the bile salt export pump, (BSEP, $A B C B 11$ ) which transport bile salts $(181,412,523)$; the breast cancer resistance protein (BCRP, ABCG2), which transports substrates similar to MRP2 $(216,376)$, and the sterolins 1 and 2, (ABCG5 and ABCG8) which are hetermeric transporters that excrete cholesterol and plant sterols $(195,227,601)$. Other apical membrane transporters include familial intra-heptic cholestasis 1 , (FIC1, ATP8B $)(96,105,286)$ which is an ATPase that functions as a flippase by transferring phosphatidylserine to the inner cytoplasmic face of the canalicular membrane which together with MDR3 maintains apical membrane lipid asymmetry (201) and the multidrug and toxin extrusion transporter, (MATE1, SLC47A1) that uses the proton gradient to extrude cationic substrates (387).

Mutations in many of these apical transporters result in cholestatic liver disease and serve as definitive proof of their critical roles in bile formation and so will also be discussed in this section $(407,554)$.

MDR1/mdr1a+b P-glycoprotein (ABCB1, Abcb1)—MDR1, originally called Pglycoprotein, and its murine homologues, Mdr1a and Mdr1b, were first described in colchicine-resistant Chinese hamster ovary cells (253), where they conferred drug resistance by exporting anticancer drugs out of the cell (484). ABCB1 is expressed on a number of luminal membranes such as the intestine and choroid plexus where it serves a "barrier" function by extruding various drugs and toxins from these cells. Mdr1 and MDR1 were the first $\mathrm{ABC}$ transporters to be localized to the canalicular excretory membrane of the hepatocyte (547) yet its endogenous substrates are still uncertain and no mutations have been described that produce human disease. Nevertheless, studies in knockout mice have demonstrated the importance of this transporter in the biliary excretion of a variety of large hydrophobic compounds, many of which are organic cations, including exogenous and endogenous metabolites, drugs and toxins, hydrophobic peptides, glycolipids, and steroid hormones (482-484). Known as "hydrophobic vacuum cleaners," many substrates of MDR1/Mdr1a and b are amphipathic cationic drugs (type II) such as quinidine, verapamil, and daunorubicin. MDR1 is a 1280-amino-acid, 170-kDa protein. Mdr1a and Mdr1b are 150-kDa mouse homologues of the human MDR1. The Mdr1b appears to be the major canalicular transporter for bulky amphipathic organic cations in mice based on double knockout studies of Mdrla (-/-) and Mdrlb null mice (483), whereas Mdr1a is also expressed in cholangiocytes (184). Recent studies in canalicular membrane vesicles indicate that MDR1 is capable of transporting bile salts but with fivefold lower affinity than the bile salt export pump (309). Unlike most other canalicular membrane transporters, Mdr1a and Mdr1b are usually upregulated in several different forms of liver injury including Spgp (Bsep) null mice (577), bile duct ligation, alpha-1-napthylisothiocyanate administration, and partial hepatectomy $(2,489)$ suggesting that Mdr1 may facilitate bile excretion as part of the adaptive response to cholestasis, at least in mice. MDR1 expression in human liver is quite 
variable. NFkB affects Mdrlb transcription in insulin treated rat hepatoma cells (608) and rodent Mdr1a is inducible by PXR (519).

The multidrug resistance protein 3 (ABCB4/Abcb4)-Despite close homology to MDR1, MDR3/Mdr2 does not confer drug resistance but is a floppase that maintains PC on the external face of the canalicular membrane bilayer $(228,426)$. By doing so, this phospholipid becomes available for excretion into bile and participates in the formation of mixed micelles along with bile salts and cholesterol (504). This important function of MDR3 was established after discovering that deletion of the gene $M d r 2$ in the mouse homolog resulted in the absence of $\mathrm{PC}$ in bile, despite normal biliary bile salt transport capacity $(425,505)$. Over the time, the inability to extrude phospholipids into bile in $\mathrm{Mdr} 2^{-/}$mice results in bile duct proliferation, and progression to biliary cirrhosis, and even the development of liver tumors (361). Mdr2 $2^{-/}$mice are now recognized as a good animal model for sclerosing cholangitis in humans (161). In the absence of phospholipid in bile, the continuous exposure to hydrophobic bile salts is thought to exert direct toxic effects on the apical epithelial membrane of the cholangiocyte, resulting in liver injury. Mdr2 is a $150-\mathrm{kD}$ protein in mice and rats and a $170-\mathrm{kD}$ protein in humans where it is highly expressed on the canalicular membrane. Bile salts are thought to stimulate the excretion of PC in bile by extracting this phospholipid from areas in the outer lipid layer of the canalicular apical membrane where MDR3 has created outpouchings into the bile canaliculus $(427,471)$ (see Fig. 8). Homozyote deficiency of MDR3 would be predicted to produce significant liver disease in humans whereas MDR3 heterozygotes might require a second hit to result in a clinical phenotype. Indeed, homozygous deficiency of MDR3 results in progressive familial intrahepatic cholestasis type 3 (PFIC-3) $(131,134)$ while heterozygosity predisposes women to cholestasis of pregnancy and others to low phospholipid-associated cholelithiasis, a form of cholesterol gallstone disease (129) or drug-induced cholestasis (600). However, other acquired cholestatic liver diseases like primary biliary cirrhosis or sclerosing cholan-gitis have not been associated with MDR3 mutations. (430). Several families of adult patients have been described with MDR3 mutations who present either with progressive idiopathic cholestasis, gallstones, or cholestasis of pregnancy $(247,342,467)$. PFIC3 is distinguished from PFIC1 and 2 by high levels of gamma-glutamyl transferase in the serum as well as the complete absence of phospholipid in bile.

A number of mutations have been described in patients with PFIC3 as well as genetic variants in patients with cholestasis of pregnancy and acquired cholestatic liver disease. However little mechanistic information has been published, although defects in protein trafficking (142) and temperature-sensitive folding defects have been reported (133). Functional studies of MDR3 mutations and single nucleotide polymorphisms (SNPs) have been limited because of the difficulty in measuring phospholipid transport from the inner to the outer leaflet of the plasma membrane and apparent toxicity of PC in transfected cells (407).

MDR3 is a regulated transporter and its expression is upregulated via bile acid activation of FXR (238). 
Familial intrahepatic cholestasis 1 (ATP8B1/Atp8b1)-Familial intrahepatic cholestasis 1 (FIC1), also resides on the canalicular membrane and is a flippase that is responsible for maintaining aminophospholipids on the inner bilayer of the canalicular membrane. It is a type IV P-type ATPase, rather than an ABC transporter and counter balences the canalicular lipid membrane asymmetry established by MDR3 (201). Using positional cloning, Laura Bull first identified a mutant ATP8B1 gene on chromosome 18q21 in patients with PFIC1 and benign recurrent intrahepatic cholestasis 1 (BRIC1) (97). ATP8B1 functions as a complex in association with the accessory protein CDC50 (434). In the absence of this flippase, membrane lipid asymmetry is disrupted and the function of BSEP is impaired leading to cholestasis $(105,435)$. PFIC1 was first described in an Amish family cohort in Pennsylvania whose founder name was Joseph Byler (120). Electron microscopic studies in patients with PFIC1 and in vitro models of FIC1 deficiency demonstrate disruption of the canalicular membrane bilayer $(96,105)$ and luminal accumulation of intracellular membranous material known as Byler's bile (120). Patients with "Byler's disease" have now been described in many countries including clusters of disease in Eastern Greenland Inuits (25).

ATP8B1 is predicted to have ten transmembrane domains and is expressed in a number of tissues in addition to the liver, including small intestine, uterus and pancreas $(97,437)$. Mutations in ATP8B1 produce PFIC1, with low $\gamma$-GT levels, BRIC1, and rare cases of intrahepatic cholestasis of pregnancy (ICP). Presumably, the different clinical phenotypes result from different mutations but this has not been clearly established. However, in vitro expression of constructs with PFIC1, BRIC1, and ICP mutations in Chinese Hamster cells suggest that some PFIC1 mutations fail to interact with CDC50, and all PFIC1 mutations result in complete absence of protein on the plasma membrane. In contrast residual canalicular protein is seen with BRIC1 and ICP mutations (164) and may be partially restored by treatment with 4-phenyl butyrate (566).

Because ATP8B1 is highly expressed in the small intestine, cochlear hair cells, and pancreas, extrahepatic systemic symptoms of diarrhea (346) are often present, as well as sensorineural hearing loss (518) and occasionally pancreatitis (560). Patients undergoing liver transplantation for cirrhosis and end stage liver failure which often develops in the second decade of life in patients with PFIC1, are usually left with these extrahepatic manifestations of PFIC1 deficiency after liver transplantation (346). Unlike PFIC2 where mutations that produce severe disease present with advanced liver disease, the extrahepatic diseases are the more prominent manifestations of severe PFIC1 mutations (439).

\section{Multidrug resistant associated protein 2, previously known as the multispecific organic anion transporter-MRP2/Mrp2 is the major $\mathrm{ABC}$ conjugate} export pump in the canalicular membrane, the primary determinant of BSIF, and the gene, when mutated in humans, results in the Dubin-Johnson syndrome. The Eisai hyperbilirubinemic rat (EHBR) and the Groninger Yellow/transporter deficient rat $\left(\mathrm{TR}^{-}\right)$ strains $(237,250)$ are animal models of Mrp2 deficiency and have provided much information about the function of this important $\mathrm{ABC}$ transporter. Studies in $\mathrm{Mrp2}^{-/-}$mice give similar results $(119,297)$. MRP/Mrp2 functions to transport a large number of different amphipathic, usually multivalent organic anion conjugates from the liver into bile $(69,273$, 
274, 297, 408). The major endogenous substrates for this transporter include bilirubin diglucuronides, GSH conjugates, GSSG, leukotrienes, heavy metals, sulfated and glucuronidated substrates, including bile salts, as well as a variety of different drug conjugates, antibiotics, and a number of other exogenous compounds [see Table 2 in ref (273) and Table 1 in Ref. (408) for a more complete list of substrates].

In rat strains deficient in Mrp2, point mutations lead to a stop codon and inhibition of expression of the Mrp2 protein. Similar mutations in the MRP2 gene are found in the DubinJohnson syndrome $(265,436)$. Some mutations in human MRP2 result in retention in the ER and failure of the protein to traffic to the canalicular membrane (269). MRP2 mutants have significant reductions in BSIF as a result of the inability to excrete GSH, a low-affinity substrate $(40,250,281,432)$.

In hepatocytes, Mrp2 is also localized to intracellular vesicles that are associated with microtubules (512). This intracellular pool of transporters cycles to and from the canalicular membrane in response to both choleretic and cholestatic stimuli, respectively. Dibutyrl cAMP increases bile salt independent bile flow (219) and insertion of Mrp2 protein into the canalicular membrane, increasing the canalicular transport capacity for Mrp2 substrates (461-463). This process can be inhibited by depolymerizing microtubules (461). Recent studies suggest that cAMP-induced MRP2 translocation in hepatic cells is mediated via phosphatidylinositol 3-kinase (PI3K)-independent and mitogen-activated protein kinase kinase 3 (MKK3) mediated activation of p38alpha mitogen-activated proatein kinase (MAPK) (488).

Mrp2 contains Discs-large homologous regions (PDZ binding domains) in its C-terminus that bind to $\mathrm{Na}^{+} / \mathrm{H}^{+}$exchanger regulatory factor 1 (NHERF-1), a PDZ protein that cross links proteins to actin filaments. Nherf-1 knockout mice have reduced expression of Mrp2 at the canalicular membrane and a 50\% reduction in GSH excretion and BSIF, while maintaining normal bile salt excretion (335). Radixin, an apically located Ezrin-radixinmoesin protein (166) is also required for the insertion of Mrp2, as well as other ABC transporters, in the canalicular membrane in rat liver, but does not appear to bind directly to Mrp2 (276, 578). Radixin and ezrin are both independently required for apical expression of human MRP2 in human intestinal Caco-2 cells (596).

In contrast, protein kinase $\mathrm{C}$ agonists counterregulate the activity of cAMP (463) and reduce bile formation in isolated perfused rat livers (122) and the canalicular insertion of membrane proteins in isolated rat hepatocyte couplets (56). Cholestatic liver injury in rats rapidly diminishes Mrp2 protein at the canalicular membrane by retrieval of the transporter into submembranous vesicles induced by bile duct ligation (431), TLC (61, 379), estrogens, (390), endotoxin $(143,299)$, or oxidative stress (462). Estrogen-induced internalization of Mrp2 is independent of microtubule function while its reinsertion is not (391). Many human cholestatic liver diseases also result in internalization of MRP2 as well as other canalicular export pumps emphasizing the importance of this mechanism for maintaining the bile secretory process. (462). Inhibition of transcription of Mrp2 mRNA during cholestasis also results in diminished levels of expression of this transporter, but this is a delayed response compared to its retrieval from the apical membrane $(325,552)$. 
Bile salt export pump (ABCB11/Abcb11)—Prior to the molecular discovery that the sister of P-glycoprotein was the key canalicular membrane bile salt transporter, bile salt transport had been functionally characterized as an ATP-dependent transport system in isolated canalicular membrane vesicles inititally by Nishida (411) and subsequently by three other groups $(3,393,524)$. Originally cloned as a close relative of P-glycoprotein, and thus named the sister of P-glycoprotein (115), the full length rat homolog Abcb11 was ultimately found to function as a bile salt export pump when expressed in an Sf9 insect cell expression system, and thereafter was renamed the bile salt export pump (Bsep) (181). Northern analysis demonstrated that Bsep mRNA was expressed primarily in the liver and subsequently the full length human ortholog of ABCB11 was obtained by positional cloning $(181,412)$ and validated when a series of mutations were associated with patients with PFIC2 (528). Small amounts of RNA have been identified in other tissues but lack confirmation with protein so that the functional significance of these extrahepatic BSEP mRNAs is not certain (521).

The BSEP gene is located on chromosome 2q23-31 and encodes 1321 amino acids. Rodent Bseps are $\sim 80 \%$ identical with their human orthologue. Human BSEP is a glycoprotein containing four putative glycosylation sites and has a MW of $\sim 140$ to $170 \mathrm{kDa}$ $(102,181,412)$. It is predicted to have two transmembrane domains, each with six transmembrane spanning helices [see Ref. (521) for more details].

Interestingly, Bsep knockout mice develop a nonprogressive form of cholestasis unless infused with cholic acid, probably because they have a relatively hydrophilic bile salt pool and form tetrahydroxy bile salts and $\beta$-muricholic acid which can be transported into bile (577). Upregulation of Mdr1 (Abc1a) may also play a role in protecting these genetic Bsep knockout mice (309). BSEP is highly expressed in liver and is present throughout the lobule at the canalicular membrane where it has been localized to the microvilli by immunogold labeling (181) and thought to reside in caveolin enriched lipid microdomains resistant to extraction by Lubrol WX (244). Overexpression of caveolins increase bile salt secretion in the mouse (385), suggesting that caveolins may alter the cholesterol environment in the membrane. Canalicular membrane cholesterol is known to affect Bsep activity (433).

BSEP is present in lower vertebrates and is $69 \%$ identical in the marine skate Leucoraja erinacea, indicating considerable conservation of this transporter during vertebrate evolution (104). BSEP is first expressed in human liver at midgestation but is considerably below adult levels at birth (110), probably contributing to the transient elevation in serum bile salts observed at birth (536).

Substrate specificity for BSEP/Bsep is predominantly restricted to bile salts with good correlations between transport properties for different bile salts among species. See Ref. (521) for details of the specific bile acid substrates that have been tested for Bsep in various species. Pravastatin is the only nonbile salt solute yet confirmed as a substrate for BSEP (230).

BSEP/Bsep is a major target for drug-induced cholestatic liver injury (428). Based largely on studies in Sf9 vesicles, cholestatic drugs or their metabolites can either inhibit the 
transporter directly from the cytoplasmic side; examples are bosantin, glibenclamide, rifampicicn, and cyclosporine $(155,522)$, or indirectly after excretion into the canaliculus by MRP2 as shown for estradiol-17ß-glucuronide (522). The list of drugs that can inhibit Bsep continues to grow [see Table 4 in Ref. (521) for the most complete recent list].

BSEP/Bsep is highly regulated both at the transcriptional and posttranscriptional levels. Studies in rodents suggest that Bsep exists in a recycling pool for rapid mobilization and insertion into the plasma membrane (280). Bile salt secretion is stimulated by cAMP in isolated perfused rat livers and is sensitive to microtubule inhibitors $(219,221)$. Various cholestatic insults in rats, such as estradiol-17 $\beta$-glucuronide, lithocholate, lipopolysaccharide, and hypoxia among others, lead to internalization of Bsep into sub apical membrane vesicles and spotty staining of the protein at the canalicular membrane. In contrast, cAMP, tauroursodeoxycholic acid, and taurocholic acid all stimulate insertion of Bsep into the canalicular membrane (521). Altogether these observations suggest that the functional expression of Bsep is rapidly up-regulated in response to increases in its substrate as well as downregulated when cholestatic injury occurs, the latter perhaps serving as a cytoprotective mechanism. Bseps half life in the apical membrane is $\sim 4$ to 6 days and the protein constitutively recycles from the apical membrane to Rab11 positive submembranous endosomes, requiring myosin $\mathrm{Vb}(279,280,572,574)$. Mechanisms of BSEP retrieval from the apical membrane are still not well known but in vitro studies suggest that clathrindependent components, including Hax-1, cortactin, and EPS15 may be involved (422). Recent studies with human BSEP suggest that constitutive internalization of BSEP is dependent on a tyrosine-based endocytic motif at the C-terminal end of BSEP (310) that may interact with an AP2 adapter complex (222), findings consistent with clathrindependent endocytosis. Additional studies beyond the scope of this review suggest that posttranscriptional regulation of BSEP trafficking and localization can also be affected by glycosylation, phosphorylation and ubiquinylation. See Ref. (418) for more details.

Human BSEP expression is also highly regulated by transcriptional mechanisms and its expression is highly variable between individuals $(232,549)$. BSEP expression is sensitive to bile acid flux through the liver which activates the nuclear receptor FXR. FXR transactivates the proximal promoter of BSEP in humans (22) and in rodents. The critical role of FXR in BSEP expression is demonstrated by its low basal expression in $\mathrm{Fxr}^{-/}$mice and the lack of an induced response to bile salts (263). CDCA is the major endogenous ligand for FXR. The BSEP promoter is also induced by the hepatocyte-specific liver receptor homolog-1 (LRH-1, NR5A2) (510) while 1,25-dihydroxyvitamin D3 suppresses CDCA-FXR transactivation (235). The BSEP promoter is also positively regulated by the nuclear erythroid 2 p45-regulated factor 2 (NRF2) that plays a significant role in responses to oxidative stress. NRF2 binds to response elements that regulate many hepatic phase I and II enzymes and efflux transporters such as MRP3 and MRP4 (582). Altogether these transcriptional and posttranscriptional effects indicate that the expression of BSEP is regulated by multiple physiological and pathological stimuli.

The discovery that mutations in the bile salt export pump were the cause of PFIC type 2 (PFIC2) not only provided final confirmation that this transporter was the determinant of BSDF, but led to the clarification of the mechanisms of a number of other cholestatic 
disorders, including certain cases of cholestasis of pregnancy, BRIC2, and drug-induced cholestasis $(308,521)$. Currently, more than 100 different BSEP variants have been described comprising missense, nonsense, deletions and insertions, and splice-site mutations (249; 272, 306, 480, 528, 529, 568). Patients with PFIC2 may even develop hepatocellular carcinoma (128) or antibody-mediated recurrent disease following liver transplantation (251, 266).

A common result of many of these mutations is a reduction or loss of expression of the BSEP protein at the canalicular membrane (529). Some of these mutations or polymorphisms can lead to aberrant pre-mRNA splicing or exon skipping and reduced levels of mRNA resulting in variable levels of expression of the transporter. This may explain why some common mutations (p.D482G) result in variable clinical phenotypes $(103,232)$.

A large number of polymorphisms in BSEP have also been described $(232,312,313)$ with considerable variation between different ethnic groups. Most are rare events, however two common nonsynonymous SNPs, c.1331T>C (p.V444A) and c.2029A >G (p.M677V), are consistently seen in different populations. Lower levels of BSEP expression are usually seen in patients with the c.1331T allele $(232,312)$. This V444A variant is associated with ICP and drug-induced cholestasis, despite retaining functional activity with in vitro assays (141, $232,272,312,370$ ).

To understand the phenotypic expression of some of these mutations and SNPS in the BSEP gene, in vitro expression studies have been performed in various mammalian cell lines. When BSEP mutations from patients with PFIC2 (D482G, E297G) were expressed in MDCK, HEK293, or HepG2 cells, the protein failed to reach or be stabilized at the plasma membrane $(259,307,443,576)$. When these mutations for PFIC2 were compared with those from BRIC2 (A590T, R1050C) and ICP (N591S), the amount of protein expressed on the cell surface tended to correlate inversely with the severity of the clinical disease $(307,308)$. Transport activity for taurocholate is significantly reduced in PFIC2 mutants while partial or normal activity is retained in BRIC and ICP mutations, respectively (307). The majority of the mutations in BSEP lead to retention in the ER and failure to target to the apical plasma membrane as determined by immunostaining in heterologous expression systems and liver biopsies from patients. ER-associated degradation probably accounts for the removal of misfolded proteins in the ER. Ubiquitinylation with E3 ubiquitin ligases shortens the already short half life of the PFIC2 mutant D482G, although small amounts of the mutant protein still reach the plasma membrane (575). This and other studies indicate that the residence time on the cell surface of D482G and E297G mutant proteins is greatly reduced due to accelerated internalization, reduced recycling, or targeting of the endocytosed protein for degradation and have led to attempts to "rescue" the mutant proteins with small molecules $(224,259)$. In vitro studies have shown that treatment with 4-phenylbutyrate (4-PBA) can increase the cell surface expression of PFIC2 mutant proteins D482G and E297G and stimulate bile secretion and Bsep expression in rats (223). These exciting results have now led to the successful treatment of a patient with PFIC2 with 4-PBA (188).

Breast cancer resistance protein (ABCC2/Abcc2)-This member of the $\mathrm{ABC}$ family of membrane transporters has broad substrate specifity for a number of drugs, environmental 
agents, and endogenous substrates $(294,444)$. The endogenous solute, protoporphyrin, is specifically transported by BCRP, as is the drug nitrofurantoin. Other endogenous substrates include dehydroepiandrosterone sulfate, estrogen, and folic acid. BCRP expression in stem cells accounts for the "side population" characterized by dye extrusion with flow cytometry. BCRP is expressed on the apical membrane of numerous cell types and functions to protect these cells from toxic compounds. BCRP functions in a somewhat similar manner to MRP2 and other organic anion transporters and substrate specificities often overlap. However, BCRP protein expression in human liver is considerably less than the expression of MRP2 (557). Controversy exists as to whether BCRP transports bile salts. Studies in bile duct ligated mice and Bcrp null mice suggest that Bcrp does not have a significant role in the adaptive response to cholestasis in the liver but may have a more important role for solute excretion in the kidney and intestine during cholestasis (375). Bcrp deficiency impairs the biliary secretion of pitavastatin and some fluoroquinilones (305).

BCRP expression in hepatocytes can be induced by xenobiotics including phenobarbital. Studies of the BCRP promoter reveal estrogen receptor-binding elements, PPAR $\gamma$ binding sites, and aryl hydrocarbon receptor (AHR) and constitutive androstane receptor (CAR) response elements (58).

Sterolin 1 and Sterolin 2 (ABCG5/G8/Abcg5/g8)-The biliary excretion of cholesterol is an important mechanism for regulating cholesterol homeostasis and is mediated in large part by the heteromeric transporters, ABCG5 and ABCG8 known as sterolin 1 and 2, respectively (195). These transporters also regulate the excretion of plant and animal sterols and mutations in the human genes result in $\beta$-sitosterolemia $(59,239)$. Together these seven membrane spanning domain "half" ABC transporters combine at the canalicular membrane to facilitate this process (194). Mice with genetic deficiency of Abcg5 and Abcg 8 have a marked reduction in biliary cholesterol excretion (602). ABCG5/G8 functions together with Nieman Pick C1-like 1 protein (NPC1L1) which in humans is believed to reabsorb cholesterol from hepatic bile $(14,546)$. Ezetimibe is an inhibitor of NPC1L1 which is also expressed in the intestine. In contrast Nieman-Pick C2 (NPC2) is a cholesterol binding protein that is excreted in bile and helps to stimulate cholesterol excretion (594) together with ABCG5/G8. Human ABCG5/G8 and NPC1L1 are positively and negatively regulated by cholesterol, respectively, via LXR (59), reflecting the tight regulation that is exerted over cholesterol excretion (245). ABCG5 and ABCG8 are also positively and negatively regulated by bile salts and phospholipids, respectively, when overexpressed in Caco-2 cells (593). A large number of mutations and SNPs have been identified in both heteromers although their clinical significance is mostly unknown (227).

Multidrug and toxin extrusion transporters (SLC47A1/SIc47a1)-While certain organic cations enter the liver via OCT1, they exit the cell into bile via a putative 13 membrane domain transporter, MATE1. This canalicular membrane transporter utilizes the proton gradient to mediate the efflux of cation drugs such as tetramethylammonium, cimetidine, metformin, and procainamide via a proton coupled electroneutral exchange mechanism (284). The functional importance of MATE in the normal mechanisms of bile formation is not clear. However $\mathrm{Mate}^{-/-}$mice develop lactic acidosis when fed metformin 
in their drinking water (550). Neither Ahr, Car, Pxr, Ppar, or Nrf2 affect the expression of mouse Mate1. Polymorphisms in human MATE1 may influence cationic drug pharmacokinetics and toxicity (598).

\section{Concentrative and equilibrative nucleoside transporters CNT1 and 2 and} ENT1 (SLC28A1 and 2 and SLC29A1)-Nucleoside transporters contain 13 putative transmembrane domains and transport the nucleosides adenosine, cytodine, guanosine, thymidine, uridine, and inosine. They also transport nucleoside analogues which are drugs developed to treat viral infections and cancer, such as didanosine, fialuridine, 5fluorouridine, and ribivirin. CNTs transport nucleosides from bile back into hepatocytes and are an important mechanism for salvaging nucleosides for DNA and RNA synthesis. ENTs function as bidirectional transporters and facilitate transport of these substrates down their concentration gradients $(191,284)$. In human hepatocytes all of these transporters are expressed on the canalicular membrane as well as the basolateral membrane and in the cytoplasm (190).

\section{Chloride/bicarbonate exchanger, AE2/Ae2 (SLC4A2/SIca2)-A second} determinant of canalicular bile salt independent bile flow is the chloride/bicarbonate exchanger $\left(\mathrm{Cl}^{-} / \mathrm{HCO}_{3}{ }^{-}\right.$exchanger). This transporter has been characterized functionally in canalicular membrane vesicle systems in the rat and in isolated hepatocyte systems (55, 366). Immunohistochemical studies localize the AE2 isoform specifically to the apical membrane in human hepatocytes, as well as to the luminal surface of the bile duct epithelium (359). This $\mathrm{Cl}^{-} / \mathrm{HCO}_{3}{ }^{-}$exchanger functions as an acid-loading mechanism to protect the hepatocyte against increases in intracellular $\mathrm{pH}$ when intracellular $\mathrm{pH}$ rises above its set point (530), as well as a mechanism to stimulate the secretion of an alkaline bile (530). This $\mathrm{Cl}^{-} / \mathrm{HCO}_{3}{ }^{-}$exchanger is also present on intracellular pericanalicular membrane vesicles that are associated with microtubules and translocates to the apical membrane when stimulated by increases in cell $\mathrm{pH}$ (91), cell swelling (92), or cAMP (57). The latter effect is opposed by PKC. Canalicular bicarbonate secretion is also regulated by glucagon which stimulates a bicarbonate rich choleresis (330). Glucagon acts through the cAMP-dependent protein kinase A pathway, which also stimulates AQP 8 insertion into the canalicular membrane in rat hepatocytes via microtubular-dependent intracellular membrane vesicles $(17,174,193)$.

The $\mathrm{Cl}^{-} / \mathrm{HCO}_{3}{ }^{-}$exchanger is also thought to work in concert with an apical membrane chloride channel. The presence of outwardly rectifying chloride channels has previously been demonstrated in rat canalicular membrane vesicles (491). Two isoforms of the CIC-3 chloride channel have subsequently been identified at the molecular level in rat canalicular membrane and intracellular sites that are consistent with this finding (494). These anion channels allow for electrogenic chloride efflux to compensate for chloride influx via the $\mathrm{Cl}^{-} / \mathrm{HCO}_{3}{ }^{-}$exchanger. Hepatocyte cell swelling, such as occurs after meals with the influx of amino acids, results in activation of this chloride channel to maintain cell volume homeostasis (339). Substrates of Mrp2 have also been shown to activate chloride channels in hepatocytes which does not occur in $\mathrm{TR}^{-}$rats that are deficient in Mrp2. This suggests that Mrp2 is capable of accelerating this volume-activated response (337). 
Sodium proton exchanger 3 (SLC9A3 /SIc9a3)-Although the sodium proton exchanger 3 (NHE3) isoform of the sodium hydrogen exchanger has been localized to the canalicular membrane in rat hepatocytes, its functional role at the canalicular domain remains unclear. In contrast, this isoform plays an important role in the regulation of cholangiocyte fluid reabsorption (373).

Aquaporins: AQP0, AQP8, and AQP9-AQPs are small (25-34 kD) 6-transmembrane domain proteins that function as water channels in membranes. Some AQPs also transport glycerol and urea. There are three AQPs that have been described in rat hepatocytes (AQP0, AQP8, and AQP9). Studies of hydraulic water permeability across the basolateral and apical membranes of isolated rat hepatocyte couplets and the paracellular pathway demonstrate

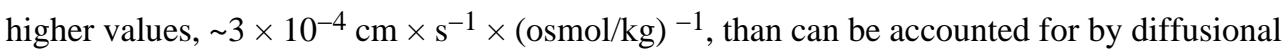
water permeability measured by tracer flux of ${ }^{3} \mathrm{H}_{2} \mathrm{O}$ (7). These findings support a functional role for water channels in hepatocytes membranes and the formation of bile (252).

AQ8 is localized to intracellular vesicles in the hepatocyte but can redistribute to the canalicular membrane in response to choleretic stimuli such as dibutyrl cAMP or glucagon which increases the apical membrane water permeability. AQ9 is an aquaglycerol AQP and is located at the basolateral membrane of hepatocytes. Although AQ8 knockout mice do not have a defect in bile secretion (595), the rapid insertion of water channels into the canalicular membrane would provide a molecular mechanism for efficient coupling of osmotically active substrates and the production of canalicular bile (355). Several animal models of cholestasis including estrogen administration, bile duct ligation, and sepsisinduced cholestasis have been associated with downregulation of AQ8 protein suggesting that a decrease in water permeability at the canalicular membrane might also contribute to cholestasis (351).

\section{Phase III basolateral membrane transporters}

These export pumps function primarily to protect the hepatocytes from the accumulation of toxic compounds but they can influence the overall clearance of bile salts and other organic anions excreted into bile by limiting the concentrations of these substances within individual hepatocytes.

Multidrug resistance associated protein 3 (ABCC3,Abcc3)-MRP3/Mrp3 is a member of the $\mathrm{ABC}$ superfamily expressed in the liver and is localized to the basolateral membrane of hepatocytes and cholangiocytes. MRP3/Mrp3 has two 6-membrane spanning domains and an extra 4-membrane spanning domain at its N-terminus similar to MRP2/ Mrp2. MRP3 transports a wide range of substrates consisting primarily of solutes conjugated with glucuronides and GSH $(603,607)$. MRP3/Mrp3 excretes bile salts conjugated with sulfate, glycine or taurine, bilirubin glucuronides, 17a-glucuronosyl estradiol, leukotriene, and a number of drugs $(5,231,290)$. However, human MRP3 has a lower affinity for bile salts compared to Mrp3 in the rat.

One of its main physiologic functions may be to protect the hepatocyte in the proximal portion of the hepatic lobule from an overload of substrates such as bilirubin by extruding these solutes back into the blood sinusoids so that they are distributed to more distal 
hepatocytes along the hepatic lobule $(564,565)$. MRP3/Mrp3 expression in the liver is normally low but it is upregulated in cholestatic liver injury in rodents $(144,511)$ and humans $(106,114,267,290,609)$ as part of the adaptive protective response. MRP3/Mrp3 may also function to extrude GSH conjugates into the blood during oxidative stress and when MRP2/ Mrp2 expression is deficient in the conjugated hyperbilirubinemic DubinJohnson syndrome in humans and the $\mathrm{TR}^{-} /$Groningen/EHBR mutant rat models $(95,265$, $362,436)$.

MRP3/Mrp3 expression is transcriptionally regulated. Bile duct ligation in mice results in upregulation and binding of the nuclear receptor Lrh-1 to the Mrp3 promoter which increases Mrp3 expression, a process that is dependent on TNF-a signaling pathways (68). This appears to be a protective adaptation since $T n f$ receptor knockout mice are more susceptible to liver injury following bile duct ligation (68). Both MRP3 expression and TNF-a expression are also increased in obstructive cholestasis in humans in association with increased SP1 and LRH-1 expression and binding to the MRP3 promoter (106). This is associated with activation of the stress-activated protein kinase/c-Jun NH2-terminal kinase pathway (JNK/SAPK) which is known to activate SP1. SP1 is a known positive activator of both rat and human MRP3 $(542,561)$ and binds to its proximal promoter. RXRa:RARa compete with SP1 for binding to the human MRP3 promoter (111). Since RXRa:RARa expression is diminished by cholestatic liver injury, loss of RXRa:RARa may contribute to the upregulation of MRP3/Mrp3 expression in these disorders (111). Nrf2 may also upregulate Mrp2 in rodents (503). Dioxin response elements have been identified in the human $M R P 3$ promoter where Ahr/Arnt (the aryl hydrocarbon receptor /aryl hydrocarbon nuclear translocator) heterodimers may bind (542), thus MRP3 may also be upregulated by Ahr. Mrp3 can also be acutely regulated by protein kinase A and C pathways (108).

Multidrug resistance associated protein 4 (ABCC4/Abcc4)-MRP4/Mrp4 is also expressed on the basolateral membrane of the hepatocyte and is one of the short forms of the MRP ABC transporters as it lacks the N-terminus 4 membrane spanning domain seen in MRP2 and 3. MRP4/Mrp4 transports sulfated organic conjugates such as estrone-S04, estradiol 17-beta-D-glucuronide, dehydroepiandrosterone 3-sulphate (DHEAS), sulfated and glucuronidated bile salts, and nucleoside analogues $(472 ; 490 ; 588,603,606)$. MRP4 also transports urate, the end product of purine metabolism in man (563), prostaglandins (449), and GSH (455). In the presence of GSH, human MRP4 also has high affinity for glycine and taurine conjugates and therefore may compete with BSEP for export of bile salts under cholestatic conditions (454).

MRP4 expression in human liver is highly variable and this difference in expression levels is not explained by genetic variations (192). However, cholestatic liver injury is a major stimulus for upregulation of this efflux transporter both in animal models and in patients with clinical cholestatic disorders $(107,192,610)$. Studies in Mrp4 null mice (374), unlike Mrp3 null mice $(53,607)$, indicate that MRP4/Mrp4 plays a major role in the adaptive protective response to cholestatic liver injury. Oxidative stress also stimulates increases in Mrp4 expression in animal studies $(348,419)$. The AhR and NF-E2-related factor 2 (Nrf2) play important roles in protecting cells from oxidative stress and agonists of these receptors upregulate human MRP4 expression, suggesting that agents that enhance their activity may 
be of therapeutic benefit for cholestasis (591). Activators of the nuclear receptor CAR induce the expression of MRP4 in primary human hepatocytes and HepG2 cells; however, CAR response elements have been difficult to identify in the human MRP4 promoter (591). Recent studies suggest that FXR response elements are embedded in CAR response elements in the human MRP4 promoter and that FXR agonists may impair CAR-mediated activation of MRP4. Mrp4 mRNA is also increased in Fxr knockout mice (500).

Organic solute transporter alpha and beta-Organic solute transporter alpha and beta (OSTa-OST $\beta$ ) is a unique heteromeric sterol transporter that is located on the basolateral membrane of hepatocytes, cholangiocytes and gallbladder, the renal proximal tubule, and the terminal ileum $(39,130)$. OSTa-OST $\beta$ is responsible for the transfer of bile salts from these tissues into the venous blood and is a major link in the enterohepatic, cholehepatic, and renal-hepatic circulation for bile salts. It is also expressed in tissues that transport sterols such as the adrenal gland, ovaries and testes. OSTa has 7 membrane spanning domains and a molecular weight of 360 daltons while OST $\beta$ has a single membrane spanning domain and is 128 amino acids in size. There are no known homologs in the human or mouse genomes. Both subunits are required for the functional expression of this transporter. The beta subunit is required for formation of the heterodimer as well its trafficking to the surface membrane (562). OSTa-OST $\beta$ is a facilitated transporter and bile salts and other sterols can be driven bidirectionally across the membrane of the cell according to the electrical chemical gradient. In addition to bile salts, OSTa-OST $\beta$ transports sterols conjugated with sulphate or glucuronic acid, including DHEAS, estrone-3sulfate, digoxin, and prostaglandin E2 (45). Unconjugated sterols do not seem to be substrates (inhibitors) for OSTa-OST $\beta$ (153). Both subunits of OSTa-OST $\beta$ are highly regulated by bile salts via FXR response elements. Two FXR response elements have been identified in the promoter of OSTa and one in OSTB (311). Under cholestatic conditions, OSTa-OST $\beta$ can efflux bile salts from the liver into the systemic circulation as part of the adaptive response to increases in concentration of bile salts in the liver (88).

\section{Bile Duct Cells (Cholangiocytes)}

The primary function of cholangiocytes is to fluidize and alkalinize canalicular bile, a process that involves a number of secretory and absorptive functions of these cells. Cholangiocytes form the epithelium of the intrahepatic biliary tree. The biliary tree is a complex heterogenious network of ducts that begins when bile flows from the bile canaliculi into the Canals of Hering ( $<15 \mu \mathrm{m}$ in diameter) (also the site of progenitor cells), and leads progressively to interlobular (15-100 $\mu \mathrm{mol} / \mathrm{L})$, septal $(100-300 \mu \mathrm{m})$, area ducts (300-400 $\mu \mathrm{m})$, segmental ducts $(400-800 \mu \mathrm{m})$, hepatic ducts $(>800 \mu \mathrm{m})$, and major ducts as originally defined by Ludwig (214) (Fig. 9). Ultimately, these conduits deliver bile to the gallbladder and intestine. Three-dimensional reconstruction of the biliary system from human liver provides estimates of its volume (mean $20.4 \mu \mathrm{m}^{3}$ ) and surface area $\left(398 \mathrm{~cm}^{2}\right)(343)$. Microvilli that line the biliary tree magnify this surface area approximately fivefold which increases geometrically from segment to segment as bile proceeds down this conduit (343).

The cholangiocytes that line the biliary tree also vary in structure, with the canals of Hering being lined in part by hepatocytes and in part by cholangiocytes (466). The cholangioles are 
cuboidal in shape and lead to the bile ductules. The shape of the cholangiocytes progressively enlarge and become more columnar the more distal their location in the biliary tree. All cholangiocytes contain primary cilia in their apical membrane that regulate cell differentiation, proliferation, and secretion (317). Cilia activate intracellular signaling pathways which sense changes in bile flow rates and osmolarity, as well as other molecular constituents (317). Cholangiocyte cilia express specific proteins, including polycystin-1, polycystin-2, fibrocystin, TRPV4, P2Y12, and AC6, that account for ciliary mechano-, osmo-, and chemo-sensory functions (360).

Cholangiocyte secretory and absorptive functions provide a variable component to the final volume of bile in different species but can significantly modify the final secretion that is delivered to the duodenum $(74,261,350)$. Although comprising only $3 \%$ to $5 \%$ of the total population of liver cells, the biliary epithelium accounts for $\sim 30 \%$ of daily bile production in humans and thus is an important component of BSIF $(80,447)$. In contrast, it accounts for less than $10 \%$ of basal bile flow in the rat (545).

To carry out these secretory and absorptive functions, cholangiocytes contain a number of specific transport systems that are highly regulated by meal-induced hormone release and their specific receptors (183). Since the major function of cholangiocytes is to alkalinize the bile, many of these mechanisms involve transporters that regulate intracellular $\mathrm{pH}$. By increasing bile luminal $\mathrm{pH}$, lipophilic weak acids are prevented from being protonized and reabsorbed by diffusion across the biliary epithelium. In addition, the alkaline bile helps to neutralize the acidic $\mathrm{pH}$ of gastric secretions. Although all bile duct epithelial cells express the bile ductspecific markers cytokeratin 19 and $\gamma$-glutamyl transpeptidase (except in mice), only medium and large bile duct cells express the secretin receptor, cystic fibrosis transmembrane regulataor (CFTR), and the $\mathrm{Cl}^{-} / \mathrm{HCO}^{-}{ }_{3}$ exchanger as described for rats and mice $(12,262,263,185)$ or show a secretory or $\mathrm{pH}$ response to secretin or cAMP $(8,261)$ (Fig. 9). In human liver CFTR has also been localized to or near the apical membrane of cholangiocytes but not hepatocytes (121) and secretin receptors have been identified at the molecular level in normal bile duct and ductules (291). Immunohistocheical studies have identified $\mathrm{AE} 2\left(\mathrm{Cl}^{-} / \mathrm{HCO}_{3}{ }^{-}\right.$exchanger $)$on the canalicular membrane and the apical membrane of small and medium bile ducts (359).

Secretion of fluid and bicarbonate anions from bile duct cells occurs as a physiologic response to meals. The major transporters and receptors involved in fluid secretion in cholangiocytes are illustrated in Figure 10. Specifically, acidic pH, and to a lesser extent fatty acids and bile salts, stimulate the duodenum to release secretin (277) and cholecystokinin into the portal circulation. Secretin stimulates fluid and bicarbonate secretion while cholecystokinin stimulates gallbladder contraction (338). Secretin is a 27amino acid peptide that is produced from $\mathrm{S}$ cells in the mucosa of the proximal intestine. After release to the circulation, it binds to heteromeric $\mathrm{G}$ protein-coupled basolateral receptors on the basolateral surface of large bile duct cells (8), which then leads to activation of adenyl cyclase and production of cAMP (329). PKA is then activated, leading to phosphorylation and activation of CFTR $(19,246)$, a chloride channel present on the luminal membrane of bile duct cells which is required to facilitate bicarbonate extrusion $(356,531)$. Another $\mathrm{Cl}^{-}$channel, which is sensitive to $\mathrm{Ca}^{2+}{ }_{\mathrm{i}}$ rather than cAMP, also is expressed 
apically $(158,163)$, and may provide an alternative mechanism for chloride secretion. As chloride is secreted, the bile duct cell is depolarized which activates basolateral $\mathrm{Na}^{+}$/ $\mathrm{Cl}^{-} / \mathrm{HCO}_{3}{ }^{-}$or $\mathrm{Na}^{+} / \mathrm{HCO}_{3}{ }^{-}$cotransport (in humans or rodents, respectively), resulting in increased cellular levels of $\mathrm{HCO}_{3}{ }^{-}$anions (532). The changing gradients for $\mathrm{HCO}_{3}{ }^{-}$and $\mathrm{Cl}^{-}$ drive apical $\mathrm{Cl}^{-} / \mathrm{HCO}_{3}{ }^{-}$exchange. The net result is $\mathrm{HCO}_{3}{ }^{-}$secretion $(16,74) . \mathrm{Na}^{+}, \mathrm{K}^{+},-2 \mathrm{Cl}^{-}$ cotransporters are also expressed on the basolateral membrane of cholangiocytes, as in other chloride secreting epithelia, and contribute to chloride entry into the cell, thereby facilitating conductive chloride excretion into the biliary lumen (501). At the same time, cAMP stimulates the insertion of water channels (AQPs) into the cell membrane, which increases the water permeability of this epithelium and thus further facilitates fluid movement (352354). Once secretin is removed, protein phosphatases 1 and/or $2 \mathrm{~A}$ inactivate the process (19) probably by inducing conformational changes in the R domain of CFTR which is a critical determinant of the chloride conduction pathway (332).

NHE3 is also localized to the apical membrane of cholangiocytes in rodents where it functions to reabsorb fluid from the biliary tree in the resting state (373). cAMP and protein kinase A may inhibit this activity. Fluid reabsorption fails to occur from IBDUs following forskolin stimulated secretion in Nhe3 knockout mice or with NHE3 inhibitors in the rat (373). Thus inhibition of fluid reabsorption during meal-induced elevations in cAMP may also contribute to the secretion of biliary fluids, possibly by recycling NHE3 between subapical compartments and the apical membrane of cholangiocytes as described in other epithelia $(6,302)$.

A variety of other neural and humoral factors also influence bicarbonate secretion from cholangiocytes (183). Acetylcholine, a parasympathetic neurostimulator binds to $\mathrm{M}_{3}$ receptors on cholangiocytes and potentiates secretin's stimulation of $\mathrm{Cl}^{-} / \mathrm{HCO}^{-}{ }_{3}$ exchange (15). VIP and bombesin, two neuropeptides, also stimulate cholangiocyte bicarbonate secretion via specific receptors but by cAMP-independent pathways $(116,118)$. In contrast, somatostatin, gastrin, and insulin have inhibitory effects on cholangiocyte secretion. Somatostatin binds to SSTR2 subtype receptors in large bile ducts and inhibits secretin induced cAMP levels (548). Gastrin inhibits secretin-induced secretion by binding to CCK$\mathrm{B} /$ gastrin receptors which inhibit secretin receptor expression via $\mathrm{Ca}^{2+}$-dependent $\mathrm{PKCa}$ mechanisms (186). Insulin works through a similar mechanism (331). Finally, glucocorticoids activate glucocorticoid receptors in rodent cholangiocytes and enhance the activity and protein expression of apical $\mathrm{Cl}^{-} / \mathrm{HCO}_{3}{ }^{-}$exchangers and basolateral $\mathrm{Na}^{+} / \mathrm{H}^{+}$ exchange (18).

Cholangiocytes also contain other transporters on the apical luminal membrane that function to recover certain substances that are excreted in the bile (205). SGLT1, a Na ${ }^{+} / g l u c o s e$ cotransporter, is responsible for uptake of glucose from bile (322). Bile duct cells express another glucose transporter, GLUT1, on their basolateral domain (322). Together these transporters permit reabsorption of glucose from bile to blood. The tripeptides glutathione and GSSH are excreted into bile in $\mathrm{mM}$ amounts as major determinants of BSIF (48). Canalicular and ductular $\gamma$-glutamyltransferase metabolizes GSH to glutamic acid plus cysteinylglycine, while a dipeptidase metabolizes the latter to cysteine and glycine. These GSH constituents are reabsorbed, in turn, by specific dipeptide and aminoacid transporters 
on the luminal membrane $(44,46)$. Biliary epithelia cells also express the intestinal-type $\mathrm{H}^{+}-$ peptide cotransporter PEPT1 in their apical membrane which should function to recover peptides from bile (287).

The apical sodium-dependent bile salt transporter ASBT (SLC10A) is also localized to the luminal membrane of large but not small bile duct cells as well as the gallbladder $(8,132$, 321). Together with the organic solute transporter OSTa-OST $\beta$, bile salts can recycle back to the liver from the bile in a manner similar to the terminal ileum and proximal renal tubule $(39,41)$. This process probably occurs normally in the gallbladder during periods of fasting, although it is unclear to what extent cholehepatic recycling takes place in cholangiocytes since the relatively high $K_{\mathrm{m}}$ of Asbt in bile duct epithelium suggests that only small amounts of bile salt would be taken up by this route (10). However, Asbt may function to reabsorb bile salts from the biliary tree during obstructive cholestasis. TGR5, a G-coupled protein bile acid receptor is also expressed on the luminal surface and cilia of cholangiocytes and gallbladder epithelium $(268,271)$. Bile salts stimulate bile duct proliferation via this receptor since bile duct ligation in $\operatorname{Tg} r 5$ knockout mice prevent this proliferation (268). Bile duct proliferation is a characteristic response to obstructive cholestasis and Asbt continues to be expressed on the luminal membrane of proliferating cholangiocytes $(9,324)$. Bile salt stimulation of TGR5 results in increases in cAMP and upregulation of secretin receptors in human gallbladder epithelium and an increase in biliary bicarbonate secretion $(268,456)$. This process is presumably regulated by secretin-induced recruitment of intracellular subapical membrane vesicles containing the needed transporters $(11,94)$.

\section{Signal Transduction Pathways in the Regulation of Bile Secretion}

Multiple posttranscriptional regulatory pathways exist in both hepatocytes and cholangiocytes for modulating the final bile secretory product. These consist of signal transduction second messenger pathways that are modulated in large part by hormones via hormone receptors, calcium via Inositol tiriphosphate receptors, nucleotides via purigenic receptors, and cytokines via cytokine receptors. In general, hormone receptor-mediated increases in adenyl cyclase activity and cAMP production result in a net increase in bile secretion while receptor-mediated mobilization of $\mathrm{Ca}^{2+}{ }_{\mathrm{i}}$ and activation of PKC tend to decrease bile flow $(122,220,399,400)$.

Hormones that increase intracellular calcium in hepatocytes, such as vasopressin, noradrenaline, or angiotensin, activate PKC by hydrolysis of $\mathrm{PIP}_{2}$, leading to formation of InsP3 and diacylglycerol, and result in a decrease in bile flow (400). In contrast, glucagon also increases $\mathrm{Ca}^{2+}{ }_{\mathrm{i}}$ but activates adenyl cyclase, resulting in an increase in bile flow, possibly because glucagon activates both calcium and chloride channels as noted in rat hepatocytes (32).

Hepatocytes functionally express P1 and P2 nucleotide (purigenic) receptors on the plasma membrane (157). By activating these receptors, extracellular nucleotides and nucleosides regulate a number of functions in the hepatocyte, including bile secretion. Ectonucleotidases (NTPDases, ecto 5'nucleotidase) are also expressed on the cell surface where they regulate the concentration of extracellular nucleotides including those in bile (597). NTPDase8 is 
restricted to the bile canaliculus and converts ATP to AMP, which, in turn, is broken down to adenosine by ecto 5'-nucleotdiase (156). Hepatocytes secrete sufficient amounts of ATP, ADP, and AMP in bile $[\sim 5 \mu \mathrm{mol} / \mathrm{L}(109)]$ to stimulate these receptors, which result in either increases in intracellular calcium or cAMP (157). $\mathrm{P}_{2} \mathrm{Y}$ receptors are also expressed on cholangiocytes and can respond to ATP secreted in bile. Hepatocytes can secrete ATP in sufficient amounts to stimulate $\mathrm{P}_{2} \mathrm{Y}$ receptors $(146,485)$ and can stimulate increases in intracellular calcium and alkalization of bile (146). cAMP-induced ductular bicarbonate secretion also depends in part on an autocrine signaling pathway that involves CFTR, apical release of ATP, stimulation of apical nucleotide receptors, and subsequent activation of apical, type III InsP3Rs. Thus, another role of CFTR in cholangiocyte secretion may be to regulate secretion of ATP in addition to secretion of chloride and/or bicarbonate (380).

Tauroursodeoxycholic acid and ursodeoxycholic acid, but not taurocholic acid, can also promote bile flow by inducing hepatocytes to release ATP into bile, which then stimulates fluid and electrolyte secretion by bile duct epithelia downstream via changes in cytosolic $\mathrm{Ca}^{2+}(402)$. Thus, biliary secretion of ATP by hepatocytes provides a paracrine mechanism for regulation of secretion in bile ducts via $\mathrm{Ca}^{2+}{ }_{\mathrm{i}}$ signaling (159) (Fig. 11).

\section{Cytokine and other receptors}

Proinflammatory cytokines, IL-1 $\beta$, IL-6, and TNF-a, all inhibit the formation of bile secretion by reducing the expression of both basolateral and canalicular transport proteins, as well as by altering cytoskeletal proteins and the permeability of the tight junction (180, $200,389,446,554)$. Administration of either IL-1 $\beta$ or TNF-a decreases bile flow by decreasing expression and activity of Ntcp at the transcriptional level $(136,264,551)$ as a result of decreased binding of the nuclear receptor Hnf1 a to the Ntcp promoter. Oatps are also downregulated $(179,325)$. Expression of apical transporters, Mrp2 and Bsep, is also impaired (325) as a result of decreased expression of nuclear hormone receptors, Fxr, Pxr, and $\operatorname{Car}(136,179)$. Cytokine-induced inflammation also increases circulating and hepatic nitric oxide (NO), alters the cytoskeleton and increases tight junction permeability (99). In contrast, exogenous sources of NO in isolated perfused rat livers increase BSIF by stimulating GSH disulfide excretion, effects that are independent of cyclic guanosine monophosphate (cGMP) (556). On the other hand, endotoxin impairs the biliary excretion of GSH and blocks the choleretic effects of NO (555). Proinflammatory cytokines also inhibit secretion from the bile duct epithelium (516).

\section{Second messengers}

Cyclic adenosine monophosphate-cAMP is a primary agonist for stimulation of bile secretion from both hepatocytes and cholangiocytes. cAMP stimulates vesicular transcytosis (219), targeting of vesicles to the canalicular membrane, $(87,461)$ exocytosis, and BSIF (219) and also decreases the intracellular transit time it takes for bile salts to stimulate BSDF (87). cAMP stimulates taurocholate uptake via Ntcp but not Oatp (203). This is potentiated by $\mathrm{Ca}^{2+}{ }_{\mathrm{i}} /$ calmodulin, although increases in $\mathrm{Ca}^{2+}{ }_{\mathrm{i}}$ alone do not stimulate Ntcp. cAMP increases bile acid uptake by translocating Ntcp to the plasma membrane (392) and increasing the transport maximum. The PI3 kinase/PKB signaling pathway also seems to be 
involved (581). However, cAMP-mediated phosphoinositide-3-kinase-independent activation of Rab4 facilitates Ntcp translocation in HuH-Ntcp cells (487).

cAMP stimulates organic anion excretion into bile by increased targeting of Mrp2 to the canalicular membrane (461) by PI3K-independent and MKK3-mediated activation of p38alpha MAPK (488). cAMP also increases lipid (sphingomeylin) transport to the canalicular membrane, a process that is opposed by PKC in HepG2 cells (604). cAMP has no effect on paracellular permeability in hepatocytes (405).

In bile duct cells, cAMP also stimulates secretion through multiple mechanisms, as briefly reviewed in the section on cholangiocyte secretion. Forskolin administration to rats in vivo stimulated secretion by cAMP/PKA/Src/MEK/ERK1/2 pathway, presumably at the level of cholangiocytes (167).

$\mathrm{Ca}^{2+}{ }_{\mathrm{i}}$ and protein kinase $\mathrm{C}-\mathrm{Ca}^{2+}{ }_{\mathrm{i}}$ and $\mathrm{PKC}$ have variable effects on bile secretion from hepatocytes although in general they are opposite to the effects of cAMP. $\mathrm{Ca}^{2+}{ }_{i}$ and PKC exert several different effects that stimulate secretion. First, $\mathrm{Ca}^{2+}$ induces contractions of the bile canaliculus which promotes biliary peristalsis and pulsatile increases in flow of bile (403, 405, 579, 580). Second, activation of PKC by phorbol dibutyrate stimulates apical exocytosis in the isolated perfused rat liver (93). Third, activators of PKC stimulate biliary excretion of Mrp2 substrates (460). Tauroursodeoxycholic acid stimulates canalicular exocytosis in association with mobilization of extracellular calcium (63), presumably by activating aPKC (64) and inserting Mrp2 into the canalicular membrane (61). Thus, PKC seems to be intimately involved in biliary exocytosis. In contrast, $\mathrm{Ca}^{2+}{ }_{\mathrm{i}}$ and $\mathrm{PKC}$ also exert inhibitory effects on bile flow. First, $\mathrm{Ca}^{2+}{ }_{\mathrm{i}}$ increases tight junction permeability, which is dependent on activation of PKC (405). Second, PKC opposes the effects of cAMP by inhibiting the transfer of lipid (sphingomyelin) to the canalicular membrane, as shown in HepG2 cells (604). Finally, both $\mathrm{Ca}^{2+}{ }_{\mathrm{i}}$ agonists and PKC activators decrease BSIF in the perfused rat liver $(122,404)$.

In contrast to hepatocytes, increases in $\mathrm{Ca}^{2+}{ }_{i}$ promote secretion in bile duct cells as noted previously (159). Increases in $\mathrm{Ca}^{2+}{ }_{\mathrm{i}}$ also potentiate secretin-induced cAMP production and secretin's stimulatory effect on bile duct secretion (15). In cholangiocytes, PKC is thought to prime a pool of intracellular vesicles for exocytosis induced by cell swelling. This process is dependent on both activation of PKC and PI-3 kinases (176).

PI-protein kinases-Regulation of canalicular exocytosis and targeting of vesicles to the canalicular domain appear to involve PI-3-kinases $(303,382)$ although the precise mechanisms remain complex and it is difficult to provide an overall view $(218,558)$. Trafficking of Bsep to the canalicular domain in response to taurocholate seems to be dependent on PI3K activity, in contrast to cAMP stimulation of other ABC transporters which are PI3K independent $(382,383)$. Rather, in hepatocytes, cAMP stimulates Mrp2 translocation by activating p38aMAPK (488). p38(MAPK) has been shown to regulate BSEP trafficking from the Golgi to the canalicular membrane in HepG2 cells and in rat hepatocytes (298). Tauroursodeoxycholic acid-induced stimulation of canalicular 
taurocholate excretion also involves a MAP kinase-dependent translocation of subcanalicular Bsep to the canalicular membrane (304).

Recent studies suggest that a series of kinases are necessary for the development of the canalicular and bile duct systems. The master kinase LKB1 when knocked out in mice results in a cholestatic phenotype with failure to insert Bsep and radixin into the apical domain and defective canalicular and bile duct structural development. Other studies show that AMPK and its upstream kinase, LKB1, regulate canalicular network formation, and maintenance in rat hepatocyte sandwich cultures (168). Further studies indicate that bile salts stimulate canalicular network formation via this cAMP-Epac-MEK-LKB1-AMPK pathway (169).

Prostaglandins-Early studies on the role of prostaglandins in bile formation reported stimulatory effects on bile flow $(260,319)$. Later studies examined the effects of prostaglandins F2 alpha, D2, and E2 and found inhibitor effects on bile flow and bile salt secretion that were independent of hemodynamic changes (52). When prostaglandin synthesis was suppressed, bile flow was stimulated (52). Prostaglandins function by binding to specific receptors that exert multiple metabolic functions via $\mathrm{G}$ protein-coupled receptors. $\mathrm{PGF}_{2 \mathrm{a}}$ and $\mathrm{PGE}_{2}$ induce $\mathrm{Ins}(1,4,5) \mathrm{P}_{3}$-mediated increases in intracellular $\mathrm{Ca}^{2+}$ which regulate many cell functions, including bile secretion (448). Other studies suggest that $\mathrm{PGF}_{2 a}$ can enhance or diminish propagation of $\mathrm{Ca}^{2+}$ signals, depending on the time of exposure, and thus may play a moderating role on other determinants of the bile secretory process, for example by inhibiting gap junction permeability $(292,406)$.

Nitric oxide-NO is a gaseous substance that mediates many biologic functions including bile formation. NO increases BSIF at the level of the hepatocyte by oxidation of GSH to GSSG (556) which is excreted into bile by the canalicular transporter Mrp2. NO also activates guanylyl cyclase, which increases cGMP (556). cGMP can also stimulate hepatocyte bicarbonate secretion and bile flow (397), but this effect of NO appears to be minor (556). Bile salts can also activate nitric oxide synthase in endothelial cells in the liver (eNos) presumably via TGR5, the G protein-coupled bile acid receptor which is expressed on endothelial cells but not hepatocytes (270).

NO can also directly activate PKC, which, in turn, increases tight junction permeability in hepatocytes (99), as well as inhibiting canalicular contractions (147), effects that would be expected to decrease bile flow. Chronic elevations of NO in circumstances of infection might contribute to the cholestasis of inflammation by this mechanism. NO can also inhibit bile salt uptake in hepatocytes by a process of S-nitrosylation of NTCP (486).

NO has no acute effects on cholangiocyte secretion when assessed in IBDUs (556).

However, NO has a very short half life of approximately a millisecond or less, but its effect can be prolonged by nitroslyation of cysteinyl residues of proteins such as albumin and GSH (517). These nitrosylthiols then can act outside the site of NO synthesis. An example of this is the stimulation of formation of S-nitrosoglutathione in hepatocytes by UDCA but not TUDCA or cholic acid infusions. This is followed by excretion of S-nitrosoglutathione into bile via Mrp2 where it subsequently acts on protein kinase B in cholangiocytes leading to 
enhancement of UDCA-stimulated ATP release and bile duct secretion. Presumably, this mechanism contributes to the hypercholeretic effect of UDCA in the intact animal (459).

In cholangiocytes, stimulation of nitric oxide production by cytokines leads to inhibition of adenylyl cyclase and cAMP-dependent secretion, possibly contributing to the cholestasis of inflammation (515).

Carbon monoxide and $\mathbf{H}_{\mathbf{2}} \mathrm{S}$-While $\mathrm{CO}$ is another diffusible messenger molecule that shares many properties with NO, it can regulate bile secretion by independent mechanisms. $\mathrm{CO}$ is endogenously produced during heme metabolism by heme oxygenase. Early studies suggested that inhibition of CO production is associated with decreased hepatic cGMP and leads to increased BSDF and bile salt output in isolated perfused rat liver, despite increases in microvascular resistance secondary to constriction of sinusoids (478). Increases in bile flow appear to be mediated by increases in both canalicular contractile frequency and intracellular $\mathrm{Ca}^{2+}$ concentrations that are attenuated by the addition of $\mathrm{CO}$ in isolated hepatocyte couplets (496).

In addition to $\mathrm{CO}$, heme oxygenase also produces bilirubin $1 \mathrm{Xa}$. When perfused rat livers are administered concentrations of $\mathrm{CO}$ in the 4 to $6 \mu \mathrm{mol} / \mathrm{L}$ range, a choleresis is induced in which increased biliary excretion of bilirubin $1 \mathrm{Xa}, \mathrm{GSH}$, and bicarbonate are seen. These effects are dependent on the function of Mrp2 and tetraethylammonium (TEA) sensitive $\mathrm{K}^{+}$ channels but are independent from cGMP-mediated secretion (414). This effect of CO may be a beneficial response to "stress" related events such as hypoxia and oxidative stress.

$\mathrm{CO}$ binds to the prosthetic heme of cystathionine betasynthase (CBS), the rate-limiting enzyme in transsulfuration pathways and $\mathrm{H}_{2} \mathrm{~S}$ generation, suggesting that $\mathrm{CBS}$ serves as a CO-sensitive modulator of $\mathrm{H}_{2} \mathrm{~S}$ production (497). $\mathrm{H}_{2} \mathrm{~S}$ generated through the enzymatic action of cystathionine gammalyase (CSE) modulates biliary bicarbonate excretion and thus is another determinant of bile salt-independent bile formation in rat liver (171). H2S generated by CSE also affects hepatic perfusion and loss of these functions may reduce sinusoidal perfusion (162) and affect bile flow.

Epigenetic regulation of bile acid metabolism and transport-In addition to transcriptional and posttranscriptional regulation of the determinants of bile formation reviewed in previous sections, recent studies have revealed that the activity of enzymes and transporters that determine bile acid synthesis, metabolism and transport can be regulated by posttranscriptional reversible epigenetic modifications of histones and chromatin (507).

There are two classes of factors that modify chromatin. The first class are histone modifying transcriptional cofactors that catalyze enzymatic posttranscriptional modifications of core histones by acetylation and methylation. These reactions modify the chromatin structure allowing access of transcription factors and other transcriptional machinery that reversibly increase or decrease gene transcription. Histone acetylation is catalyzed by histone acetyltransferases and counteracted by histone deacetylases (HDACs). These two enzymes add or remove acetyl groups on lysine residues of core histones which generally activate and represss genes, respectively. Histone methyltransferases and demethylases add or remove methyl groups to lysine or arginine residues in histones which either activate or repress gene 
function depending on the amino acid residues that are methylated and whether they form mono-, di-, or trimethylated substrates, The second class of transcriptional cofactors are ATP-dependent remodelers of chromatin. Examples include Swi/Snf complexes that contain the ATPases Brm or Brg-1. For a much more detailed summary of this field see Ref. (507).

Examples of epigenomic transcriptional cofactors that regulate bile acid metabolism and transport include:

1. SHP, the nuclear receptor the short heterodimer partner, while not directly modifying histones, coordinates the sequential recruitment of chromatin modifying cofactors to the promoter of Cyp7A1, the rate limiting enzyme in forming bile salts from cholesterol, resulting in inhibition of bile salt synthesis. These cofactors include HDACs, G9a, and Brm-Swi/Snf (378).

2. The histone lysine methyltransferase MLL3 has been identified in histone H3K4 tri-methylation and is important in Fxr activation of bile salt transporter genes, including $S H P, B S E P, M R P 2$, and NTCP. MLL3 methyltransferase is downregulated in bile duct ligated mice. MLL3 occupancy of the (ASC-2)containing coactivator complex in Bsep, Mrp2, and Ntcp promoters was reduced in these cholestatic mice $(24,282)$.

3. The coactivator-associated arginine methyltransferase 1 (CARM1) is an epigenomic regulator of the BSEP gene initiated by the nuclear receptor, FXR. Occupancy of CARM1 and FXR on the BSEP promoter increases in response to FXR agonists (23). Thus, FXR potentiates the expression of BSEP by recruiting this chromatin modifier.

4. The protein arginine methyltransferase also functions as a FXR coactivator, increasing the activation of Bsep and Shp genes in response to 6-EDCA (457), a potent FXR ligand.

5. Set7/9, a lysine methyltransferase, has also been determined to methylate FXR and contribute to the transcriptional activation of FXR-target genes (37).

These few examples of this emerging field illustrate how epigenomic modifications of chromatin regulate key determinants of bile secretory function.

\section{Transport and Excretion of Specific Substances}

\section{Lipid Secretion}

The major lipid constituents of bile are PC and cholesterol. Their concentrations range from 140 to $810 \mathrm{mg} / \mathrm{dL}$ and 97 to $320 \mathrm{mg} / \mathrm{dL}$, respectively (73). PC accounts for nearly all biliary phospholipids in bile even though the canalicular membrane also contains sphingomyelin, phosphatidylethanolamine, and phosphatidylserine (427). Excretion of PC requires a canalicular floppase (MDR3 in humans or the mouse homologue, $M d r 2$ ) and is dependent on the output of bile salts $(425,505)$ (see section on MDR3/Mdr2). PC is absent from bile in $M d r 2$ null mice (505) irrespective of bile salt output (425). There are two proposed mechanisms to explain how PC is excreted into bile (Fig. 8). First PC is delivered to the canalicular membrane via either a cytosolic transport protein or within vesicles, and then is 
flopped to the outer leaflet via MDR3/Mdr2. The resultant accumulation of PC on the outer leaflet of the canalicular membrane is inherently unstable, thus bile salts excreted into the canalicular lumen might directly facilitate PC extraction (427). An alternative hypothesis suggests that bile salts destabilize microdomains of PC that have accumulated on the outer leaflet, leading to vesicles that first bud, then pinch off into bile (125). Both hypotheses account for the observations that MDR3/Mdr2 and bile salts are required for phospholipid excretion.

As discussed earlier [see section on sterolin 1 and $2(A B C G 5 / G 8)$ ] most cholesterol is excreted into bile by these heteromeric $\mathrm{ABC}$ transporters. Phospholipid excretion via MDR3/Mdr2 may play some role in cholesterol excretion as well, since mice lacking Mdr2 have little to no cholesterol in bile $(425,505)$, although administration of bile salts to $M d r 2$ null mice stimulates excretion of cholesterol, but not phospholipid (425). While the mechanism by which $\mathrm{ABCG} / \mathrm{G} 8$ results in extrusion of cholesterol is still unclear, evidence indicates that this process requires micelle forming bile salts rather than other cholesterol acceptors such as APA1 or high-density lipoprotein (HDL) (571). Cholesterol excretion in bile is counteracted by Nieman-Pick C1-like 1 (NPC1L1) protein on the canalicular membrane while NPC2, a cholesterol-binding protein secreted by the biliary system, is a positive regulator of biliary cholesterol secretion by stimulating ABCG5/G8- mediated cholesterol transport (594). Hepatic NPC1L1 may control cholesterol homeostasis via the downregulation of NPC2 (592).

Cholesterol associated with HDL is taken up by the receptor SR-B1 at the basolateral membrane of hepatocytes and directly excreted into bile (452). The mechanism by which cholesterol reaches the canalicular membrane is not entirely clear, although it has been suggested that the cytosolic protein sterol carrier protein-2 binds cholesterol to aid in its delivery to the canaliculus $(21,170)$. Overexpression of the HDL receptor SR-B1 increases biliary cholesterol while decreasing serum cholesterol (293). Since SR-B1 is also expressed on the canalicular membrane it presumably plays a role in facilitating cholesterol excretion in bile. See ref (140) for more details regarding the multiple factors involved with cholesterol excretion into bile.

\section{Proteins in bile}

See earlier discussion.

\section{Amino acids and peptides}

Rat bile contains significantly more acidic amino acids (aspartic and glutamic) and sulfur containing amino acids (cystine and methionine) than in serum and much lower amounts of basic amino acids (lysine and ornithine) (165). Acidic and sulfur-containing amino acids are present in $\mathrm{mmol} / \mathrm{L}$ amounts in bile (73). The tripeptide GSH is a major biliary peptide whose secretion by Mrp2 represents the principle determinant of canalicular BSIF (48). The enzymatic activity of $\gamma$-glutamyltransferase in the luminal membranes of the bile canaliculus and bile ducts metabolizes GSH to glutamic acid plus cysteinylglycine, while a dipeptidase metabolizes the latter to cysteine and glycine. These amino acid and peptide constituents are then reabsorbed from bile by specific transport systems $(44,48)$ discussed previously. 


\section{Metals}

Bile is the major route of excretion of divalent heavy metal cations, including copper, iron, zinc, manganese, mercury, lead, silver, and cadmium $(123,283)$. The precise mechanisms by which most of these metals are excreted remains unclear. (38). Metals are normally complexed with amino acids, peptides, proteins, and other tissue constituents and usually do not exist in free solution. A few metals like $\mathrm{Ca}^{2+}$ and $\mathrm{Mg}^{2+}$ which are similar in concentration in blood plasma and bile, may enter bile by a paracellular pathway by diffusion across the tight junctions (73). A P-type ATPase, ATP7B, is required for the biliary excretion of copper and is mutated in Wilson's disease $(98,217,345,465,544)$. This protein is localized to the trans-Golgi apparatus and nearby vesicles (241). ATP7B traffics in vesicles where it fuses either to the canalicular membrane or to pericanalicular lysosomes so that copper is excreted into bile either directly across the canalicular membrane or by exocytosis from lysosomes (139). Some paracellular excretion may also occur (229). Manganese may also enter bile after transport into vesicles at the basolateral and sinusoidal pole of the hepatocyte. In rat hepatocytes and WIF-B cells (328) this is mediated by secretory pathway $\mathrm{Ca}^{2}$-ATPase isoform 1 (SPCA1). Accumulation of manganese in cholestatic liver disease can lead to neurotoxicity resembling Parkinsonism and may play a role in hepatic encephalopathy in chronic liver injury. The $\mathrm{ABC}$ canalicular transporter, Mrp2 (ABCC2), mediates the transport of a number of metals that can complex with high affinity to the cysteine moiety of GSH including arsenic, lead, gold, zinc, cisplatin, possibly copper, cadmium, silver, and mercury (38). Mutant rats that lack Mrp2 are not able to excrete zinc, copper, silver, cadmium, and methyl mercury into bile, whereas copper excretion is unaffected $(42,538)$.

The role of other canalicular transporters in metal transport including MDR1, MDR3, and MATE remains unclear (38). Some metals can be reabsorbed from bile by amino acid transporters, presumably as cysteine complexes.

\section{Vitamins}

Both water-soluble and fat-soluble vitamins are found in bile although little is known about their specific mechanisms of excretion. Many reports have established that radiolabeled retinol, retinyl acetate, or retinoic acid or their metabolites are rapidly excreted into bile following administration to rodents $(413,420)$. Vitamin A metabolites in bile reflect hepatic levels and increase when liver levels are high (395). Vitamin E (tocopherol) and its oxidative metabolites are excreted in bile and its biliary excretion can be blocked by verapamil in mice and rats, so presumably ABC transporters are involved $(395,396)$. Vitamin D is 25-hydroxylated in the liver, excreted in bile, absorbed in the intestine, and then 1,25-hydroxylated in the kidney. This metabolite is the most bioactive form of vitamin $\mathrm{D}$, and up to $25 \%$ of circulating 1,25-dihydroxy vitamin D may be recirculated via the bile each day (301). Studies in man suggest that glucuronide metabolites are the predominant form (323). Vitamin B2 (Riboflavin) is excreted into bile and undergoes a limited enterohepatic recirculation (258). Dietary folate is first transported into the liver, reduced to tetrahydrofolic acid, then methylated. Most of the methylated tetrahydrofolic acid is excreted into bile, then reabsorbed by the intestine. Methylated tetrahydrofolic acid is less avidly taken up by hepatocytes but then is also largely excreted into bile $(364,520)$. Since 
Mrps and BCRPs can transport naturally occurring folates, it is likely that these $\mathrm{ABC}$ transporters are also important in their biliary excretion as well (34). Vitamin $\mathrm{B}_{12}$ (cyanocobalmin) is largely stored in the liver. Approximately $5 \mu \mathrm{g}$ are excreted in bile each day in man and primates $(198,199)$. Most is reabsorbed together with intrinsic factor. This steady biliary excretion of cyanocobalamin contributes to the development of pernicious anemia in settings where production or absorption of intrinsic factor is defective (364). Studies with radiolabeled vitamin B6 (pyridoxine) in rats suggest that biliary excretion and enterohepatic circulation play a minor role in the economy of this vitamin (344).

\section{Conclusions}

Bile formation and secretion is a unique and vital function of the liver. Although a "hidden secretion" whose primary source is secreted into minute $1 \mu \mathrm{m}$ diameter canaliculi, the application of cellular and molecular techniques to the study of bile formation in the last two to three decades has resulted in considerable expansion of knowledge in this field. The historical development of these important concepts is detailed in the beginning of this review. Most of the major transporters and enzymes that determine the mechanisms of bile formation have now been characterized at the molecular level in animals and in man. Mutations and polymorphisms in some of these determinants have been discovered that have served to illuminate the specific function of a given transporter or enzyme. Details of these important mechanisms form the body of this text. Much has been learned about the determinants of both BSDF and BSIF and about the specific mechanisms of hepatocyte vs. cholangiocyte secretion. These secretory processes are highly regulated both at transcriptional and posttranscriptional levels with the latter involving complex receptor mediated signal transduction pathways. This knowledge now offers the opportunity to regulate this secretory process therapeutically and future research should offer new insights into these mechanisms which should be beneficial to patients where bile formation is impaired from cholestatic liver disease. The number of different solutes that are excreted into bile is large and in many cases their mechanism of excretion still remains to be studied, particularly for minor constituents such as metals, vitamins and proteins. Although bile is a "hidden secretion" its major determinants are now much better understood.

\section{Acknowledgments}

I am greatly indebted to the many postdoctoral fellows and colleagues whose work has done much to advance information in this field during the past 40 years, since I first became fascinated to understand the mechanisms of bile formation. In many instances, they have become major leaders in the field in their own right. To those whose important work I have omitted or incorrectly cited, please accept my apologies. I welcome your comments for improvement of this on-line overview. I also thank my colleague Carol Soroka for her careful review of the article and for help with illustrations. Publications cited in this review from my laboratory have been continuously supported by NIH USPHS Grant DK25636 since 1972 and P30-34989 since 1984.

\section{References}

1. Abu-Hayyeh S, Martinez-Becerra P, Sheikh Abdul Kadir SH, Selden C, Romero MR, Rees M, Marschall HU, Marin JJ, Williamson C. Inhibition of $\mathrm{Na}^{+}$-taurocholate Co-transporting polypeptide-mediated bile acid transport by cholestatic sulfated progesterone metabolites. J Biol Chem. 2010; 285:16504-16512. [PubMed: 20177056] 
2. Accatino L, Pizarro M, Solís N, Koenig CS, Vollrath V, Chianale J. Modulation of hepatic content and biliary excretion of P-glycoproteins in hepatocellular and obstructive cholestasis in the rat. $\mathrm{J}$ Hepatol. 1996; 25:349-361. [PubMed: 8895015]

3. Adachi Y, Kobuyashi H, Kurumi Y. ATP-dependent taurocholate transport by rat liver canalicular membrane vesicles. Hepatology. 1991; 14:655-659. [PubMed: 1916666]

4. Agre P, Bonhivers M, Borgnia MJ. The aquaporins, blueprints for cellular plumbing systems. J Biol Chem. 1998; 273:14659-14662. [PubMed: 9614059]

5. Akita H, Suzuki H, Hirohashi T, Takikawa H, Sugiyama Y. Transport activity of human MRP3 expressed in Sf9 cells: Comparative studies with rat MRP3. Pharm Res. 2002; 19:34-41. [PubMed: 11837698]

6. Alexander RT, Grinstein S. Tethering, recycling and activation of the epithelial sodium-proton exchanger, NHE3. J Exp Biol. 2009; 212:1630-1637. [PubMed: 19448073]

7. Alpini G, Garrick RA, Jones MJT, Nunes R, Tavoloni N. Water and nonelectrolyte permeability of isolated rat hepatocytes. Am J Physiol. 1986; 251:C872-C882. [PubMed: 2431623]

8. Alpini G, Glaser S, Robertson W, Rodgers RED, Phinizy JL, Lasater J, LeSage GD. Large but not small intrahepatic bile ducts are involved in secretin-regulated ductal bile secretion. Am J Physiol. 1997; 35:G1064-G1074. [PubMed: 9176215]

9. Alpini G, Glaser SS, Robertson WE. Bile acids stimulate proliferative and secretory events in large but not small scholangiocytes. Am J Physiol Gastrointest Liver Physiol. 1997; 273:G518-G529.

10. Alpini G, Glaser SS, Rodgers R, Phinizy JL, Robertson WE, Lasater J, LeSage GD. Functional expression of the apical $\mathrm{Na}^{+}$-dependent bile acid transporter in large but not small rat cholangiocytes. Gastroenterology. 1997; 113:1734-1740. [PubMed: 9352879]

11. Alpini G, Lenzi R, Sarkozi L, Tavoloni N. Biliary physiology in rats with bile ductular cell hyperplasia Evidence for a secretory function of proliferated bile ductules. J Clin Invest. 1988; 81:569-578. [PubMed: 2448343]

12. Alpini G, Roberts S, Kuntz SM, Uneno Y, Gubba S, Podila PV, LeSage G, LaRusso NF. Morphological, molecular, and functional heterogeneity of cholangiocytes from normal rat liver. Gastroenterology. 1996; 110:1636-1643. [PubMed: 8613073]

13. Alrefai WA, Gill RK. Bile Acid transporters: Structure, function, regulation and pathophysiological implications 1. Pharm Res. 2007; 24:1803-1823. [PubMed: 17404808]

14. Altmann SW, Davis HR Jr, Zhu LJ, Yao X, Hoos LM, Tetzloff G, Iyer SP, Maguire M, Golovko A, Zeng M, Wang L, Murgolo N, Graziano MP. Niemann-Pick C1 Like 1 protein is critical for intestinal cholesterol absorption. Science. 2004; 303:1201-1204. [PubMed: 14976318]

15. Alvaro D, Alpini G, Jezequel AM, Bassotti C, Francia C, Fraioli F, Romeo R, Marucci L, Le Sage G, Glaser SS, Benedetti A. Role and mechanisms of action of acetylcholine in the regulation of rat cholangiocyte secretory functions. J Clin Invest. 1997; 100:1349-1362. [PubMed: 9294100]

16. Alvaro D, Cho WK, Mennone A, Boyer JL. Effect of secretin on intracellular pH regulation in isolated rat bile duct epithelial cells. J Clin Invest. 1993; 92:1314-1325. [PubMed: 8397224]

17. Alvaro D, Della Guardia P, Bini A, Gigliozzi A, Furfaro S, LaRosa T, Piat C, Capocaccia L. Effect of glucagon on intracellular $\mathrm{pH}$ regulation in isolated rat hepatocyte couplets. J Clin Invest. 1995; 96:664-675.

18. Alvaro D, Gigliozzi A, Marucci L, Alpini G, Barbaro B, Monterubbianesi R, Minetola L, Mancino MG, Medina JF, Attili AF, Benedetti A. Corticosteroids modulate the secretory processes of the rat intrahepatic biliary epithelium. Gastro. 2002; 122:1058-1069.

19. Alvaro D, Mennone A, Boyer JL. Role of kinases and phosphatases in the regulation of fluid secretion and $\mathrm{C1}^{-} / \mathrm{HCO}_{3}{ }^{-}$exchange in cholangiocytes. Am J Physiol. 1997; 273:G303-G313. [PubMed: 9277408]

20. Ambudkar SV, Dey S, Hrycyna CA, Ramachandra M, Pastan I, Gottesman MM. Biochemical, cellular, and pharmacological aspects of the multidrug transporter. Ann Rev Pharmacol Toxicol. 1999; 39:361-398. [PubMed: 10331089]

21. Amigo L, Zanlungo S, Miguel JF, Glick JM, Hyogo H, Cohen DE, Rigotti A, Nervi F. Hepatic overexpression of sterol carrier protein-2 inhibits VLDL production and reciprocally enhances biliary lipid secretion. J Lipid Res. 2003; 44:399-407. [PubMed: 12576522] 
22. Ananthanarayanan M, Balasubramanian N, Makishima M, Mangelsdorf DJ, Suchy FJ. Human bile salt export pump promoter is transactivated by the farnesoid $\mathrm{X}$ receptor/bile acid receptor. J Biol Chem. 2001; 276:28857-28865. [PubMed: 11387316]

23. Ananthanarayanan M, Li S, Balasubramaniyan N, Suchy FJ, Walsh MJ. Ligand-dependent activation of the farnesoid X-receptor directs arginine methylation of histone H3 by CARM1. J Biol Chem. 2004; 279:54348-54357. [PubMed: 15471871]

24. Ananthanarayanan M, Li Y, Surapureddi S, Balasubramaniyan N, Ahn J, Goldstein JA, Suchy FJ. Histone H3K4 trimethylation by MLL3 as part of ASCOM complex is critical for NR activation of bile acid transporter genes and is downregulated in cholestasis. Am J Physiol Gastrointest Liver Physiol. 2011; 300:G771-G781. [PubMed: 21330447]

25. Andersen S, Okkels H, Krarup H, Laurberg P. Geographical clustering and maintained health in individuals harbouring the mutation for Greenland familial cholestasis: A population-based study. Scand J Gastroenterol. 2006; 41:445-450. [PubMed: 16635913]

26. Anderson JM, VanItallie CM. Tight junctions and the molecular basis for regulation of paracellular permeability. Am J Physiol. 1996; 38:G467-G475.

27. Anwer MS. Cellular regulation of hepatic bile acid transport in health and cholestasis. Hepatology. 2004; 39:581-590. [PubMed: 14999673]

28. Anwer MS, Gillin H, Mukhopadhyay S, Balasubramaniyan N, Suchy FJ, Ananthanarayanan M. Dephosphorylation of Ser-226 facilitates plasma membrane retention of Ntcp. J Biol Chem. 2005; 280:33687-33692. [PubMed: 16027164]

29. Anwer MS, Hegner D. Effect of Na on bile acid uptake by isolated rat hepatocytes. Evidence for a heterogeneous system. Hoppe-Seyler's Z Physiol Chem. 1978; 359:181-192. [PubMed: 649053]

30. Aoyama N, Tokamo H, Ohya T, Chandler K, Holzbach RT. A novel transcellular transport pathway for non-bile salt cholephilic organic anions. Am J Physiol. 1991; 261:G305-G311. [PubMed: 1872399]

31. Arias IM, Che MX, Gatmaitan Z, Leveille C, Nishida T, St Pierre M. The biology of the bile canaliculus, 1993. Hepatology. 1993; 17:318-329. [PubMed: 8428731]

32. Aromataris EC, Roberts ML, Barritt GJ, Rychkov GY. Glucagon activates $\mathrm{Ca}^{2+}$ and $\mathrm{Cl}^{-}$channels in rat hepatocytes. J Physiol. 2006; 573:611-625. [PubMed: 16581855]

33. Arrese M, Trauner M, Ananthananarayanan M, Pizarro M, Solis N, Accatino L, Soroka C, Boyer JL, Karpen SJ, Miquel JF, Suchy FJ. Down-regulation of the $\mathrm{Na}^{+} /$taurocholate cotransporting polypeptide during pregnancy in the rat. J Hepatology. 2003; 38:148-155.

34. Assaraf YG. The role of multidrug resistance efflux transporters in antifolate resistance and folate homeostasis. Drug Resist Update. 2006; 9:227-246.

35. Badagnani I, Castro RA, Taylor TR, Brett CM, Huang CC, Stryke D, Kawamoto M, Johns SJ, Ferrin TE, Carlson EJ, Burchard EG, Giacomini KM. Interaction of methotrexate with organicanion transporting polypeptide 1A2 and its genetic variants. J Pharmacol Exp Ther. 2006; 318:521-529. [PubMed: 16702441]

36. Baker AL, Wood RAB, Moossa AR, Boyer JL. Sodium taurocholate modifies the bile acidindependent fraction of canalicular bile flow in the rhesus monkey. J Clin Invest. 1979; 64:312320. [PubMed: 109471]

37. Balasubramaniyan N, Ananthanarayanan M, Suchy FJ. Direct methylation of FXR by Set7/9, a lysine methyltransferase, regulates the expression of FXR target genes. Am J Physiol Gastrointest Liver Physiol. 2012; 302:G937-G947. [PubMed: 22345554]

38. Ballatori, N.; Aremy, DA.; Madejczyik, MS. Essential and toxic metal transport in the liver. In: Rudolfs, K.; Zalups, D.; Koropatnick, James, editors. Cellular and Molecular Biology of Metals. CRC Press; 2010. p. 79-112.

39. Ballatori N, Christian WV, Lee JY, Dawson Pa, Soroka CJ, Boyer JL, Madejczyk MS, Li N. OSTa-OST $\beta$ : A major basolateral bile acid and steroid transporter in human intestinal, renal, and biliary epithelia. Hepatology. 2005; 42:1270-1279. [PubMed: 16317684]

40. Ballatori N, Dutczak WJ. Identification and characterization of high and low affinity transport systems for reduced glutathione in liver cell canalicular membranes. J Biol Chem. 1994; 269:19731-7. [PubMed: 8051053] 
41. Ballatori N, Fang F, Christian WV, Li N, Hammond CL. Ost \{alpha $\}$-Ost $\{$ beta $\}$ is required for bile acid and conjugated steroid disposition in the intestine, kidney, and liver. Am J Physiol Gastrointest Liver Physiol. 2008; 295:G179-G186. [PubMed: 18497332]

42. Ballatori N, Gatmaitan Z, Truong AT. Impaired biliary excretion and whole body elimination of methylmercury in rats with congenital defect in biliary glutathione excretion. Hepatology. 1995; 22:1469-1473. [PubMed: 7590665]

43. Ballatori N, Jacob R, Boyer JL. Intrabiliary glutathione hydrolysis. J Biol Chem. 1986; 261:78607865. [PubMed: 2872220]

44. Ballatori N, Jacob R, Boyer JL. Biliary catabolism of glutathione and differential reabsorption of its amino acid constituents. Am J Physiol. 1988; 254:G1-G7. [PubMed: 2892423]

45. Ballatori N, Li N, Fang F, Boyer JL, Christian WV, Hammond CL. OST alpha-OST beta: A key membrane transporter of bile acids and conjugated steroids. Front Biosci. 2009; 14:2829-2844.

46. Ballatori N, Moseley RH, Boyer JL. Sodium gradient-dependent L-glutamate transport is localized to the canalicular domain of liver plasma membranes. J Biol Chem. 1986; 261:6216-6221. [PubMed: 2871024]

47. Ballatori N, Truong AT. Relation between biliary glutathione excretion and bile acid-independent bile flow. Am J Physiol. 1989; 256:G22-G30. [PubMed: 2912148]

48. Ballatori N, Truong AT. Glutathione as a primary osmotic driving force in hepatic bile formation. Am J Physiol. 1992; 263:G617-G624. [PubMed: 1443136]

49. Ballatori N, Truong AT, Ma AK, Boyer JL. Determinants of glutathione efflux and biliary GSH/ GSSG Ratio in perfused rat liver. Am J Physiol. 1989; 256:G482-G490. [PubMed: 2564253]

50. Barbhuiya MA, Sahasrabuddhe NA, Pinto SM, Muthusamy B, Singh TD, Nanjappa V, Keerthikumar S, Delanghe B, Harsha HC, Chaerkady R, Jalaj V, Gupta S, Shrivastav BR, Tiwari PK, Pandey A. Comprehensive proteomic analysis of human bile. Proteomics. 2011; 11:44434453. [PubMed: 22114102]

51. Barr VA, Hubbard AL. Newly synthesized hepatocyte plasma membrane proteins are transported in transcytotic vesicles in the bile ductligated rat. Gastroenterology. 1993; 105:554-571. [PubMed: 8335210]

52. Beckh K, Kneip S, Arnold R. Direct regulation of bile secretion by prostaglandins in perfused rat liver. Hepatology. 1994; 19:1208-1213. [PubMed: 8175143]

53. Belinsky MG, Dawson Pa, Shchaveleva I, Bain LJ, Wang R, Ling V, Chen ZS, Grinberg A, Westphal H, Klein-Szanto A, Lerro A, Kruh GD. Analysis of the in vivo functions of Mrp3. Mol Pharmacol. 2005; 68:160-168. [PubMed: 15814571]

54. Benedetti A, Bassotti C, Rapino K, Marucci L, Jezequel AM. A morphometric study of the epithelium lining the rat intrahepatic biliary tree. J Hepatology. 1996; 24:335-342.

55. Benedetti A, Strazzabosco M, Corasanti JG, Haddad P, Graf J, Boyer JL. $\mathrm{Cl}^{-} \mathrm{HCO}_{3}$ exchanger in isolated rat hepatocytes: Role in regulation of intracellular pH. Am J Physiol. 1991; 261:G512G522. [PubMed: 1887897]

56. Benedetti A, Strazzabosco M, Ng OC, Boyer JL. Regulation of activity and apical targeting of the $\mathrm{Cl}^{-}$/. Proc Natl Acad Sci U S A. 1994; 91:792-796. [PubMed: 8290601]

57. Benedetti A, Strazzabosco M, Ng OC, Boyer JL. Regulation of activity and apical targeting of the $\mathrm{Cl}^{-} / \mathrm{HCO}_{3}{ }^{-}$exchanger in rat hepatocytes. Proc Natl Acad Sci U S A. 1994; 91:792-796. [PubMed: 8290601]

58. Benoki S, Yoshinari K, Chikada T, Imai J, Yamazoe Y. Transactivation of ABCG2 through a novel cis-element in the distal promoter by constitutive androstane receptor but not pregnane $\mathrm{X}$ receptor in human hepatocytes. Arch Biochem Biophys. 2012; 517:123-130. [PubMed: 22093699]

59. Berge KE, Tian H, Graf GA, Yu L, Grishin NV, Schultz J, Kwiterovich P, Shan B, Barnes R, Hobbs HH. Accumulation of dietary cholesterol in sitosterolemia caused by mutations in adjacent ABC transporters. Science. 2000; 290:1771-1775. [PubMed: 11099417]

60. Beuers, U.; Boyer, JL. Bile: A historical review of studies on its form and function. In: Kirsner, JB., editor. The Growth of Gastroenterologic Knowledge During the Twentieth Century. Philadelphia: Lea \& Febiger; 1994. p. 267-288.

61. Beuers U, Bilzer M, Chittattu A, Kullak-Ublick GA, Keppler D, Paumgartner G, Dombrowski F. Tauroursodeoxycholic acid inserts the apical conjugate export pump, Mrp2, into canalicular 
membranes and stimulates organic anion secretion by protein kinase $\mathrm{C}$-dependent mechanisms in cholestatic rat liver. Hepatology. 2001; 33:1206-1216. [PubMed: 11343250]

62. Beuers U, Nathanson MH, Boyer JL. Effects of tauroursodeoxycholic acid on cytosolic $\mathrm{Ca}^{2+}$ signals in isolated rat hepatocytes. Gastroenterology. 1993; 104:604-612. [PubMed: 8425704]

63. Beuers U, Nathanson MH, Isales CM, Boyer JL. Tauroursodeoxycholic acid stimulates hepatocellular exocytosis and mobilizes extracellular $\mathrm{Ca}^{++}$mechanisms defective in cholestasis. $\mathrm{J}$ Clin Invest. 1993; 92:2984-2993. [PubMed: 8254052]

64. Beuers U, Throckmorton DC, Anderson MS, Isales CM, Thasler W, Kullak-Ublick G-A, Sauter G, Koebe HG, Paumgartner G, Boyer JL. Tauroursodeoxycholic acid activates protein kinase C in isolated rat hepatocytes. Gastroenterology. 1996; 110:1553-1563. [PubMed: 8613063]

65. Bizard, G. Enzyme inhibitors and biliary secretion. In: Taylor, W., editor. The Biliary System. Oxford: Blackwell; 1965. p. 315-324.

66. Blitzer BL, Boyer JL. Cytochemical localization of $\mathrm{Na}^{+}, \mathrm{K}^{+}$-ATPase in the rat hepatocyte. J Clin Invest. 1978; 62:1104-1108. [PubMed: 213446]

67. Bloomer J, Enriquez R. Evidence that hepatic crystalline deposits in a patient with protoporphyria are composed of protoporphyrin. Gastroenterology. 1982; 82:569-572. [PubMed: 7054049]

68. Bohan A, Chen WS, Denson LA, Held MA, Boyer JL. Tumor necrosis factor alpha-dependent upregulation of Lrh-1 and Mrp3(Abcc3) reduces liver injury in obstructive cholestasis. J Biol Chem. 2003; 278:36688-36698. [PubMed: 12837754]

69. Borst P, Evers R, Kool M, Wijnholds J. The multidrug resistance protein family. Biochim Biophys Acta. 1999; 1461:347-357. [PubMed: 10581366]

70. Boyer JL. Canalicular bile formation in the isolated perfused rat liver. Am J Physiol. 1971; 221:1156-1163. [PubMed: 4255749]

71. Boyer JL. New concepts of mechanisms of hepatocyte bile formation. Physiol Rev. 1980; 60:303326. [PubMed: 6247725]

72. Boyer JL. Tight junctions in normal and cholestatic liver: Does the paracellular pathway have functional significance? Hepatology. 1983; 3:614-617. [PubMed: 6345333]

73. Boyer, JL. Mechanisms of bile secretion and hepatic transport. In: Andreoli, TE.; Hoffman, JF.; Fanestil, DD.; Schultz, SG., editors. Physiology of Membrane Disorders. Plenum Publishing Corp; New York, NY: 1986. p. 609-636.

74. Boyer JL. Bile duct epithelium: Frontiers in transport physiology. Am J Physiol. 1996; 270:G1G5. [PubMed: 8772494]

75. Boyer, JL. Effects of bile acids on bile secretion. In: Paumgartner, G.; Stiehl, A.; Gerok, W., editors. Bile Acids in Hepatobiliary Diseases: Basic Research and Clinical Application. Dordrecht: Kluwer Academic Publishers; 1997. p. 205-212.

76. Boyer, JL. Bile Formation and Cholestasis. In: Schiff, ER.; Sorrell, MF.; Maddrey, WC., editors. Schiff's Diseases of the Liver. Philadelphia: Lippincott, Williams \& Wilkins; 2002. p. 135-165.

77. Boyer JL. Milestones in liver disease - a commentary. J Hepatology. 2002; 36:4-7.

78. Boyer JL. Nuclear receptor ligands: Rational and effective therapy for chronic cholestatic liver disease? Gastroenterology. 2005; 129:735-740. [PubMed: 16083726]

79. Boyer, JL. Adaptive regulation of hepatocyte traransporters in cholestasis. In: Arias, IM.; Alter, HJ.; Boyer, JL.; Cohen, DE.; Fausto, N.; Shafritz, DA.; Wolkoff, AW., editors. The Liver Biology and Pathobiology. Chichester: John Wiley \& Sons; 2009. p. 681-702.

80. Boyer JL, Bloomer JR. Canalicular bile secretion in man: Studies utilizing the biliary clearance of (14C) mannitol. J Clin Invest. 1974; 54:773-781. [PubMed: 4610005]

81. Boyer JL, Klatskin G. Canalicular bile flow and bile secretory pressure: Evidence for a non-bile salt dependent fraction in the isolated perfused rat liver. Gastro. 1970; 59:853-859.

82. Boyer, JL.; Meier, PJ. Characterizing mechanisms of hepatic bile acid transport utilizing isolated membrane vesicles. In: Fleischer, S.; Fleischer, B., editors. Methods in Enzymology. New York: Academic Press Inc; 1990. p. 517-533.

83. Boyer JL, Ng OC, Ananthanarayanan M, Hofmann AF, Schteingart CD, Hagenbuch B, Stieger B, Meier PJ. Expression and characterization of a functional rat liver $\mathrm{Na}^{+}$bile acid cotransport system in COS-7 cells. Am J Physiol. 1994; 266:G382-G387. [PubMed: 8166278] 
84. Boyer JL, Schwarz J, Smith N. Biliary secretion in elasmobranchs. II. Hepatic uptake and biliary excretion of organic anions. Am J Physiol. 1976; 230:974-981. [PubMed: 1267029]

85. Boyer JL, Schwarz J, Smith N. Biliary secretion in elasmobranchs. I. Bile collection and composition. Am J Physiol. 1976; 230:970-973. [PubMed: 4983]

86. Boyer, JL. Mechanisms of bile secretion and hepatic transport. In: Andreoli, TEHJFDaSS., editor. Physiology of Membrane Disorders. New York, NY: Plenum Publishing Corporation; 1986. p. 609-636.

87. Boyer JL, Soroka CJ. Vesicle targeting to the apical domain regulates bile excretory function in isolated rat hepatocyte couplets. Gastroenterology. 1995; 109:1600-1611. [PubMed: 7557144]

88. Boyer JL, Trauner M, Mennone A, Soroka CJ, Cai SY, Moustafa T, Zollner G, Lee JY, Ballatori N. Upregulation of a basolateral FXR-dependent bile acid efflux transporter, OSTalpha-OSTbeta in cholestasis in humans and rodents. Am J Physiol Gastrointest Liver Physiol. 2006; 290:G11241130. [PubMed: 16423920]

89. Bradley SE, Herz R. Permselectivity of biliary canalicular membrane in rats: Clearance probe analysis. Am J Physiol. 1978; 235:E570-E576. [PubMed: 727257]

90. Brauer RW, Leong GF, Holloway RJ. Mechanics of bile secretion: Effect of perfusion pressure and temperature on bile flow and secretion pressure. Am J Physiol. 1954; 177:103-112. [PubMed: 13148351]

91. Bruck R, Benedetti A, Strazzabosco M, Boyer JL. Intracellular alkalinization stimulates bile flow and vesicular-mediated exocytosis in IPRL. Am J Physiol. 1993; 265:G347-G353. [PubMed: 8368316]

92. Bruck R, Haddad P, Graf J, Boyer JL. Regulatory volume decrease stimulates bile flow, bile acid excretion, and exocytosis in isolated perfused rat liver. Am J Physiol. 1992; 262:G806-G812. [PubMed: 1590390]

93. Bruck R, Nathanson MH, Ward SA, Boyer JL. Exocytosis of horseradish peroxidase (HRP) is stimulated by protein kinase $\mathrm{C}(\mathrm{PKC})$ and inhibited by increased $[\mathrm{Ca}++] \mathrm{i}$ in the isolated perfused rat liver (IPRL). Hepatology. 1991; 14:148A.

94. Buanes T, Grotmol T, Landsverk T, Raeder MG. Secretin empties bile duct cell cytoplasm of vesicles when it initiates ductular $\mathrm{HCO}_{3}{ }^{-}$secretion in the pig. Gastroenterology. 1988; 95:417424. [PubMed: 3391369]

95. Buechler M, Koenig J, Brom M, Kartenbeck J, Spring H, Horie T, Keppler D. cDNA cloning of the hepatocyte canalicular isoform of the multidrug resistance protein, cMrp, reveals a novel conjugate export pump deficient in hyperbilirubinemic mutant rats. J Biol Chem. 1996; 271:15091-15098. [PubMed: 8662992]

96. Bull LN, Carlton VEH, Stricker NL, Baharloo S, De Young JA, Freimer NB, Magid MS, Kahn E, Markowitz J, Di Carlo FJ, McLoughlin L, Boyle JT, Dahms BB, Faught PR, Fitzgerald JF, Piccoli DA, Witzleben CL, O’Connell NC, Setchell KDR, Agostini RM Jr, Kocoshis SA, Reyes J, Knisely AS. Genetic and morphological findings in progressive familial intrahepatic cholestasis (Byler disease [PFIC-1] and Byler syndrome): Evidence for heterogeneity. Hepatology. 1997; 26:155-164. [PubMed: 9214465]

97. Bull LN, van Eijk MJ, Pawlikowska L, DeYoung JA, Juijn JA, Liao M, Klomp LW, Lomri N, Berger R, Scharschmidt BF, Knisely AS, Houwen RH, Freimer NB. A gene encoding a P-type ATPase mutated in two forms of hereditary cholestasis. Nat Genet. 1998; 18:219-224. [PubMed: 9500542]

98. Bull PC, Thomas GR, Rommens JM, Forbes JR, Cox DW. The Wilson disease gene is a putative copper transporting P-type ATPase similar to the Menkes gene. Nat Genet. 1993; 5:327-337. [PubMed: 8298639]

99. Burgstahler AD, Nathanson MH. NO modulates the apicolateral cytoskeleton of isolated hepatocytes by a PKC-dependent, cGMP-independent mechanism. Am J Physiol. 1995; 269:G789-G799. [PubMed: 7491972]

100. Busch AE, Quester S, Ulzheimer JC, Waldegger S, Gorboulev V, Arndt P, Lang F, Koepsell H. Electrogenic properties and substrate specificity of the polyspecific rat cation transporter rOCT1. J Biol Chem. 1996; 271:32599-32604. [PubMed: 8955087] 
101. Buscher HP, Schramm U, Macnelly S, Kurz G, Gerok W. The acinar location of the sodiumindependent and the sodium-dependent component of taurocholate uptake - a histoautoradiographic study of rat liver. JH. 1991; 13:169.

102. Byrne JA. The human bile salt export pump: Characterization of substrate specificity and identification of inhibitors. Gastro. 2002; 123:1649-1658.

103. Byrne JA, Strautnieks SS, Ihrke G, Pagani F, Knisely AS, Linton KJ, Mieli-Vergani G, Thompson RJ. Missense mutations and single nucleotide polymorphisms in ABCB11 impair bile salt export pump processing and function or disrupt pre-messenger RNA splicing. Hepatology. 2009; 49:553-567. [PubMed: 19101985]

104. Cai S-Y, Wang L, Ballatori N, Boyer JL. Bile salt export pump is highly conserved during vertebrate evolution and its expression is inhibited by PFIC type II mutations. Am J Physiol. 2001; 281:G316-G322.

105. Cai SY, Gautam S, Nguyen T, Soroka CJ, Rahner C, Boyer JL. ATP8B1 deficiency disrupts the bile canalicular membrane bilayer structure in hepatocytes, but FXR expression and activity are maintained. Gastroenterology. 2009; 136:1060-1069. [PubMed: 19027009]

106. Chai J, He Y, Cai SY, Jiang Z, Wang H, Li Q, Chen L, Peng Z, He X, Wu X, Xiao T, Wang R, Boyer JL, Chen W. Elevated hepatic MRP3/ABCC3 expression in human obstructive cholestasis is mediated through TNFalpha and JNK/SAPK signaling pathway. Hepatology. 2011; 55:14851494. [PubMed: 22105759]

107. Chai J, Luo D, Wu X, Wang H, He Y, Li Q, Zhang Y, Chen L, Peng ZH, Xiao T, Wang R, Chen W. Changes of organic anion transporter MRP4 and related nuclear receptors in human obstructive cholestasis. J Gastrointest Surg. 2011; 15:996-1004. [PubMed: 21359593]

108. Chandra $P$, Zhang $P$, Brouwer KL. Short-term regulation of multidrug resistance-associated protein 3 (Mrp3/MRP3) in rat and human hepatocytes. Am J Physiol Gastrointest Liver Physiol. 2005; 288:G1252-G1258. [PubMed: 15650133]

109. Chari RS, Schutz SM, Haebig JE, Shimokura GH, Cotton PB, Fitz JG, Meyers WC. Adenosine nucleotides in bile. Am J Physiol. 1996; 270:G246-G252. [PubMed: 8779965]

110. Chen HL, Chen HL, Liu YJ, Feng CH, Wu CY, Shyu MK, Yuan RH, Chang MH. Developmental expression of canalicular transporter genes in human liver. JH. 2005; 43:472-477.

111. Chen W, Cai SY, Xu S, Denson LA, Soroka CJ, Boyer JL. Nuclear receptors RXRalpha:RARalpha are repressors for human MRP3 expression. Am J Physiol Gastrointest Liver Physiol. 2007; 292:G1221-G1227. [PubMed: 17272513]

112. Cheng JB, Levine MA, Bell NH, Mangelsdorf DJ, Russell DW. Genetic evidence that the human CYP2R1 enzyme is a key vitamin D 25-hydroxylase. Proc Natl Acad Sci U S A. 2004; 101:7711-7715. [PubMed: 15128933]

113. Cheng JB, Motola DL, Mangelsdorf DJ, Russell DW. De-orphanization of cytochrome P450 2R1: A microsomal vitamin D 25-hydroxilase. J Biol Chem. 2003; 278:38084-38093. [PubMed: 12867411]

114. Cheng K, Ashby D, Smyth R. Ursodeoxycholic acid for cystic fibrosis-related liver disease. Cochrane Database Syst Rev. 2000; 10:CD000222.

115. Childs S, Yeh RL, Georges E, Ling V. Identification of a sister gene to p-glycoprotein. Cancer Res. 1995; 55:2029-2034. [PubMed: 7538046]

116. Cho WK, Boyer JL. Vasoactive intestinal polypeptide is a potent regulator of bile secretion from rat cholangiocytes. Gastroenterology. 1999; 117:420-428. [PubMed: 10419925]

117. Cho WK, Mennone A, Boyer JL. Effect of bombesin on secretion in isolated polarized intrahepatic bile ductular units (IBDU). Gastroenterology. 1995; 108:A1049.

118. Cho WK, Mennone A, Rydberg SA, Boyer JL. Bombesin stimulates bicarbonate secretion from rat cholangiocytes: Implications for neural regulation of bile secretion. Gastroenterology. 1997; 113:311-321. [PubMed: 9207292]

119. Chu X, Strauss JR, Mariano MA, Li J, Newton DJ, Cai X, Wang RW, Yabut J, Hartley DP, Evans DC, Evers R. Characterization of mice lacking the multidrug resistance protein Mrp2 (Abcc2). J Pharmacol Exp Ther. 2006; 317:579-589. [PubMed: 16421286]

120. Clayton RJ, Iber FL, Ruebner BH, McKusick VA. Byler Disease: Fatal familial intrahepatic cholestasis in an Amish Kindred. Am J Dis Child. 1969; 117:112-124. [PubMed: 5762004] 
121. Cohn JA, Strong TV, Picciotto MR, Nairn AC, Collins FS, Fitz JG. Localization of the cystic fibrosis transmembrane conductance regulator in human bile duct epithelial cells. Gastroenterology. 1993; 105:1857-1864. [PubMed: 7504645]

122. Corasanti JG, Smith ND, Gordon ER, Boyer JL. Protein kinase C agonists inhibit bile secretion independently of effects on the microcirculation in the isolated perfused rat liver. Hepatology. 1989; 10:8-13. [PubMed: 2737605]

123. Cousins RJ. Absorption, transport, and hepatic metabolism of copper and zinc: Special reference to metallothionein and ceruloplasmin. Physiol Rev. 1985; 65:238-309. [PubMed: 3885271]

124. Craddock AL, Love MW, Daniel RW, Kirby LC, Walters HC, Wong MH, Dawson PA. Expression and transport properties of the human ileal and renal sodium-dependent bile acid transporter. Am J Physiol. 1998; 37:157-169.

125. Crawford AR, Smith AJ, Hatch VC, Oude ER, Borst P, Crawford JM. Hepatic secretion of phospholipid vesicles in the mouse critically depends on mdr2 or MDR3 P-glycoprotein expression. Visualization by electron microscopy. J Clin Invest. 1997; 100:2562-2567. [PubMed: 9366571]

126. Crawford JM. Role of vesicle-mediated transport pathways in hepatocellular bile secretion. Semin Liver Dis. 1996; 16:169-189. [PubMed: 8781022]

127. Crawford JM, Strahs DCJ, Crawford AR, Barnes S. Role of bile salt hydrophobicity in hepatic microtubule-dependent bile salt secretion. J Lipid Res. 1994; 35:1738-1748. [PubMed: 7852851]

128. Davit-Spraul A, Fabre M, Branchereau S, Baussan C, Gonzales E, Stieger B, Bernard O, Jacquemin E. ATP8B1 and ABCB11 analysis in 62 children with normal gamma-glutamyl transferase progressive familial intrahepatic cholestasis (PFIC): Phenotypic differences between PFIC1 and PFIC2 and natural history. Hepatology. 2010; 51:1645-1655. [PubMed: 20232290]

129. Davit-Spraul A, Gonzales E, Baussan C, Jacquemin E. The spectrum of liver diseases related to ABCB4 gene mutations: Pathophysiology and clinical aspects. Semin Liver Dis. 2010; 30:134146. [PubMed: 20422496]

130. Dawson PA, Hubbert M, Haywood J, Craddock AL, Zerangue N, Christian WV, Ballatori N. The heteromeric organic solute transporter alphabeta, Osta-Ost $\beta$, is an ileal basolateral bile acid transporter. J Biol Chem. 2005; 280:6960-6968. [PubMed: 15563450]

131. De Vree JM, Jacquemin E, Sturm E, Cresteil D, Bosma PJ, Aten J, Deleuze JF, Desrochers M, Burdelski M, Bernard O, Elferink RPO, Hadchouel M. Mutations in the MDR3 gene cause progressive familial intrahepatic cholestasis. Proc Natl Acad Sci U S A. 1998; 95:282-287. [PubMed: 9419367]

132. Debray D, Rainteau D, Barbu V, Rouahi M, El Mourabit H, Lerondel S, Rey C, Humbert L, Wendum D, Cottart CH, Dawson P, Chignard N, Housset C. Defects in gallbladder emptying and bile acid homeostasis in mice with cystic fibrosis transmembrane conductance regulator deficiencies. Gastroenterology. 2012; 142:1581-1591. [PubMed: 22370478]

133. Delaunay JL, Durand-Schneider AM, Delautier D, Rada A, Gautherot J, Jacquemin E, AitSlimane T, Maurice M. A missense mutation in ABCB4 gene involved in progressive familial intrahepatic cholestasis type 3 leads to a folding defect that can be rescued by low temperature. Hepatology. 2009; 49:1218-1227. [PubMed: 19185004]

134. Deleuze JF, Jacquemin E, Dubuisson C, Crestell D, Dumont M, Erlinger S, Bernard O, Hadchouel M. Defect on multidrug-resistance 3 gene expression in a subtype of progressive familial intrahepatic cholestasis. Hepatology. 1996; 23:904-908. [PubMed: 8666348]

135. Denk GU, Soroka CJ, Mennone A, Koepsell H, Beuers U, Boyer JL. Down-regulation of the organic cation transporter 1 of rat liver in obstructive cholestasis. Hepatology. 2004; 39:13821389. [PubMed: 15122767]

136. Denson LA, Auld KL, Schiek DS, McClure MH, Mangelsdorf DJ, Karpen SJ. Interleukin-1 $\beta$ suppresses retinoid transactivation of two hepatic transporter genes involved in bile formation. $\mathrm{J}$ Biol Chem. 2000; 275:8835-8843. [PubMed: 10722729]

137. Denson LA, Sturm E, Echevarria W, Zimmerman TL, Makishima M, Mangelsdorf DJ, Karpen SJ. The orphan nuclear receptor, shp, mediates bile acid-induced inhibition of the rat bile acid transporter, ntcp. Gastroenterology. 2001; 121:140-147. [PubMed: 11438503] 
138. Dijkstra M, Havinga R, Vonk RJ, Kuipers F. Bile secretion of cadmium, silver, zinc and copper in the rat. Involvement of various transport systems. Life Sciences. 1996; 59:1237-1246. [PubMed: 8845010]

139. Dijkstra M, Intveld G, vandenBerg GJ, Muller M, Kuipers F, Vonk RJ. Adenosine triphosphatedependent copper transport in isolated rat liver plasma membranes. J Clin Invest. 1995; 95:412416. [PubMed: 7814642]

140. Dikkers A, Tietge UJ. Biliary cholesterol secretion: More than a simple ABC. World J Gastroenterol. 2010; 16:5936-5945. [PubMed: 21157969]

141. Dixon PH, van Mil SW, Chambers J, Strautnieks S, Thompson RJ, Lammert F, Kubitz R, Keitel V, Glantz A, Mattsson LA, Marschall HU, Molokhia M, Moore GE, Linton KJ, Williamson C. Contribution of variant alleles of ABCB11 to susceptibility to intrahepatic cholestasis of pregnancy. Gut. 2009; 58:537-544. [PubMed: 18987030]

142. Dixon PH, Weerasekera N, Linton KJ, Donaldson O, Chambers J, Egginton E, Weaver J, NelsonPiercy C, de Swiet M, Warnes G, Elias E, Higgins CF, Johnston DG, McCarthy MI, Williamson C. Heterozygous MDR3 missense mutation associated with intrahepatic cholestasis of pregnancy: Evidence for a defect in protein trafficking. Hum Mol Genet. 2000; 9:1209-1217. [PubMed: 10767346]

143. Dombrowski F, Kubitz R, Chittattu A, Wettstein M, Saha N, Haussinger D. Electron-microscopic demonstration of multidrug resistance protein 2 (Mrp2) retrieval from the canalicular membrane in response to hyperosmolarity and lipopolysaccharide. Biochem J. 2000; 348:183-188. [PubMed: 10794730]

144. Donner MG, Keppler D. Up-regulation of basolateral multidrug resistance protein 3 (Mrp3) in cholestatic rat liver. Hepatology. 2001; 34:351-359. [PubMed: 11481620]

145. Dowling RH, Mack E, Picott J, Berger J, Small DM. Experimental model for the study of the enterohepatic circulation of bile in rhesus monkeys. J Lab Clin Med. 1968; 72:169-176. [PubMed: 4968980]

146. Dranoff JA, Masyuk AI, Kruglov EA, LaRusso NF, Nathanson MH. Polarized expression and function of P2Y ATP receptors in rat bile duct epithelia. Am J Physiol Gastrointest Liver Physiol. 2001; 281:G1059-G1067. [PubMed: 11557527]

147. Dufour J-FJ, Turner TJ, Arias IM. Nitric oxide blocks bile canalicular contraction by inhibiting inositol trisphosphate-dependent calcium mobilization. Gastroenterology. 1995; 108:841-849. [PubMed: 7875487]

148. Dumont M, Erlinger S, Uchman S. Hypercholeresis induced by ursodeoxycholic acid and 7ketolithocholic acid in the rat: Possible role of bicarbonate transport. Gastroenterology. 1980; 79:82-89. [PubMed: 7380227]

149. Ekataksin, W.; Wake, K. New concepts in biliary and vascular anatomy of the liver. In: Boyer, JL.; Ockner, RK., editors. Progress in Liver Diseases. Philadelphia: W. B. Saunders; 1997. p. 1-30.

150. Elferink RPJO, Ottenhoff R, van Wijland M, Smit JJM, Schinkel AH, Groen AK. Regulation of biliary lipid secretion by mdr2 P-glycoprotein in the mouse. J Clin Invest. 1995; 95:31-38. [PubMed: 7814632]

151. Erlinger, S. Bile flow. In: Arias, IM.; Boyer, JL.; Fausto, N.; Jakoby, WB.; Schachter, DA.; Shafritz, DA., editors. The Liver:Biology and Pathobiology. New York: Raven Press; 1994. p. 769-786.

152. Esteller A. Physiology of bile secretion. World J Gastroenterol. 2008; 14:5641-5649. [PubMed: 18837079]

153. Fang F, Christian WV, Gorman SG, Cui M, Huang J, Tieu K, Ballatori N. Neurosteroid transport by the organic solute transporter OSTalpha-OSTbeta. J Neurochem. 2010; 115:220-233. [PubMed: 20649839]

154. Farina A, Dumonceau JM, Lescuyer P. Proteomic analysis of human bile and potential applications for cancer diagnosis. Expert Rev Proteomics. 2009; 6:285-301. [PubMed: 19489700] 
155. Fattinger K, Funk C, Pantze M, Weber C, Reichen J, Stieger B, Meier PJ. The endothelin antagonist bosentan inhibits the canalicular bile salt export pump: A potential mechanism for hepatic adverse reactions. Clin Pharmacol Ther. 2001; 69:223-231. [PubMed: 11309550]

156. Fausther M, Lecka J, Soliman E, Kauffenstein G, Pelletier J, Sheung N, Dranoff JA, Sevigny J. Coexpression of ecto-5'-nucleotidase/CD73 with specific NTPDases differentially regulates adenosine formation in the rat liver. Am Physiol Gastrointest Liver Physiol. 2012; 302:G447G459.

157. Fausther M, Sevigny J. Extracellular nucleosides and nucleotides regulate liver functions via a complex system of membrane proteins. C R Biol. 2011; 334:100-117. [PubMed: 21333941]

158. Feranchak AP, Fitz JG. Adenosine triphosphate release and purinergic regulation of cholangiocyte transport. Sem Liv Dis. 2002; 22:251-262.

159. Feranchak AP, Fitz JG. Thinking outside the cell: The role of extracellular adenosine triphosphate in bile formation. Gastroenterology. 2007; 133:1726-1728. [PubMed: 17983816]

160. Ferdinandusse S, Denis S, Faust PL, Wanders RJ. Bile acids: The role of peroxisomes. J Lipid Res. 2009; 50:2139-2147. [PubMed: 19357427]

161. Fickert P, Fuchsbichler A, Wagner M, Zollner G, Kaser A, Tilg H, Krause R, Lammert F, Langner C, Zatloukal K, Marschall HU, Denk H, Trauner M. Regurgitation of bile acids from leaky bile ducts causes sclerosing cholangitis in Mdr2 (Abcb4) knockout mice. Gastroenterology. 2004; 127:261-274. [PubMed: 15236191]

162. Fiorucci S, Antonelli E, Mencarelli A, Orlandi S, Renga B, Rizzo G, Distrutti E, Shah V, Morelli A. The third gas: H2S regulates perfusion pressure in both the isolated and perfused normal rat liver and in cirrhosis. Hepatology. 2005; 42:539-548. [PubMed: 16108046]

163. Fitz JG, Basavappa S, McGill J, Melhus O, Cohn JA. Regulation of membrane chloride currents in rat bile duct epithelial cells. J Clin Invest. 1993; 91:319-328. [PubMed: 7678606]

164. Folmer DE, van der Mark VA, Ho-Mok KS, Oude Elferink RP, Paulusma CC. Differential effects of progressive familial intrahepatic cholestasis type 1 and benign recurrent intrahepatic cholestasis type 1 mutations on canalicular localization of ATP8B1. Hepatology. 2009; 50:15971605. [PubMed: 19731236]

165. Folsch UR, Wormsley KG. The amino acid composition of rat bile. Experientia. 1977; 33:10551056. [PubMed: 891809]

166. Fouassier L, Duan C, Feranchak AP, Yun CH, Sutherland E, Simon F, Fitz JG, Doctor RB. Ezrinradixin-moesin-binding phosphoprotein 50 is expressed at the apical membrane of rat liver epithelia. Hepatology. 2001; 33:166-176. [PubMed: 11124833]

167. Francis H, Glaser S, Ueno Y, LeSagE G, Marucci L, Benedetti A, Taffetani S, Marzioni M, Alvaro D, Venter J, Reichenbach R, Fava G, Phinizy JL, Alpini G. cAMP stimulates the secretory and proliferative capacity of the rat intrahepatic biliary epithelium through changes in the PKA/Src/MEK/ERK1/2 pathway. J Hepatol. 2004; 41:528-537. [PubMed: 15464232]

168. Fu D, Wakabayashi Y, Ido Y, Lippincott-Schwartz J, Arias IM. Regulation of bile canalicular network formation and maintenance by AMP-activated protein kinase and LKB1. J Cell Sci. 2010; 123:3294-3302. [PubMed: 20826460]

169. Fu D, Wakabayashi Y, Lippincott-Schwartz J, Arias IM. Bile acid stimulates hepatocyte polarization through a cAMP-Epac-MEK-LKB1-AMPK pathway. Proc Natl Acad Sci U S A. 2011; 108:1403-1408. [PubMed: 21220320]

170. Fuchs M, Lammert F, Wang DWH, Paigen B, Carey MC, Cohen DE. Sterol carrier protein 2 participates in hypersecretion of biliary cholesterol during gallstone formation in genetically gallstone-susceptible mice. Biochem J. 1998; 336:33-37. [PubMed: 9806881]

171. Fujii K, Sakuragawa T, Kashiba M, Sugiura Y, Kondo M, Maruyama K, Goda N, Nimura Y, Suematsu M. Hydrogen sulfide as an endogenous modulator of biliary bicarbonate excretion in the rat liver. Antioxid Redox Signal. 2005; 7:788-794. [PubMed: 15890026]

172. Ganguly TC, Liu Y, Hyde JF, Hagenbuch B, Meier PJ, Vore M. Prolactin increases hepatic $\mathrm{Na}^{+} /$ taurocholate co-transport activity and messenger RNA post partum. Biochem J. 1994; 303:33-36. [PubMed: 7945260] 
173. Ganguly TC, O’Brien ML, Karpen SJ, Hyde JF, Suchy FJ, Vore M. Regulation of the rat liver sodium-dependent bile acid cotransporter gene by prolactin. J Clin Invest. 1997; 99:2906-2914. [PubMed: 9185514]

174. Garcia F, Kierbel A, Larocca MC, Gradilone SA, Splinter P, LaRusso NF, Marinelli RA. The water channel aquaporin- 8 is mainly intracellular in rat hepatocytes, and its plasma membrane insertion is stimulated by cyclic AMP. J Biol Chem. 2001; 276:12147-12152. [PubMed: 11278499]

175. Gartung C, Ananthanarayanan M, Rahman MA, Schuele S, Nundy S, Soroka CJ, Stolz A, Suchy FJ, Boyer JL. Down-regulation of expression and function of the rat liver $\mathrm{Na}^{+} / \mathrm{bile}$ acid cotransporter in extrahepatic cholestasis. Gastroenterology. 1996; 110:199-209. [PubMed: 8536857]

176. Gatof D, Kilic G, Fitz JG. Vesicular exocytosis contributes to volume-sensitive ATP release in biliary cells. Am J Physiol Gastrointest Liver Physiol. 2004; 286:G538-G546. [PubMed: 14604861]

177. Gautam A, Ng O-C, Boyer JL. Isolated rat hepatocyte couplets in short-term culture: Structural characteristics and plasma membrane reorganization. Hepatology. 1987; 7:216-223. [PubMed: 3557300]

178. Gautam A, Scaramuzza D, Boyer JL. Quantitative assessment of primary canalicular secretion in isolated rat hepatocyte couplets (IRHC) by optical planimetry. Gastroenterology. 1986; 90:1727.

179. Geier A, Dietrich CG, Voigt S, Ananthanarayanan M, Lammert F, Schmitz A, Trauner M, Wasmuth HE, Boraschi D, Balasubramaniyan N, Suchy FJ, Matern S, Gartung C. Cytokinedependent regulation of hepatic organic anion transporter gene transactivators in mouse liver. Am J Physiol Gastrointest Liver Physiol. 2005; 289:G831-G841. [PubMed: 15860642]

180. Geier A, Fickert P, Trauner M. Mechanisms of disease: Mechanisms and clinical implications of cholestasis in sepsis. Nat Clin Pract Gastroenterol Hepatology. 2006; 3:574-585.

181. Gerloff T, Stieger B, Hagenbuch B, Madon J, Landmann L, Roth J, Hofmann AF, Meier PJ. The sister P-glycoprotein represents the canalicular bile salt export pump of mammalian liver. J Biol Chem. 1998; 273:10046-10050. [PubMed: 9545351]

182. Giaquinto PC, Hara TJ. Discrimination of bile acids by the rainbow trout olfactory system: Evidence as potential pheromone. Biol Res. 2008; 41:33-42. [PubMed: 18769761]

183. Gigliozzi, A.; Fraioli, F.; Boyer, JL. Hormonal regulation of cholangiocyte secretion. In: Alpini, G.; Alvaro, D.; Marzioni, M.; LeSage, G.; LaRusso, N., editors. The Pathophysiology of Biliary Epithelia. Georgetown, Texas, USA: Landes Bioscience; 2004. p. 89-95.

184. Gigliozzi A, Fraioli F, Sundaram P, Lee J, Mennone A, Alvaro D, Boyer JL. Molecular identification and functional characterization of mdrla in rat cholangiocytes. Gastroenterology. 2000; 119:1113-1122. [PubMed: 11040198]

185. Glaser SS, Gaudio E, Rao A, Pierce LM, Onori P, Franchitto A, Francis HL, Dostal DE, Venter JK, DeMorrow S, Mancinelli R, Carpino G, Alvaro D, Kopriva SE, Savage JM, Alpini GD. Morphological and functional heterogeneity of the mouse intrahepatic biliary epithelium. Lab Invest. 2009; 89:456-469. [PubMed: 19204666]

186. Glaser SS, Rodgers RED, Phinizy JL, Robertson WE, Lasater J, Caligiuri A, Tretjak Z, LeSage GD, Alpini G. Gastrin inhibits secretininduced ductal secretion by interaction with specific receptors on rat cholangiocytes. Am J Physiol. 1997; 36:G1061-G1070. [PubMed: 9374703]

187. Godfrey PP, Warner MJ, Coleman R. Enzymes and proteins in bile. Variations in output in rat cannula bile during and after depletion of the bile-salt pool. Biochem J. 1981; 196:11-16. [PubMed: 7306064]

188. Gonzales E, Grosse B, Cassio D, Davit-Spraul A, Fabre M, Jacquemin E. Successful mutationspecific chaperone therapy with 4-phenylbutyrate in a child with progressive familial intrahepatic cholestasis type 2. J Hepatol. 2012; 57:695-698. [PubMed: 22609309]

189. Gottesman MM, Pastan I. Biochemistry of multidrug resistance mediated by the multidrug transporter. Ann Rev Biochem. 1993; 62:385-427. [PubMed: 8102521]

190. Govindarajan R, Bakken AH, Hudkins KL, Lai Y, Casado FJ, Pastor-Anglada M, Tse CM, Hayashi J, Unadkat JD. In situ hybridization and immunolocalization of concentrative and 
equilibrative nucleoside transporters in the human intestine, liver, kidneys, and placenta. Am J Physiol Regul Integr Comp Physiol. 2007; 293:R1809-R1822. [PubMed: 17761511]

191. Govindarajan R, Endres CJ, Whittington D, Lecluyse E, Pastor-Anglada M, Tse CM, Unadkat JD. Expression and hepatobiliary transport characteristics of the concentrative and equilibrative nucleoside transporters in sandwich-cultured human hepatocytes. Am J Physiol Gastrointest Liver Physiol. 2008; 295:G570-G580. [PubMed: 18635603]

192. Gradhand U, Lang T, Schaeffeler E, Glaeser H, Tegude H, Klein K, Fritz P, Jedlitschky G, Kroemer HK, Bachmakov I, Anwald B, Kerb R, Zanger UM, Eichelbaum M, Schwab M, Fromm MF. Variability in human hepatic MRP4 expression: Influence of cholestasis and genotype 1. Pharmacogenomics J. 2007; 8:42-52. [PubMed: 17404579]

193. Gradilone SA, Garcia F, Huebert RC, Tietz PS, Larocca MC, Kierbel A, Carreras FI, LaRusso NF, Marinelli RA. Glucagon induces the plasma membrane insertion of functional aquaporin-8 water channels in isolated rat hepatocytes. Hepatology. 2003; 37:1435-1441. [PubMed: 12774023]

194. Graf GA, Li WP, Gerard RD, Gelissen I, White A, Cohen JC, Hobbs HH. Coexpression of ATPbinding cassette proteins ABCG5 and ABCG8 permits their transport to the apical surface. J Clin Invest. 2002; 110:659-669. [PubMed: 12208867]

195. Graf GA, Yu L, Li WP, Gerard R, Tuma PL, Cohen JC, Hobbs HH. ABCG5 and ABCG8 are obligate heterodimers for protein trafficking and biliary cholesterol excretion. J Biol Chem. 2003; 278:48275-48282. [PubMed: 14504269]

196. Graf J, Gautam A, Boyer JL. Isolated rat hepatocyte couplets: A primary secretory unit for electrophysiologic studies of bile secretory function. Proc Natl Acad Sci U S A. 1984; 81:65166520. [PubMed: 6149546]

197. Graf J, Henderson RM, Krumpholz B, Boyer JL. Cell membrane and transepithelial voltages and resistances in isolated rat hepatocyte couplets. J Membrane Biol. 1987; 95:241-254. [PubMed: 3585979]

198. Grasbeck R, Nyberg W, Reizenstein P. Biliary and fecal vitamin B 12 excretion in man: An isotope study. Proc Soc Exp Biol Med. 1958; 97:780-784. [PubMed: 13554481]

199. Green R, Jacobsen DW, van Tonder SV, Kew MC, Metz J. Enterohepatic circulation of cobalamin in the nonhuman primate. Gastroenterology. 1981; 81:773-776. [PubMed: 7262521]

200. Green RM, Beier D, Gollan JL. Regulation of hepatocyte bile salt transporters by endotoxin and inflammatory cytokines in rodents. Gastroenterology. 1996; 111:193-198. [PubMed: 8698199]

201. Groen A, Romero MR, Kunne C, Hoosdally SJ, Dixon PH, Wooding C, Williamson C, Seppen J, Van den OK, Mok KS, Paulusma CC, Linton KJ, Oude Elferink RP. Complementary functions of the flippase ATP8B1 and the floppase ABCB4 in maintaining canalicular membrane integrity. Gastroenterology. 2011; 141:1927-1937. [PubMed: 21820390]

202. Grundemann D, Gorboulev V, Gambaryan S, Veyhl M, Koepsell H. Drug excretion mediated by a new prototype of polyspecific transporter. Nature (Lond). 1994; 372:549-552. [PubMed: 7990927]

203. Grune S, Engelking LR, Anwer MS. Role of intracellular calcium and protein kinases in the activation of hepatic $\mathrm{Na}^{+} /$taurocholate cotransport by cyclic AMP. J Biol Chem. 1993; 268:17734-17741. [PubMed: 8394349]

204. Gurantz D, Hofmann AF. Influence of bile acid structure on bile flow and biliary lipid secretion in the hamster. Am J Physiol. 1984; 247:G736-G748. [PubMed: 6507626]

205. Guzelian P, Boyer JL. Glucose reabsorption from bile: Evidence for a biliohepatic circulation. J Clin Invest. 1974; 53:526-535. [PubMed: 11344566]

206. Hagenbuch B, Gui C. Xenobiotic transporters of the human organic anion transporting polypeptides (OATP) family. Xenobiotica. 2008; 38:778-801. [PubMed: 18668430]

207. Hagenbuch B, Meier PJ. Molecular cloning, chromosomal localization, and functional characterization of a human liver $\mathrm{Na}^{+}$/bile acid cotransporter. J Clin Invest. 1994; 93:1326-1331. [PubMed: 8132774]

208. Hagenbuch B, Meier PJ. Sinusoidal (basolateral) bile salt uptake systems of hepatocytes. Sem Liv Dis. 1996; 16:129-136. 
209. Hagenbuch B, Meier PJ. The superfamily of organic anion transporting polypeptides. Biochim Biophys Acta. 2003; 1609:1-18. [PubMed: 12507753]

210. Hagenbuch B, Meier PJ. Organic anion transporting polypeptides of the OATP/ SLC21 family: Phylogenetic classification as OATP/ SLCO superfamily, new nomenclature and molecular/ functional properties. Pflugers Arch. 2004; 447:653-665. [PubMed: 14579113]

211. Hagenbuch B, Scharschmidt BF, Meier PJ. Effect of antisense oligonucleotides on the expression of hepatocellular bile acid and organic anion uptake systems in Xenopus laevis oocytes. Biochem J. 1996; 216:901-904. [PubMed: 8670169]

212. Hagenbuch B, Stieger B, Foguet M, Lubbert H, Meier PJ. Functional expression cloning and characterization of the hepatocyte $\mathrm{Na}^{+}$/bile acid cotransport system. Proc Natl Acad Sci U S A. 1991; 88:10629-10633. [PubMed: 1961729]

213. Hagey LR, Moller PR, Hofmann AF, Krasowski MD. Diversity of bile salts in fish and amphibians: Evolution of a complex biochemical pathway. Physiol Biochem Zool. 2010; 83:308-321. [PubMed: 20113173]

214. Hagey LR, Vidal N, Hofmann AF, Krasowski MD. Complex evolution of bile salts in birds. Auk. 2010; 127:820-831. [PubMed: 21113274]

215. Hagey LR, Vidal N, Hofmann AF, Krasowski MD. Evolutionary diversity of bile salts in reptiles and mammals, including analysis of ancient human and extinct giant ground sloth coprolites. BMC Evol Biol. 2010; 10:133. [PubMed: 20444292]

216. Haimeur A, Conseil G, Deeley RG, Cole SP. The MRP-related and BCRP/ABCG2 multidrug resistance proteins: Biology, substrate specificity and regulation 1. Curr Drug Metab. 2004; 5:21-53. [PubMed: 14965249]

217. Harada M, Sakisaka S, Terada K, Kimura R, Kawaguchi T, Koga H, Kim M, Taniguchi E, Hanada S, Suganuma T, Furuta K, Sugiyama T, Sata M. A mutation of the wilson disease protein, atp7b, is degraded in the proteasomes and forms protein aggregates. Gastroenterology. 2001; 120:967-974. [PubMed: 11231950]

218. Haussinger D, Schmitt M, Weiergraber O, Kubitz R. Short-term regulation of canalicular transport. Semin Liver Dis. 2000; 20:307-321. [PubMed: 11076398]

219. Hayakawa T, Bruck R, Ng OC, Boyer JL. DBcAMP stimulates vesicle transport and HRP excretion in isolated perfused rat liver. Am J Physiol. 1990; 259:G727-G735. [PubMed: 2173414]

220. Hayakawa T, Corasanti JG, Phillips KA, Boyer JL. The protein kinase C agonist, 12,13 phorbol dibutyrate (PDB) counteracts cAMP-stimulated horseradish peroxidase (HRP) excretion in the isolated perfused rat liver (IPRL). Hepatology. 1989; 10:598.

221. Hayakawa T, Ng OC, Ma A, Boyer JL. Taurocholate stimulates transcytotic vesicular pathways labelled by horseradish peroxidase in the isolated perfused rat liver. Gastroenterology. 1990; 99:216-228. [PubMed: 2344927]

222. Hayashi H, Inamura K, Aida K, Naoi S, Horikawa R, Nagasaka H, Takatani T, Fukushima T, Hattori A, Yabuki T, Horii I, Sugiyama Y. AP2 mediates BSEP internalization and modulates its hepatocanalicular expression and transport function. Hepatology. 2012; 55:1889-1900. [PubMed: 22262466]

223. Hayashi H, Sugiyama Y. 4-phenylbutyrate enhances the cell surface expression and the transport capacity of wild-type and mutated bile salt export pumps 1. Hepatology. 2007; 45:1506-1516. [PubMed: 17538928]

224. Hayashi H, Sugiyama Y. Short-chain ubiquitination is associated with the degradation rate of a cell-surface-resident bile salt export pump (BSEP/ABCB11). Mol Pharmacol. 2009; 75:143-150. [PubMed: 18829893]

225. Hayes JH, Soroka CJ, Rios-Velez L, Boyer JL. Hepatic sequestration and modulation of the canalicular transport of the organic cation, daunorubicin, in the rat. Hepatology. 1999; 29:483493. [PubMed: 9918926]

226. Hayhurst GP, Lee YH, Lambert G, Ward JM, Gonzalez FJ. Hepatocyte nuclear factor 4alpha (nuclear receptor 2A1) is essential for maintenance of hepatic gene expression and lipid homeostasis. Mol Cell Biol. 2001; 21:1393-1403. [PubMed: 11158324] 
227. Hazard SE, Patel SB. Sterolins ABCG5 and ABCG8: Regulators of whole body dietary sterols. Pflugers Arch. 2007; 453:745-752. [PubMed: 16440216]

228. Helvoort A, Smith AJ, Sprong H, Fritzsche I, Schinkel AH, Borst P, van Meer G. MDR1 Pglycoprotein is a lipid translocase of broad specificity, while MDR3 P-glycoprotein specifically translocates phosphatidylcholine. Cell. 1996; 87:507-517. [PubMed: 8898203]

229. Hernandez S, Tsuchiya Y, Garcia-Ruiz JP, Lalioti V, Nielsen S, Cassio D, Sandoval IV. ATP7B copper-regulated traffic and association with the tight junctions: Copper excretion into the bile. Gastroenterology. 2008; 134:1215-1223. [PubMed: 18395099]

230. Hirano M, Maeda K, Hayashi H, Kusuhara H, Sugiyama Y. Bile salt export pump (BSEP/ ABCB11) can transport a nonbile acid substrate, pravastatin. J Pharmacol Exp Ther. 2005; 314:876-882. [PubMed: 15901796]

231. Hirohashi T, Suzuki H, Takikawa H, Sugiyama Y. ATP-dependent transport of bile salts by rat multidrug resistance-associated protein 3 (Mrp3). J Biol Chem. 2000; 275:2905-2910. [PubMed: 10644759]

232. Ho RH, Leake BF, Kilkenny DM, Meyer Zu Schwabedissen HE, Glaeser H, Kroetz DL, Kim RB. Polymorphic variants in the human bile salt export pump (BSEP; ABCB11): Functional characterization and interindividual variability. Pharmacogenet Genomics. 2010; 20:45-57. [PubMed: 20010382]

233. Hofmann AF, Hagey LR. Bile acids: Chemistry, pathochemistry, biology, pathobiology, and therapeutics. Cell Mol Life Sci. 2008; 65:2461-2483. [PubMed: 18488143]

234. Hofmann AF, Hagey LR, Krasowski MD. Bile salts of vertebrates: Structural variation and possible evolutionary significance. J Lipid Res. 2010; 51:226-246. [PubMed: 19638645]

235. Honjo Y, Sasaki S, Kobayashi Y, Misawa H, Nakamura H. 1,25-dihydroxyvitamin D3 and its receptor inhibit the chenodeoxycholic acid-dependent transactivation by farnesoid $\mathrm{X}$ receptor. $\mathrm{J}$ Endocrinol. 2006; 188:635-643. [PubMed: 16522742]

236. Hoppe CA, Connolly TP, Hubbard AL. Transcellular transport of polymeric IgA in the rat hepatocyte: Biochemical and morphological characterization of the transport pathway. J Cell Biol. 1985; 101:2113-2123. [PubMed: 4066752]

237. Hosokawa S, Tagaya O, Mikami T, Nozaki Y, Kawaguchi A, Yamatsu K, Shamoto M. A new rat mutant with chronic conjugated hyperbilirubinemia and renal glomerular lesions. Lab Anim Sci. 1992; 42:27-34. [PubMed: 1316504]

238. Huang L, Zhao A, Lew JL, Zhang T, Hrywna Y, Thompson JR, de Pedro N, Royo I, Blevins RA, Pelaez F, Wright SD, Cui J. Farnesoid X receptor activates transcription of the phospholipid pump MDR3. J Biol Chem. 2003; 278:51085-51090. [PubMed: 14527955]

239. Hubacek JA, Berge KE, Cohen JC, Hobbs HH. Mutations in ATP-cassette binding proteins G5 (ABCG5)and G8 (ABCG8)causing sitosterolemia. Hum Mutat. 2001; 18:359-360. [PubMed: 11668628]

240. Hubbard AL, Stieger B, Bartles JR. Biogenesis of endogenous plasma membrane proteins in epithelial cells. Ann Rev Physiol. 1989; 51:755-770. [PubMed: 2653204]

241. Hung IH, Suzuki M, Yamaguchi Y, Yuan DS, Klausner RD, Gitlin JD. Biochemical characterization of the Wilson disease protein and functional expression in the yeast Saccharomyces cerevisiae. J Biol Chem. 1997; 272:21461-21466. [PubMed: 9261163]

242. Ieiri I, Suzuki H, Kimura M, Takane H, Nishizato Y, Irie S, Urae A, Kawabata K, Higuchi S, Otsubo K, Sugiyama Y. Influence of common variants in the pharmacokinetic genes (OATP-C, UGT1A1, and MRP2) on serum bilirubin levels in healthy subjects. Hepatol Res. 2004; 30:9195. [PubMed: 15519273]

243. Ihrke, G.; Hubbard, AL. Control of vesicle traffic in hepatocytes. In: Boyer, JL.; Ockner, RK., editors. Progress in Liver Diseases. Philadelphia: W.B. Saunders Company; 1995. p. 63-99.

244. Ismair MG, Hausler S, Stuermer CA, Guyot C, Meier PJ, Roth J, Stieger B. ABC-transporters are localized in caveolin-1-positive and reggie-1-negative and reggie-2-negative microdomains of the canalicular membrane in rat hepatocytes. Hepatology. 2009; 49:1673-1682. [PubMed: 19197976]

245. Iwayanagi Y, Takada T, Suzuki H. HNF4alpha is a crucial modulator of the cholesteroldependent regulation of NPC1L1. Pharm Res. 2008; 25:1134-1141. [PubMed: 18080173] 
246. Jacob G, Said O, Finberg J, Bomzon A. Peripheral vascular neuroeffector mechanisms in experimental cholestasis. Am J Physiol. 1993; 28:G579-G586. [PubMed: 8105696]

247. Jacquemin E, De Vree JM, Cresteil D, Sokal EM, Sturm E, Dumont M, Scheffer GL, Paul M, Burdelski M, Bosma PJ, Bernard O, Hadchouel M, Oude Elferink RPJ. The wide spectrum of multidrug resistance 3 deficiency: From neonatal cholestasis to cirrhosis of adulthood.

Gastroenterology. 2001; 120:1448-1458. [PubMed: 11313315]

248. Jansen P, Hooiveld G, Jacquemin E, Sokal E, Van Goor H, Koning J, Kuipers F, Stellaard F, Hadchouel M, Muller M. The canalicular bile salt exporting protein BSEP is not expressed in patients with progressive familial intrahepatic cholestasis type 2. Hepatology. 1998; 28(4):498A.

249. Jansen PL, Strautnieks SS, Jacquemin E, Hadchouel M, Sokal EM, Hooiveld GJ, Koning JH, De Jager-Krikken A, Kuipers F, Stellaard F, Bijleveld CM, Gouw A, Van GH, Thompson RJ, Muller M. Hepatocanalicular bile salt export pump deficiency in patients with progressive familial intrahepatic cholestasis. Gastroenterology. 1999; 117:1370-1379. [PubMed: 10579978]

250. Jansen PLM, Peters WH, Lamers WH. Hereditary chronic conjugated hyperbilirubinemia in mutant rats caused by defective hepatic anion transport. Hepatology. 1985; 5:573-579. [PubMed: 4018730]

251. Jara P, Hierro L, Martinez-Fernandez P, Alvarez-Doforno R, Yanez F, Diaz MC, Camarena C, De la Vega A, Frauca E, Munoz-Bartolo G, Lopez-Santamaria M, Larrauri J, Alvarez L. Recurrence of bile salt export pump deficiency after liver transplantation. N Engl J Med. 2009; 361:13591367. [PubMed: 19797282]

252. Jessner W, Zsembery A, Graf J. Transcellular water transport in hepatobiliary secretion and role of aquaporins in liver. Wien Med Wochenschr. 2008; 158:565-569. [PubMed: 18998074]

253. Juliano RL, Ling V. A surface glycoprotein modulating drug permeability in Chinese hamster ovary cell mutants. Biochim Biophys Acta. 1976; 455:152-162. [PubMed: 990323]

254. Jung D, Hagenbuch B, Gresh L, Pontoglio M, Meier PJ, Kullak-Ublick GA. Characterization of the human OATP-C (SLC21A6) gene promoter and regulation of liver-specific OATP genes by hepatocyte nuclear factor 1 alpha. J Biol Chem. 2001; 276:37206-37214. [PubMed: 11483603]

255. Jung D, Kullak-Ublick G-A. Hepatocyte nuclear factor 1a: A key mediator of the effect of bile acids on gene expression. Hepatology. 2003; 37:622-631. [PubMed: 12601360]

256. Jung D, Podvinec M, Meyer UA, Mangelsdorf DJ, Fried M, Meier PJ, Kullak-Ublick GA. Human organic anion transporting polypeptide 8 promoter is transactivated by the farnesoid X receptor/ bile acid receptor. Gastroenterology. 2002; 122:1954-1966. [PubMed: 12055601]

257. Jung N, Lehmann C, Rubbert A, Knispel M, Hartmann P, van Lunzen J, Stellbrink HJ, Faetkenheuer G, Taubert D. Relevance of the organic cation transporters 1 and 2 for antiretroviral drug therapy in human immunodeficiency virus infection. Drug Metab Dispos. 2008; 36:1616-1623. [PubMed: 18490433]

258. Jusko WJ, Levy G. Absorption, metabolism, and excretion of riboflavin-5'-phosphate in man. J Pharm Sci. 1967; 56:58-62. [PubMed: 6030496]

259. Kagawa T, Watanabe N, Mochizuki K, Numari A, Ikeno Y, Itoh J, Tanaka H, Arias IM, Mine T. Phenotypic differences in PFIC2 and BRIC2 correlate with protein stability of mutant Bsep and impaired taurocholate secretion in MDCK II cells. Am J Physiol Gastrointest Liver Physiol. 2008; 294:G58-G67. [PubMed: 17947449]

260. Kaminski DL, Ruwart M, Willman VL. The effect of prostaglandin A1 and E1 on canine hepatic bile flow. Surg Res. 1975; 18:391-397.

261. Kanno N, LeSagE G, Glaser S, Alpini G. Regulation of cholangiocyte bicarbonate secretion. Am J Physiol Gastrointest Liver Physiol. 2001; 281:G612-G625. [PubMed: 11518673]

262. Kanno N, LeSagE G, Glaser S, Alvaro D, Alpini G. Functional heterogeneity of the intrahepatic biliary epithelium. Hepatology. 2000; 31:555-561. [PubMed: 10706542]

263. Kaplan MM, Schmid C, Provenzale D, Sharma A, Dickstein G, McKu-sick A. A prospective trial of colchicine and methotrexate in the treatment of primary biliary cirrhosis. Gastroenterology. 1999; 117:1173-1180. [PubMed: 10535881]

264. Karpen SJ, Sun A, Kudish B, Hagenbuch B, Meier PJ, Ananthanarayanan M, Suchy FJ. Multiple factors regulate the rat liver basolateral sodium-dependent bile acid cotransporter gene promoter. J Biol Chem. 1996; 271:15211-15221. [PubMed: 8662994] 
265. Kartenbeck J, Leuschner U, Mayer R, Keppler D. Absence of the canalicular isoform of the MRP gene-encoded conjugate export pump from the hepatocytes in Dubin-Johnson syndrome. Hepatology. 1996; 23:1061-1066. [PubMed: 8621134]

266. Keitel V, Burdelski M, Vojnisek Z, Schmitt L, Haussinger D, Kubitz R. De novo bile salt transporter antibodies as a possible cause of recurrent graft failure after liver transplantation: A novel mechanism of cholestasis. Hepatology. 2009; 50:510-517. [PubMed: 19642168]

267. Keitel V, Burdelski M, Waqrskulat U, Kuhlkamp T, Keppler D, Haussinger D, Kubitz R. Expression and localization of hepatobiliary transport proteins in progressive familial intrahepatic cholestasis. Hepatology. 2005; 41:1160-1172. [PubMed: 15841457]

268. Keitel V, Haussinger D. TGR5 in the biliary tree. Dig Dis. 2011; 29:45-47. [PubMed: 21691103]

269. Keitel V, Kartenbeck J, Nies AT, Spring H, Brom M, Keppler D. Impaired protein maturation of the conjugate export pump multidrug resistance protein 2 as a consequence of a deletion mutation in dubinjohnson syndrome. Hepatology. 2000; 32:1317-1328. [PubMed: 11093739]

270. Keitel V, Reinehr R, Gatsios P, Rupprecht C, Gorg B, Selbach O, Haussinger D, Kubitz R. The G-protein coupled bile salt receptor TGR5 is expressed in liver sinusoidal endothelial cells. Hepatology. 2007; 45:695-704. [PubMed: 17326144]

271. Keitel V, Ullmer C, Haussinger D. The membrane-bound bile acid receptor TGR5 (Gpbar-1) is localized in the primary cilium of cholangiocytes. Biol Chem. 2010; 391:785-789. [PubMed: 20623999]

272. Keitel V, Vogt C, Haussinger D, Kubitz R. Combined mutations of canalicular transporter proteins cause severe intrahepatic cholestasis of pregnancy. Gastroenterology. 2006; 131:624629. [PubMed: 16890614]

273. Keppler D. Multidrug resistance proteins (MRPs, ABCCs): Importance for pathophysiology and drug therapy. Handb Exp Pharmacol. 2011:299-323. [PubMed: 21103974]

274. Keppler D, Konig J. Hepatic secretion of conjugated drugs and endogenous substances. Sem Liv Dis. 2000; 20:265-272.

275. Keppler D, Konig J, Buchler M. The canalicular multidrug resistance protein, cMRP/MRP2, a novel conjugate export pump expressed in the apical membrane of hepatocytes. Adv Enzyme Regul. 1997; 37:321-333. [PubMed: 9381978]

276. Kikuchi S, Hata M, Fukumoto K, Yamane Y, Matsui T, Tamura A, Yonemura S, Yamagishi H, Keppler D, Tsukita S, Tsukita S. Radixin deficiency causes conjugated hyperbilirubinemia with loss of Mrp2 from bile canalicular membranes. Nat Genet. 2002; 31:320-325. [PubMed: 12068294]

277. Kim MS, Lee KY, Chey WY. Plasma secretin concentrations in fasting and postprandial states in dog. Am J Physiol Endocrinol Metab. 1979; 236:E539-E544.

278. Kipp H, Arias IM. Intracellular trafficking and regulation of canalicular ATP-binding cassette transporters. Semin Liver Dis. 2000; 20:339-351. [PubMed: 11076400]

279. Kipp H, Arias IM. Trafficking of canalicular ABC transporters in hepatocytes. Annu Rev Physiol. 2002; 64:595-608. [PubMed: 11826281]

280. Kipp H, Pichetshote N, Arias IM. Transporters on demand: Intrahepatic pools of canalicular ATPbinding cassette transporters in rat liver. J Biol Chem. 2001; 276:7218-7224. [PubMed: 11113123]

281. Kitamura T, Jansen P, Hardenbrook C, Kamimoto Y, Gatmaitan Z, Arias IM. Defective ATPdependent bile canalicular transport of organic anions in mutant (TR-) rats with conjugated hyperbilirubinemia. Proc Natl Acad Sci U S A. 1990; 87:3557-3561. [PubMed: 2333302]

282. Kitani K, Kanai S. Effect of ursodeoxycholate on the bile flow in the rat. Life Sci. 1982; 31:1973-1985. [PubMed: 7176806]

283. Klaassen CD. Biliary excretion of metals. Drug Metab Rev. 1976; 5:165-196. [PubMed: 802467]

284. Klaassen CD, Aleksunes LM. Xenobiotic, bile acid, and cholesterol transporters: Function and regulation. Pharmacol Rev. 2010; 62:1-96. [PubMed: 20103563]

285. Klaassen CD, Watkins JBI. Mechanisms of bile formation, hepatic uptake, and biliary excretion. Pharm Reviews. 1984; 36:1-67.

286. Klomp LW, Vargas JC, van Mil SW, Pawlikowska L, Strautnieks SS, van Eijk MJ, Juijn JA, Pabon-Pena C, Smith LB, DeYoung JA, Byrne JA, Gombert J, van der BG, Berger R, Jankowska 
I, Pawlowska J, Villa E, Knisely AS, Thompson RJ, Freimer NB, Houwen RH, Bull LN. Characterization of mutations in ATP8B1 associated with hereditary cholestasis. Hepatology. 2004; 40:27-38. [PubMed: 15239083]

287. Knutter I, Rubio-Aliaga I, Boll M, Hause G, Daniel H, Neubert K, Brandsch M. H+-peptide cotransport in the human bile duct epithelium cell line SK-ChA-1. Am J Physiol Gastrointest Liver Physiol. 2002; 283:G222-G229. [PubMed: 12065310]

288. Koepsell H, Lips K, Volk C. Polyspecific organic cation transporters: Structure, function, physiological roles, and biopharmaceutical implications. Pharm Res. 2007; 24:1227-1251. [PubMed: 17473959]

289. Konig J, Nies AT, Cui Y, Leier I, Keppler D. Conjugate export pumps of the multidrug resistance protein (MRP) family: Localization, substrate specificity, and MRP2-mediated drug resistance. Biochim Biophys Acta. 1999; 1461:377-394. [PubMed: 10581368]

290. Kool M, van der Linden M, deHaas M, Scheffer GL, de Vree JML, Smith AJ, Jansen G, Peters GJ, Ponne N, Scheper RJ, Oude Elferink RPJ, Baas F, Borst P. MRP3, an organic anion transporter able to transport anti-cancer drugs. Proc Natl Acad Sci U S A. 1999; 96(12):69146919. [PubMed: 10359813]

291. Korner M, Hayes GM, Rehmann R, Zimmermann A, Scholz A, Wiedenmann B, Miller LJ, Reubi JC. Secretin receptors in the human liver: Expression in biliary tract and cholangiocarcinoma, but not in hepatocytes or hepatocellular carcinoma. J Hepatol. 2006; 45:825-835. [PubMed: 16935383]

292. Koukoui O, Boucherie S, Sezan A, Prigent S, Combettes L. Effects of the prostaglandins PGF2alpha and PGE2 on calcium signaling in rat hepatocyte doublets. Am J Physiol Gastrointest Liver Physiol. 2006; 290:G66-G73. [PubMed: 16081764]

293. Kozarsky KF, Donahee MH, Rigotti A, Iqbal SN, Edelman ER, Krieger M. Overexpression of the HDL receptor SR-BI alters plasma HDL and bile cholesterol levels. Nature. 1997; 387:414-417. [PubMed: 9163428]

294. Krishnamurthy P, Schuetz JD. Role of abcg2/bcrp in biology and medicine 1 . Annu Rev Pharmacol Toxicol. 2006; 46:381-410. [PubMed: 16402910]

295. Kristiansen TZ, Bunkenborg J, Gronborg M, Molina H, Thuluvath PJ, Argani P, Goggins MG, Maitra A, Pandey A. A proteomic analysis of human bile. Mol Cell Proteomics. 2004; 3:715728. [PubMed: 15084671]

296. Kruglov EA, Gautam S, Guerra MT, Nathanson MH. Type 2 inositol 1,4,5-trisphosphate receptor modulates bile salt export pump activity in rat hepatocytes. Hepatology. 2011; 54:1790-1799. [PubMed: 21748767]

297. Kruh GD, Belinsky MG, Gallo JM, Lee K. Physiological and pharmacological functions of Mrp2, Mrp3 and Mrp4 as determined from recent studies on gene-disrupted mice 1. Cancer Metastasis Rev. 2007; 26:5-14. [PubMed: 17273943]

298. Kubitz R, Sutfels G, Kuhlkamp T, Kolling R, Haussinger D. Trafficking of the bile salt export pump from the Golgi to the canalicular membrane is regulated by the p38 MAP kinase. Gastroenterology. 2004; 126:541-553. [PubMed: 14762791]

299. Kubitz R, Wettstein M, Warskulat U, Haussinger D. Regulation of the multidrug resistance protein 2 in the rat liver by lipopolysaccharide and dexamethasone. Gastroenterology. 1999; 116:401-410. [PubMed: 9922322]

300. Kullak-Ublick GA, Ismair MG, Stieger B, Landmann L, Huber R, Pizzagalli F, Fattinger K, Meier PJ, Hagenbuch B. Organic aniontransporting polypeptide B (OATP-B) and its functional comparison with three other OATPs of human liver. Gastroenterology. 2001; 120:525-533. [PubMed: 11159893]

301. Kumar R, Nagubandi S, Mattox VR, Londowski JM. Enterohepatic physiology of 1,25dihydroxyvitamin D3. J Clin Invest. 1980; 65:277-284. [PubMed: 7356679]

302. Kurashima K, Szabos EZ, Lukacs G, Orlowski J, Grinstein S. Endosomal recycling of the Na+/H + exchanger NHE3 isoform is regulated by the phosphatidylinositol 3-kinase pathway. J Biol Chem. 1998; 273:20828-20836. [PubMed: 9694828] 
303. Kurz AK, Block C, Graf D, Dahl SV, Schliess F, Haussinger D. Phosphoinositide 3-kinasedependent ras activation by tauroursodesoxycholate in rat liver. Biochem J. 2000; 350:207-213. [PubMed: 10926845]

304. Kurz AK, Graf D, Schmitt M, vom DS, Haussinger D. Tauroursodesoxycholate-induced choleresis involves $\mathrm{p} 38$ (MAPK) activation and translocation of the bile salt export pump in rats. Gastroenterology. 2001; 121:407-419. [PubMed: 11487550]

305. Kusuhara H, Sugiyama Y. In vitro-in vivo extrapolation of transporter-mediated clearance in the liver and kidney. Drug Metab Pharmacokinet. 2009; 24:37-52. [PubMed: 19252335]

306. Lam CW, Cheung KM, Tsui MS, Yan MS, Lee CY, Tong SF. A patient with novel ABCB11 gene mutations with phenotypic transition between BRIC2 and PFIC2 1. J Hepatol. 2006; 44:240-242. [PubMed: 16290310]

307. Lam P, Pearson CL, Soroka C, Xu S, Mennone A, Boyer JL. The level of plasma membrane expression in progressive and benign mutations of the bile salt export pump (Bsep/Abcb11) correlate with severity of cholestatic diseases. Am J Physiol Cell Physiol. 2007; 293:C1709_ C1716. [PubMed: 17855769]

308. Lam P, Soroka CJ, Boyer JL. The bile salt export pump: Clinical and experimental aspects of genetic and acquired cholestatic liver disease. Semin Liver Dis. 2010; 30:125-133. [PubMed: 20422495]

309. Lam P, Wang R, Ling V. Bile acid transport in sister of P-glycoprotein (ABCB11) knockout mice. Biochem. 2005; 44:12598-12605. [PubMed: 16156672]

310. Lam P, Xu S, Soroka CJ, Boyer JL. A c-terminal tyrosine-based motif in the bile salt export pump directs clathrin-dependent endocytosis. Hepatology. 2011

311. Landrier JF, Eloranta JJ, Vavricka SR, Kullak-Ublick GA. The nuclear receptor for bile acids, FXR, transactivates the human organic solute transporter-alpha and -beta genes. Am J Physiol Gastrointest Liver Physiol. 2005; 290:G476-G485. [PubMed: 16269519]

312. Lang C, Meier Y, Stieger B, Beuers U, Lang T, Kerb R, Kullak-Ublick GA, Meier PJ, PauliMagnus C. Mutations and polymorphisms in the bile salt export pump and the multidrug resistance protein 3 associated with drug-induced liver injury 1. Pharmacogenet Genomics. 2007; 17:47-60. [PubMed: 17264802]

313. Lang T, Haberl M, Jung D, Drescher A, Schlagenhaufer R, Keil A, Mornhinweg E, Stieger B, Kullak-Ublick GA, Kerb R. Genetic variability, haplotype structures, and ethnic diversity of hepatic transporters MDR3 (ABCB4) and bile salt export pump (ABCB11). Drug Metab Dispos. 2006; 34:1582-1599. [PubMed: 16763017]

314. Larkin JM, Coleman H, Espinosa A, Levenson A, Park MS, Woo B, Zervoudakis A, Tinh V. Intracellular accumulation of pIgA-R and regulators of transcytotic trafficking in cholestatic rat hepatocytes. Hepatology. 2003; 38:1199-1209. [PubMed: 14578858]

315. Larkin JM, Woo B, Balan V, Marks DL, Oswald BJ, LaRusso NF, McNiven MA. Rab3D, a small GTP-binding protein implicated in regulated secretion, is associated with the transcytotic pathway in rat hepatocytes. Hepatology. 2000; 32:348-356. [PubMed: 10915742]

316. LaRusso N. Proteins in bile: How they get there and what they do. Am J Physiol. 1984; 247:G199-G205. [PubMed: 6383073]

317. LaRusso NF, Masyuk TV. The role of cilia in the regulation of bile flow. Dig Dis. 2011; 29:6-12. [PubMed: 21691098]

318. Latham PS, Kashgarian M. The ultrastructural localization of transport ATPase in the rat liver at nonbile canalicular plasma membranes. Gastroenterology. 1979; 76:988-996. [PubMed: 220132]

319. Lauterburg B, Paumgartner G, Preisig R. Prostaglandin-induced choleresis in the rat. Experientia. 1975; 31:1191-1193. [PubMed: 1204737]

320. Layden TJ, Boyer JL. Influence of bile acids on bile canalicular membrane morphology and the lobular gradient in canalicular size. Lab Invest. 1978; 39:110-119. [PubMed: 682596]

321. Lazaridis KN, Pham L, Tietz P, Marinelli RA, deGroen PC, Levine S, Dawson PA, LaRusso NF. Rat cholangiocytes absorb bile acids at their apical domain via the ileal sodium-dependent bile acid transporter. J Clin Invest. 1997; 100:2714-2721. [PubMed: 9389734] 
322. Lazaridis KN, Pham L, Vroman B, DeGroen PC, LaRusso NF. Kinetic and molecular identification of sodium-dependent glucose transporter in normal rat cholangiocytes. Am J Physiol. 1997; 35:G1168-G1174. [PubMed: 9176227]

323. Ledger JE, Watson GJ, Compston JE. Biliary excretion of radioactivity after intravenous administration of [3H]25-hydroxyvitamin D3 in man. Dig Dis Sci. 1986; 31:361-368. [PubMed: 3956332]

324. Lee J, Azzaroli F, Wang L, Soroka CJ, Gigliozzi A, Setchell KD, Kramer W, Boyer JL. Adaptive regulation of bile salt transporters in kidney and liver in obstructive cholestasis in the rat. Gastroenterology. 2001; 121:1473-1484. [PubMed: 11729126]

325. Lee J, Boyer JL. Molecular alterations in hepatocyte transport mechanisms in acquired cholestatic liver disorders. Semin Liv Dis. 2000; 20:373-384.

326. Lee W, Glaeser H, Smith LH, Roberts RL, Moeckel GW, Gervasini G, Leake BF, Kim RB. Polymorphisms in human organic aniontransporting polypeptide 1A2 (OATP1A2): Implications for altered drug disposition and central nervous system drug entry. J Biol Chem. 2005; 280:9610-9617. [PubMed: 15632119]

327. Lehmann GL, Larocca MC, Soria LR, Marinelli RA. Aquaporins: Their role in cholestatic liver disease. World J Gastroenterol. 2008; 14:7059-7067. [PubMed: 19084912]

328. Leitch S, Feng M, Muend S, Braiterman LT, Hubbard AL, Rao R. Vesicular distribution of Secretory Pathway $\mathrm{Ca}(2)+-\mathrm{ATPase}$ isoform 1 and a role in manganese detoxification in liverderived polarized cells. Biometals. 2011; 24:159-170. [PubMed: 20981470]

329. Lenzen R, Alpini G, Tavoloni N. Secretin stimulates bile ductular secretory activity through the cAMP system. Am J Physiol. 1992; 263:G527-G532. [PubMed: 1329554]

330. Lenzen R, Hruby VJ, Tavoloni N. Mechanisms of glucagon choleresis in the guinea pig. Am J Physiol. 1990; 259:G736-G744. [PubMed: 2173415]

331. LeSage GD, Marucci L, Alvaro D, Glaser SS, Benedetti A, Marzioni M, Patel T, Francis H, Phinizy JL, Alpini G. Insulin inhibits secretin-induced ductal secretion by activation of PKC alpha and inhibition of PKA activity. Hepatology. 2002; 36:641-651. [PubMed: 12198656]

332. Lewarchik CM, Peters KW, Qi J, Frizzell RA. Regulation of CFTR trafficking by its R domain. J Biol Chem. 2008; 283:28401-28412. [PubMed: 18694937]

333. Li L, Lee TK, Meier PJ, Ballatori N. Identification of glutathione as a driving force and leukotriene $\mathrm{C} 4$ as a substrate for oatp1, the hepatic sinusoidal organic solute transporter. J Biol Chem. 1998; 273:16184-16191. [PubMed: 9632674]

334. Li L, Meier PJ, Ballatori N. Oatp2 mediates bidirectional organic solute transport: A role for intracellular glutathione. Mol Pharmacol. 2000; 58:335-340. [PubMed: 10908301]

335. Li M, Wang W, Soroka CJ, Mennone A, Harry K, Weinman EJ, Boyer JL. NHERF-1 binds to Mrp2 and regulates hepatic Mrp2 expression and function. J Biol Chem. 2010; 285:1929919307. [PubMed: 20404332]

336. Li W, Scott AP, Siefkes MJ, Yan H, Liu Q, Yun S-S, Gage DA. Bile acid secreted by male sea lamprey that acts as a sex pheromone. Science. 2002; 296:138-141. [PubMed: 11935026]

337. Li X, Weinman SA. Mrp2 modulates the acticity of chloride channels in isolated hepatocytes. Hepatology. 2002; 36:65-71. [PubMed: 12085350]

338. Liddle RA. Regulation of cholecystokinin secretion by intraluminal releasing factors. Am J Physiol. 1995; 269:G319-G327. [PubMed: 7573441]

339. Lidofsky SD, Roman RM. Alanine uptake activates hepatocellular chloride channels. Am J Physiol. 1997; 36:G849-G853. [PubMed: 9357826]

340. Logan GM, Weimer MK, Ellefson M, Pierach CA, Bloomer JR. Bile porphyrin analysis in the evaluation of variegate porphyria. N Engl J Med. 1991; 324:1408-1411. [PubMed: 2020296]

341. Lorenzini I, Sakisaka S, Meier PJ, Boyer JL. Demonstration of a transcellular vesicle pathway for biliary excretion of inulin in rat liver. Gastroenterology. 1986; 91:1278-1288. [PubMed: 3758619]

342. Lucena JF, Herrero JI, Quiroga J, Sangro B, Garcia-Foncillas J, abalegui N, Sola S, Herraiz M, Medina J, Prieto J. A multidrug resistance 3 gene mutation causing cholelithiasis, cholestasis of pregnancy, and adulthood biliary cirrhosis. Gastroenterology. 2003; 124:1037-1042. [PubMed: 12671900] 
343. Ludwig J, Ritman EL, LaRusso N, Sheedy PF, Zumpe G. Anatomy of the human biliary system studied by quantitative computer-aided three-dimensional imaging techniques. Hepatology. 1998; 27:893-899. [PubMed: 9537426]

344. Lui A, Lumeng L, Li TK. Biliary excretion of 14C-labeled vitamin B-6 in rats. J Nutr. 1983; 113:893-898. [PubMed: 6834154]

345. Luoma LM, Deeb TM, Macintyre G, Cox DW. Functional analysis of mutations in the ATP loop of the Wilson disease copper transporter, ATP7B. Hum Mutat. 2010; 31:569-577. [PubMed: 20333758]

346. Lykavieris P, van Mil S, Cresteil D, Fabre M, Hadchouel M, Klomp L, Bernard O, Jacquemin E. Progressive familial intrahepatic cholestasis type 1 and extrahepatic features: No catch-up of stature growth, exacerbation of diarrhea, and appearance of liver steatosis after liver transplantation. J Hepatol. 2003; 39:447-452. [PubMed: 12927934]

347. Maeda K, Sugiyama Y. Impact of genetic polymorphisms of transporters on the pharmacokinetic, pharmacodynamic and toxicological properties of anionic drugs. Drug Metab Pharmacokinet. 2008; 23:223-235. [PubMed: 18762709]

348. Maher JM, Dieter MZ, Aleksunes LM, Slitt AL, Guo G, Tanaka Y, Scheffer GL, Chan JY, Manautou JE, Chen Y, Dalton TP, Yamamoto M, Klaassen CD. Oxidative and electrophilic stress induces multidrug resistance-associated protein transporters via the nuclear factor-E2related factor-2 transcriptional pathway. Hepatology. 2007; 46:1597-1610. [PubMed: 17668877]

349. Marbet P, Rahner C, Stieger B, Landmann L. Quantitative microscopy reveals 3D organization and kinetics of endocytosis in rat hepatocytes. Microsc Res Tech. 2006; 69:693-707. [PubMed: 16886231]

350. Marinelli RA, LaRusso NF. Solute and water transport pathways in cholangiocytes. Semin Liv Dis. 1996; 16:221-229.

351. Marinelli RA, Lehmann GL, Soria LR, Marchissio MJ. Hepatocyte aquaporins in bile formation and cholestasis. Front Biosci. 2012; 17:2642-2652.

352. Marinelli RA, Pham L, Agre P, LaRusso NF. Secretin promotes osmotic water transport in rat cholangiocytes by increasing aquaporin-1 water channels in plasma membrane. J Biol Chem. 1997; 272:12984-12988. [PubMed: 9148905]

353. Marinelli RA, Pham LD, Tietz PS, LaRusso NF. Expression of aquaporin-4 water channels in rat cholangiocytes. Hepatology. 2000; 31:1313-1317. [PubMed: 10827157]

354. Marinelli RA, Tietz P, Pham LD, Rueckert L, Agre P, LaRusso NF. Secretin induces the apical insertion of aquaporin-1 water channels in rat cholangiocytes. Am J Physiol. 1999; 276:G280G286. [PubMed: 9887005]

355. Marinelli RA, Tietz PS, Caride AJ, Huang BQ, LaRusso NF. Water transporting properties of hepatocyte basolateral and canalicular plasma membrane domains. J Biol Chem. 2003; 278:43157-43162. [PubMed: 12939275]

356. Marino CM, Matovcik LM, Gorelick FS, Cohn JA. Localization of the cystic fibrosis transmembrane conductance regulator in pancreas. J Clin Invest. 1991; 88:712-716. [PubMed: 1713921]

357. Marks DL, LaRusso NF, McNiven MA. Isolation of the microtubulevesicle motor kinesin from rat liver: Selective inhibition by cholestatic bile acids. Gastroenterology. 1995; 108:824-833. [PubMed: 7875485]

358. Martin GG, Atshaves BP, McIntosh AL, Mackie JT, Kier AB, Schroeder F. Liver fatty-acidbinding protein (L-FABP) gene ablation alters liver bile acid metabolism in male mice. Biochem J. 2005; 391:549-560. [PubMed: 15984932]

359. Martinez-Anso E, Castillo JE, Diez J, Medina JF, Prieto J. Immunohistochemical detection of chloride/bicarbonate anion exchangers in human liver. Hepatology. 1994; 19:1400-1406. [PubMed: 8188169]

360. Masyuk AI, Masyuk TV, LaRusso NF. Cholangiocyte primary cilia in liver health and disease. Dev Dyn. 2008; 237:2007-2012. [PubMed: 18407555]

361. Mauad TH, van Nieuwkerk CMJ, Dingemans KP, Smit JJM, Schinkel AH, Notenboom RGE, vanden Bergh Weerman MA, Verkruisen RP, Groen AK, Oude Elferink RPJ, vander Valk MA, Borst P, Offerhaus GJA. Mice with homozygous disruption of the mdr2 p-glycoprotein gene. A 
novel animal model for studies of nonsuppurative inflammatory cholangitis and hepatocarcinogenesis. Am J Pathol. 1994; 145:1237-1245. [PubMed: 7977654]

362. Mayer R, Kartenbeck J, Buchler M, Jedlitschky G, Leier I, Keppler D. Expression of the MRP gene-encoded conjugate export pump in liver and its selective absence from the canalicular membrane in transport-deficient mutant hepatocytes. J Cell Biol. 1995; 131:137-150. [PubMed: 7559771]

363. McCarthy KM, Skare IB, Stankewich MD. Occludin is a functional component of the tight junction. J Cell Sci. 1996; 109:2287-2298. [PubMed: 8886979]

364. McCormick, DB.; Munroe, HN. Liver in relation to water solubale vitamins. In: Arias, IM.; Boyer, JL.; Fausto, N.; Jakoby, WB.; Schachter, DA.; Shafritz, DA., editors. The Liver: Biology and Pathobiology. New York: Raven Press; 1994. p. 563-583.

365. Meier PJ, Boyer JL. Preparation of basolateral (sinusoidal) and canalicular plasma membrane vesicles for the study of hepatic transport processes. Methods Enymol. 1990; 192:534-545.

366. Meier PJ, Knickelbein RG, Moseley RH, Dobbins JW, Boyer JL. Evidence for carrier-mediated chloride/bicarbonate exchange in canalicular rat liver plasma membrane vesicles. J Clin Invest. 1985; 75:1256-1263. [PubMed: 2985654]

367. Meier PJ, Meier-Abt AS, Barrett C, Boyer JL. Mechanisms of taurocholate transport in canalicular and basolateral rat liver plasma membrane vesicles. J Biol Chem. 1984; 259:1061410622. [PubMed: 6469975]

368. Meier PJ, Stieger B. Bile salt transporters. Ann Rev Physiol. 2002; 64:635-661. [PubMed: 11826283]

369. Meier PJ, Sztul ES, Reuben A, Boyer JL. Structural and functional polarity of canalicular and basolateral plasma membrane vesicles isolated in high yield from rat liver. J Cell Biol. 1984; 98:991-1000. [PubMed: 6699096]

370. Meier Y, Zodan T, Lang C, Zimmermann R, Kullak-Ublick GA, Meier PJ, Stieger B, PauliMagnus C. Increased susceptibility for intrahep-atic cholestasis of pregnancy and contraceptiveinduced cholestasis in carriers of the $1331 \mathrm{~T}>\mathrm{C}$ polymorphism in the bile salt export pump. World J Gastroenterol. 2008; 14:38-45. [PubMed: 18176959]

371. Meijer DKF, Smit JW, Muller M. Hepatobiliary elimination of cationic drugs: The role of Pglycoproteins and other ATP-dependent transporters. Adv Drug Deliv Rev. 1997; 25:159-200.

372. Mennone A, Alvaro D, Cho W, Boyer JL. Isolation of small polarized bile duct units. Proc Natl Acad Sci U S A. 1995; 92:6527-6531. [PubMed: 7541542]

373. Mennone A, Biemersderfer D, Negoianu D, Yang C-L, Abbiati T, Schultheis PJ, Shull GE, Aronson PS, Boyer JL. Role of sodium/hydrogen exchanger isoform NHE3 in fluid secretion and absorption in mouse and rat cholangiocytes. Am J Physiol Gastrointest Liver Physiol. 2001; 280:G247-G254. [PubMed: 11208547]

374. Mennone A, Soroka CJ, Cai SY, Harry K, Adachi M, Hagey L, Schuetz JD, Boyer JL. Mrp4-/mice have an impaired cytoprotective response in obstructive cholestasis. Hepatology. 2006; 43:1013-1021. [PubMed: 16628672]

375. Mennone A, Soroka CJ, Harry KM, Boyer JL. Role of breast cancer resistance protein in the adaptive response to cholestasis. Drug Metab Dispos. 2010; 38:1673-1678. [PubMed: 20601550]

376. Merino G, Jonker JW, Wagenaar E, van Herwaarden AE, Schinkel AH. The breast cancer resistance protein (BCRP/ABCG2) affects pharmacokinetics, hepatobiliary excretion, and milk secretion of the antibiotic nitrofurantoin. Mol Pharmacol. 2005; 67:1758-1764. [PubMed: 15709111]

377. Meyer Zu Schwabedissen HE, Kim RB. Hepatic OATP1B transporters and nuclear receptors PXR and CAR: Interplay, regulation of drug disposition genes, and single nucleotide polymorphisms. Mol Pharm. 2009; 6:1644-1661. [PubMed: 19558188]

378. Miao J, Fang S, Lee J, Comstock C, Knudsen KE, Kemper JK. Functional specificities of Brm and Brg-1 Swi/Snf ATPases in the feedback regulation of hepatic bile acid biosynthesis. Mol Cell Biol. 2009; 29:6170-6181. [PubMed: 19805516]

379. Milkiewicz P, Roma MG, Elias E, Coleman R. Hepatoprotection with tauroursodeoxycholate and [beta] muricholate against taurolithocholate induced cholestasis: Involvement of signal transduction pathways. Gut. 2002; 51:113-119. [PubMed: 12077103] 
380. Minagawa N, Nagata J, Shibao K, Masyuk AI, Gomes DA, Rodrigues MA, LeSagE G, Akiba Y, Kaunitz JD, Ehrlich BE, LaRusso NF, Nathanson MH. Cyclic AMP regulates bicarbonate secretion in cholangiocytes through release of ATP into bile. Gastroenterology. 2007; 133:15921602. [PubMed: 17916355]

381. Minuesa G, Volk C, Molina-Arcas M, Gorboulev V, Erkizia I, Arndt P, Clotet B, Pastor-Anglada M, Koepsell H, Martinez-Picado J. Transport of lamivudine [(-)-beta-L-2',3'-dideoxy-3'thiacytidine] and highaffinity interaction of nucleoside reverse transcriptase inhibitors with human organic cation transporters 1, 2, and 3. J Pharmacol Exp Ther. 2009; 329:252-261. [PubMed: 19141712]

382. Misra S, Ujhazy P, Gatmaitan Z, Varticovski L, Arias IM. The role of phosphoinositide 3-kinase in taurocholate-induced trafficking of ATP-dependent canalicular transporters in rat liver. J Biol Chem. 1998; 273:26638-26644. [PubMed: 9756904]

383. Misra S, Varticovski L, Arias IM. Mechanisms by which cAMP increases bile acid secretion in rat liver and canalicular membrane vesicles. Am J Physiol Gastrointest Liver Physiol. 2003; 285:G316-G324. [PubMed: 12702492]

384. Mitic LL, Anderson JM. Moleclar architecture of tight junctions. Ann Rev Physiol. 1998; 60:121-142. [PubMed: 9558457]

385. Moreno M, Molina H, Amigo L, Zanlungo S, Arrese M, Rigotti A, Miquel JF. Hepatic overexpression of caveolins increases bile salt secretion in mice 1. Hepatology. 2003; 38:14771488. [PubMed: 14647059]

386. Morita, KFMFKaTS. Claudin multigene family enocdoing fourtransmembrane domain protein componenets of tight junction strands. Proc Natl Acad Sci U S A. 1999; 96:511-516. [PubMed: 9892664]

387. Moriyama Y, Hiasa M, Matsumoto T, Omote H. Multidrug and toxic compound extrusion (MATE)-type proteins as anchor transporters for the excretion of metabolic waste products and xenobiotics. Xenobiotica. 2008; 38:1107-1118. [PubMed: 18668441]

388. Moseley RH, Ballatori N, Murphy SM. $\mathrm{Na}^{+}$-glycine co-transport in canalicular liver plasma membrane vesicles. Am J Physiol. 1988; 255:G253-G259. [PubMed: 3407780]

389. Moseley RH, Wang W, Takeda H, Lown K, Shick L, Ananthanarayanan M, Suchy FJ. Effect of endotoxin on bile acid transport in rat liver: A potential model for sepsis-associated cholestasis. Am J Physiol. 1996; 271:G137-G146. [PubMed: 8760117]

390. Mottino AD, Cao J, Veggi LM, Crocenzi F, Roma MG, Vore M. Altered localization and activity of canalicular Mrp2 in estradiol-17beta-D-glucuronide-induced cholestasis. Hepatology. 2002; 35:1409-1419. [PubMed: 12029626]

391. Mottino AD, Crocenzi FA, Pozzi EJ, Veggi LM, Roma MG, Vore M. Role of microtubules in estradiol-17beta-D-glucuronide-induced alteration of canalicular Mrp2 localization and activity. Am J Physiol Gastrointest Liver Physiol. 2005; 288:G327-G336. [PubMed: 15374814]

392. Mukhopadhayay S, Ananthanarayanan M, Stieger B, Meier PJ, Suchy FJ, Anwer MS. cAMP increases liver $\mathrm{Na}^{+}$-taurocholate cotransport by translocating transporter to plasma membranes. Am J Physiol. 1997; 273:G842-G848. [PubMed: 9357825]

393. Muller M, Ishikawa T, Berger U, Klunemann C, Lucka L, Schreyer A, Kannich C, Reutter W, Kurz G, Keppler D. ATP-dependent transport of taurocholate across the hepatocyte canalicular membrane mediated by a 110-kDa glycoprotein binding ATP and bile salt. J Biol Chem. 1991; 266:18920-18926. [PubMed: 1918007]

394. Muller M, Mayer R, Hero U, Keppler D. ATP-dependent transport of amphiphilic cations across the hepatocyte canalicular membrane mediated by mdr1 P-glycoprotein. FEBS Lett. 1994; 343:168-172. [PubMed: 7909523]

395. Mustacich DJ, Bruno RS, Traber MG. Vitamin E. Vitam Horm. 2007; 76:1-21. [PubMed: 17628169]

396. Mustacich DJ, Shields J, Horton RA, Brown MK, Reed DJ. Biliary secretion of alpha-tocopherol and the role of the mdr2 P-glycoprotein in rats and mice. Arch Biochem Biophys. 1998; 350:183-192. [PubMed: 9473291] 
397. Myers NC, Grune S, Jameson HL, Anwer MS. cGMP stimulates bile acid-independent bile formation and biliary bicarbonate excretion. Am J Physiol. 1996; 270:G418-G424. [PubMed: 8638707]

398. Nakano A, Marks DL, Tietz PS, deGroen PC, LaRusso NF. Quantitative importance of biliary excretion to the turnover of hepatic lysosomal enzymes. Hepatology. 1995; 22:262-266. [PubMed: 7601420]

399. Nathanson MH. Cellular and subcellular calcium signaling in gastrointestinal epithelium. Gastroenterology. 1994; 106:1349-1364. [PubMed: 8174894]

400. Nathanson MH, Boyer JL. Mechanisms and regulation of bile secretion. Hepatology. 1991; 14:551-566. [PubMed: 1874500]

401. Nathanson, MH.; Boyer, JL. Vesicular Trafficking in the Hepatocyte. In: Arias, IM.; Boyer, JL.; Fausto, N.; Jakoby, WB.; Schachter, DA.; Shafritz, DA., editors. The Liver: Biology and Pathobiology. New York: Raven Press, Ltd; 1994. p. 655-664.

402. Nathanson MH, Burgstahler AD, Masyuk A, LaRusso NF. Stimulation of ATP secretion in the liver by therapeutic bile acids. Biochem J. 2001; 358:1-5. [PubMed: 11485545]

403. Nathanson MH, Burgstahler AD, Mennone A, Fallon MB, Gonzalez CB, Saez JC. Ca ${ }^{2+}$ waves are organized among hepatocytes in the intact organ. Am J Physiol. 1995; 269:G167-G171. [PubMed: 7631796]

404. Nathanson MH, Gautam A, Bruck R, Isales CM, Boyer JL. Effects of Ca-2+ Agonists on Cytosolic Ca-2 +in Isolated Hepatocytes and on Bile Secretion in the Isolated Perfused Rat Liver. Hepatology. 1992; 15:107-116. [PubMed: 1727785]

405. Nathanson MH, Gautam A, Ng OC, Bruck R, Boyer JL. Hormonal regulation of paracellular permeability in isolated rat hepatocyte couplets. Am J Physiol. 1992; 262:G1079-G1086. [PubMed: 1616038]

406. Nathanson MH, Rios-Velez L, Burgstahler A, Mennone A. Communication via gap junctions modulates bile secretion in the isolated perfused rat liver. Gastroenterology. 1999; 116:11761183. [PubMed: 10220510]

407. Nicolaou M, Andress EJ, Zolnerciks JK, Dixon PH, Williamson C, Linton KJ. Canalicular ABC transporters and liver disease. J Pathol. 2012; 226:300-315. [PubMed: 21984474]

408. Nies AT, Keppler D. The apical conjugate efflux pump ABCC2 (MRP2). Pflugers Arch. 2007; 453:643-659. [PubMed: 16847695]

409. Nies AT, Koepsell H, Damme K, Schwab M. Organic cation transporters (OCTs, MATEs), in vitro and in vivo evidence for the importance in drug therapy. Handb Exp Pharmacol. 2011; 201:105-167. [PubMed: 21103969]

410. Nies AT, Koepsell H, Winter S, Burk O, Klein K, Kerb R, Zanger UM, Keppler D, Schwab M, Schaeffeler E. Expression of organic cation transporters OCT1 (SLC22A1) and OCT3 (SLC22A3) is affected by genetic factors and cholestasis in human liver. Hepatology. 2009; 50:1227-1240. [PubMed: 19591196]

411. Nishida T, Gatmaitan Z, Che MX, Arias IM. Rat liver canalicular membrane vesicles containing an ATP-dependent bile acid transport system. Proc Natl Acad Sci U S A. 1991; 88:6590-6594. [PubMed: 1862084]

412. Noe J, Steiger B, Meier P. Functional expression of the canalicular bile salt export pump (BSEP) of human liver. Gastroenterology. 2002; 123:1659-1666. [PubMed: 12404240]

413. Excretion of vitamin A metabolites in the bile. Nutr Rev. 1985; 43:250-252. [PubMed: 3900824]

414. Norimizu S, Kudo A, Kajimura M, Ishikawa K, Taniai H, Yamaguchi T, Fujii K, Arii S, Nimura Y, Suematsu M. Carbon monoxide stimulates mrp2-dependent excretion of bilirubin-IXalpha into bile in the perfused rat liver. Antioxid Redox Signal. 2003; 5:449-456. [PubMed: 13678533]

415. Nozawa T, Minami H, Sugiura S, Tsuji A, Tamai I. Role of organic anion transporter OATP1B1 (OATP-C) in hepatic uptake of irinotecan and its active metabolite, 7-ethyl-10hydroxycamptothecin: In vitro evidence and effect of single nucleotide polymorphisms. Drug Metab Dispos. 2005; 33:434-439. [PubMed: 15608127]

416. O’Maille ER, Kozmary SV, Hofmann AF, Gurantz D. Differing effects of norcholate and cholate on bile flow and biliary lipid secretion in the rat. Am J Physiol. 1984; 246:G67-G71. [PubMed: 6696069] 
417. O'Mallie ERL, Richards TG. The secretory characteristics of dehydrocholate in the dog: Comparison with the natural bile salts. J Physiol. 1976; 261:337-357. [PubMed: 978576]

418. Obaidat A, Roth M, Hagenbuch B. The expression and function of organic anion transporting polypeptides in normal tissues and in cancer. Annu Rev Pharmacol Toxicol. 2012; 52:135-151. [PubMed: 21854228]

419. Okada K, Shoda J, Taguchi K, Maher JM, Ishizaki K, Inoue Y, Ohtsuki M, Goto N, Sugimoto H, Utsunomiya H, Oda K, Warabi E, Ishii T, Yamamoto M. Nrf2 counteracts cholestatic liver injury via stimulation of hepatic defense systems. Biochem Biophys Res Commun. 2009; 389:431-436. [PubMed: 19732748]

420. Olson JA. Some aspects of vitamin A metabolism. Vitam Horm. 1969; 26:1-63. [PubMed: 4890102]

421. Olson JR, Fujimoto JM. Demonstration of a D-glucose transport system in the biliary tract of the rat by use of the segmented retrograde intrabiliary injection technique. Biochem Pharmacol. 1980; 24:263-219.

422. Ortiz DF, Moseley J, Calderon G, Swift AL, Li S, Arias IM. Identification of HAX-1 as a protein that binds bile salt export protein and regulates its abundance in the apical membrane of MadinDarby canine kidney cells. J Biol Chem. 2004; 279:32761-32770. [PubMed: 15159385]

423. Oshio C, Phillips MJ. Contractility of bile canaliculi, implications of liver functions. Science. 1981; 212:1041-1042. [PubMed: 7015506]

424. Oswald M, Kullak-Ublick GA, Paumgartner G, Beuers U. Expression of hepatic transporters OATP-C and MRP2 in primary sclerosing cholangitis. Liver. 2001; 21:247-253. [PubMed: 11454187]

425. Oude Elferink RP, Ottenhoff R, van Wijland M, Smit JJ, Schinkel AH, Groen AK. Regulation of biliary lipid secretion by mdr2 P-glycoprotein in the mouse. J Clin Invest. 1995; 95:31-38. [PubMed: 7814632]

426. Oude Elferink RP, Paulusma CC. Function and pathophysiological importance of ABCB4 (MDR3 P-glycoprotein). Pflugers Arch. 2007; 453:601-610. [PubMed: 16622704]

427. Oude Elferink RPJ, Tytgat GNJ, Groen AK. The role of mdr2 P-glycoprotein in hepatobiliary lipid transport. FASEB J. 1997; 11:19-28. [PubMed: 9034162]

428. Padda MS, Sanchez M, Akhtar AJ, Boyer JL. Drug-induced cholestasis. Hepatology. 2011; 53:1377-1387. [PubMed: 21480339]

429. Pappenheimer JR. Passage of molecules through capillary walls. Physiol Rev. 1953; 33:387-423. [PubMed: 13088295]

430. Pauli-Magnus C, Kerb R, Fattinger K, Lang T, Anwald B, Kullak-Ublick GA, Beuers U, Meier PJ. BSEP and MDR3 haplotype structure in healthy Caucasians, primary biliary cirrhosis and primary sclerosing cholangitis. Hepatology. 2004; 39:779-791. [PubMed: 14999697]

431. Paulusma C, Kothe MJC, Bakker CTM, Bosma PJ, van Bokhoven I, Van Marle J, Bolder U, Tytgat GNJ, Oude Elferink RPJ. Zonal downregulation and redistribution of the multidrug resistance protein 2 during bile duct ligation in rat liver. Hepatology. 2000; 31:684-693. [PubMed: 10706559]

432. Paulusma C, van Geer M, Evers R, Heijn M, Ottenhoff R, Borst P, Oude Elferink RPJ. Canalicular multispecific organic anion transporter/multidrug resistance protein 2 mediates lowaffinity transport of reduced glutathione. Biochem J. 1999; 338:393-401. [PubMed: 10024515]

433. Paulusma CC, de Waart DR, Kunne C, Mok KS, Elferink RP. Activity of the bile salt export pump (ABCB11) is critically dependent on canalicular membrane cholesterol content. J Biol Chem. 2009; 284:9947-9954. [PubMed: 19228692]

434. Paulusma CC, Folmer DE, Ho-Mok KS, de Waart DR, Hilarius PM, Verhoeven AJ, Oude Elferink RP. ATP8B1 requires an accessory protein for endoplasmic reticulum exit and plasma membrane lipid flippase activity. Hepatology. 2008; 47:268-278. [PubMed: 17948906]

435. Paulusma CC, Groen A, Kunne C, Ho-Mok KS, Spijkerboer AL, Rudi dW, Hoek FJ, Vreeling H, Hoeben KA, Van Marle J, Pawlikowska L, Bull LN, Hofmann AF, Knisely AS, Oude Elferink RP. Atp8b1 deficiency in mice reduces resistance of the canalicular membrane to hydrophobic bile salts and impairs bile salt transport. Hepatology. 2006; 44:195-204. [PubMed: 16799980] 
436. Paulusma CC, Kool M, Bosma PJ, Scheffer GL, terBorg F, Scheper RJ, Tytgat GNJ, Borst P, Baas F, Oude Elferink RPJ. A mutation in the human canalicular multispecific organic anion transporter gene causes the Dubin-Johnson syndrome. Hepatology. 1997; 25:1539-1542. [PubMed: 9185779]

437. Paulusma CC, Oude Elferink RP. The type 4 subfamily of P-type AT-Pases, putative aminophospholipid translocases with a role in human disease. Biochim Biophys Acta. 2005; 1741:11-24. [PubMed: 15919184]

438. Paumgartner G, Herz R, Sauter K, Schwarz HP. Taurocholate excretion and bile formation in the isolated perfused rat liver: An in vitro-in vivo comparison. Arch Pharmacol. 1974; 285:165-174.

439. Pawlikowska L, Strautnieks S, Jankowska I, Czubkowski P, Emerick K, Antoniou A, Wanty C, Fischler B, Jacquemin E, Wali S, Blanchard S, Nielsen IM, Bourke B, McQuaid S, Lacaille F, Byrne JA, van Eerde AM, Kolho KL, Klomp L, Houwen R, Bacchetti P, Lobritto S, Hupertz V, McClean P, Mieli-Vergani G, Shneider B, Nemeth A, Sokal E, Freimer NB, Knisely AS, Rosenthal P, Whitington PF, Pawlowska J, Thompson RJ, Bull LN. Differences in presentation and progression between severe FIC1 and BSEP deficiencies. J Hepatol. 2010; 53:170-178. [PubMed: 20447715]

440. Phillips MJ. What is actin doing in the liver cell? Hepatology. 1983; 3:433-436. [PubMed: 6682398]

441. Phillips MJ, Oshio C, Miyairi M, Katz H, Smith CR. A study of bile canalicular contractions in isolated hepatocytes: Methods and time series analysis. Hepatology. 1982; 2:777. [PubMed: 7141388]

442. Phillips MJ, Poucell S, Oda M. Biology of disease mechanisms of cholestasis. Lab Invest. 1986; 54:593-608. [PubMed: 2423777]

443. Plass JR, Mol O, Heegsma J, Geuken M, de Bruin J, Elling G, Muller M, Faber KN, Jansen PL. A progressive familial intrahepatic cholestasis type 2 mutation causes an unstable, temperaturesensitive bile salt export pump. J Hepatol. 2004; 40:24-30. [PubMed: 14672610]

444. Polgar O, Robey RW, Bates SE. ABCG2: Structure, function and role in drug response. Expert Opin Drug Metab Toxicol. 2008; 4:1-15. [PubMed: 18370855]

445. Popowski K, Eloranta JJ, Saborowski M, Fried M, Meier PJ, Kullak-Ublick GA. The human organic anion transporter 2 gene is transactivated by hepatocyte nuclear factor- 4 alpha and suppressed by bile acids. Mol Pharmacol. 2005; 67:1629-1638. [PubMed: 15692145]

446. Potter KN, Thomson RK, Hamblin A, Richards SD, Lindsay JG, Stevenson FK. Immunogenetic analysis reveals that epitope shifting occurs during B-cell affinity maturation in primary biliary cirrhosis. J Mol Biol. 2001; 306:37-46. [PubMed: 11178892]

447. Prandi D. Canalicular bile production in man. Eur J Clin Invest. 1975; 5:1-6. [PubMed: 1122919]

448. Pusl T, Nathanson MH. The role of inositol 1,4,5-trisphosphate receptors in the regulation of bile secretion in health and disease. Biochem Biophys Res Commun. 2004; 322:1318-1325. [PubMed: 15336978]

449. Reid G, Wielinga P, Zelcer N, Van Der Heijden I, Kuil A, De Haas M, Wijnholds J, Borst P. The human multidrug resistance protein MRP4 functions as a prostaglandin efflux transporter and is inhibited by nonsteroidal antiinflammatory drugs. Proc Natl Acad Sci U S A. 2003; 100:92449249. [PubMed: 12835412]

450. Rembacz KP, Woudenberg J, Hoekstra M, Jonkers EZ, van den Heuvel FA, Buist-Homan M, Woudenberg-Vrenken TE, Rohacova J, Marin ML, Miranda MA, Moshage H, Stellaard F, Faber $\mathrm{KN}$. Unconjugated bile salts shuttle through hepatocyte peroxisomes for taurine conjugation. Hepatology. 2010; 52:2167-2176. [PubMed: 21049545]

451. Reuben A. Biliary proteins. Hepatology. 1984; 4:46S-50S. [PubMed: 6384005]

452. Rhainds D, Brissette L. The role of scavenger receptor class B type I (SR-BI) in lipid trafficking. defining the rules for lipid traders. Int J Biochem Cell Biol. 2004; 36:39-77. [PubMed: 14592533]

453. Richter L, Hesselbarth N, Eitner K, Schubert K, Bosseckert H, Krell H. Increased biliary secretion of cysteinyl-leukotrienes in human bile duct obstruction. J Hepatol. 1996; 25:725-732. [PubMed: 8938552] 
454. Rius M, Hummel-Eisenbeiss J, Hofmann AF, Keppler D. Substrate specificity of human ABCC4 (MRP4)-mediated cotransport of bile acids and reduced glutathione. Am J Physiol Gastrointest Liver Physiol. 2005; 290:G640-G649. [PubMed: 16282361]

455. Rius M, Nies AT, Hummel-Eisenbeiss J, Jedlitschky G, Keppler D. Cotransport of reduced glutathione with bile salts by MRP4 (ABCC4) localized to the basolateral hepatocyte membrane. Hepatology. 2003; 38:374-384. [PubMed: 12883481]

456. Rizzo G, Passeri D, De Franco F, Ciaccioli G, Donadio L, Rizzo G, Orlandi S, Sadeghpour B, Wang XX, Jiang T, Levi M, Pruzanski M, Adorini L. Functional characterization of the semisynthetic bile acid derivative INT-767, a dual farnesoid X receptor and TGR5 agonist. Mol Pharmacol. 2010; 78:617-630. [PubMed: 20631053]

457. Rizzo G, Renga B, Antonelli E, Passeri D, Pellicciari R, Fiorucci S. The methyl transferase PRMT1 functions as co-activator of farnesoid X receptor (FXR)/9-cis retinoid X receptor and regulates transcription of FXR responsive genes. Mol Pharmacol. 2005; 68:551-558. [PubMed: 15911693]

458. Roda A, Grigolo B, Minutello A, Pellicciari R, Natalini B. Physicochemical and biological properties of natural and synthetic C-22 and C-23 hydroxylated bile acids. J Lipid Res. 1990; 31:289-298. [PubMed: 2324648]

459. Rodriguez-Ortigosa CM, Banales JM, Olivas I, Uriarte I, Marin JJ, Corrales FJ, Medina JF, Prieto J. Biliary secretion of S-nitrosoglutathione is involved in the hypercholeresis induced by ursodeoxycholic acid in the normal rat. Hepatology. 2010; 52:667-677. [PubMed: 20683964]

460. Roelofsen H, Ottenhoff R, Elferink RPJO, Jansen PLM. Hepatocanalicular organic-anion transport is regulated by Protein kinase-C. Biochem J. 1991; 278:637-641. [PubMed: 1716882]

461. Roelofsen H, Soroka C, Dietrich K, Boyer JL. Cyclic AMP stimulates sorting of the canalicular organic anion transporter (Mrp2/cMoat) to the apical domain in hepatocyte couplets. J Cell Sci. 1998; 111:1137-1145. [PubMed: 9512509]

462. Roma MG, Crocenzi FA, Mottino AD. Dynamic localization of hepatocellular transporters in health and disease. World J Gastroenterol. 2008; 14:6786-6801. [PubMed: 19058304]

463. Roma MG, Milkiewicz P, Elias E, Coleman R. Control by signaling modulators of the sorting of canalicular transporters in rat hepatocyte couplets: Role of the cytoskeleton. Hepatology. 2000; 32:1342-1356. [PubMed: 11093742]

464. Rosen HR, Winkle PJ, Kendall BJ, Diehl DL. Biliary interleukin-6 and tumor necrosis factoralpha in patients undergoing endoscopic retrograde cholangiopancreatography. Dig Dis Sci. 1997; 42:1290-1294. [PubMed: 9201097]

465. Rosencrantz R, Schilsky M. Wilson disease: Pathogenesis and clinical considerations in diagnosis and treatment. Semin Liver Dis. 2011; 31:245-259. [PubMed: 21901655]

466. Roskams TA, Theise ND, Balabaud C, Bhagat G, Bhathal PS, Bioulac-Sage P, Brunt EM, Crawford JM, Crosby HA, Desmet V, Finegold MJ, Geller SA, Gouw AS, Hytiroglou P, Knisely AS, Kojiro M, Lefkowitch JH, Nakanuma Y, Olynyk JK, Park YN, Portmann B, Saxena R, Scheuer PJ, Strain AJ, Thung SN, Wanless IR, West AB. Nomenclature of the finer branches of the biliary tree: Canals, ductules, and ductular reactions in human livers. Hepatology. 2004; 39:1739-1745. [PubMed: 15185318]

467. Rosmorduc O, Hermelin B, Poupon R. Mdr3 gene defect in adults with symptomatic intrahepatic and gallbladder cholesterol cholelithiasis. Gastroenterology. 2001; 120:1459-1467. [PubMed: 11313316]

468. Rossi SS, Converse JL, Hofmann AF. High pressure liquid chromatographic analysis of conjugated bile acids in human bile: Simultaneous resolution of sulfated and unsulfated lithocholyl amidates and the common conjugated bile acids. J Lipid Res. 1987; 28:589-595. [PubMed: 3598401]

469. Roth M, Obaidat A, Hagenbuch B. OATPs, OATs and OCTs: The organic anion and cation transporters of the SLCO and SLC22A gene superfamilies. Br J Pharmacol. 2011; 165:1260 1287. [PubMed: 22013971]

470. Rothman JE, Wieland FT. Protein sorting by transport vesicles. Science. 1996; 272:227-234. [PubMed: 8602507] 
471. Ruetz S, Gros P. Phosphatidylcholine translocase: A physiological role for the mdr2 gene. Cell. 1994; 77:1071-1081. [PubMed: 7912658]

472. Russel FG, Koenderink JB, Masereeuw R. Multidrug resistance protein 4 (MRP4/ABCC4): A versatile efflux transporter for drugs and signalling molecules. Trends Pharmacol Sci. 2008; 29:200-207. [PubMed: 18353444]

473. Russell DW. The enzymes, regulation, and genetics of bile acid synthesis. Ann Rev Biochem. 2003; 72:137-134. [PubMed: 12543708]

474. Rutishauser SC, Stone SL. Aspects ofbile secretion in the rabbit. J Physiol. 1975; 245:567-582. [PubMed: 1142218]

475. Ryder SD, Beckingham IJ. ABC of diseases of liver, pancreas, and biliary system. Other causes of parenchymal liver disease. BMJ. 2001; 322:290-292. [PubMed: 11157536]

476. Saborowski M, Kullak-Ublick GA, Eloranta JJ. The human organic cation transporter-1 gene is transactivated by hepatocyte nuclear factor-4alpha. J Pharmacol Exp Ther. 2006; 317:778-785. [PubMed: 16436500]

477. Sakisaka S, Ng OC, Boyer JL. Tubulovesicular transcytotic pathway in isolated rat hepatocyte couplets in culture. Gastroenterology. 1988; 95:793-804. [PubMed: 3396824]

478. Sano T, Shiomi M, Wakabayashi Y, Shinoda Y, Goda N, Yamaguchi T, Nimura Y, Ishimura Y, Suematsu M. Endogenous carbon monoxide suppression stimulates bile acid-dependent biliary transport in perfused rat liver. Am J Physiol. 1997; 35:G1268-G1275. [PubMed: 9176239]

479. Satlin LM, Amin V, Wolkoff AW. Organic anion transporting polypeptide mediates organic anion/ $\mathrm{HCO}_{3}{ }^{-}$Exchange. J Biol Chem. 1997; 272:26340-26345. [PubMed: 9334206]

480. Scheimann AO, Strautnieks SS, Knisely AS, Byrne JA, Thompson RJ, Finegold MJ. Mutations in bile salt export pump (ABCB11) in two children with progressive familial intrahepatic cholestasis and cholangiocarcinoma. J Pediatr. 2007; 150:556-559. [PubMed: 17452236]

481. Schell MJ, Maurice M, Stieger B, Hubbard AL. $5^{\prime}$ nucleotidase is sorted to the apical domain of hepatocytes via an indirect route. J Cell Biol. 1992; 119:1173-1182. [PubMed: 1447295]

482. Schinkel AH. The physiological function of drug-transporting P-glycoproteins. Semin Cancer Biol. 1997; 8:161-170. [PubMed: 9441946]

483. Schinkel AH, Mayer U, Wagenaar E, Mol CAAM, van Deemter L, Smit JJ, van der Valk MA. Normal viability and altered pharmacokinetics in mice lacking mdr1-type (drug-transporting) Pglycoproteins. Proc Natl Acad Sci U S A. 1997; 94:4028-4033. [PubMed: 9108099]

484. Schinkel AH, Smit JJM, van Tellingen mO, Beijnen JH, Wagenaar E, van Deemter L, Mol CAAM, vanderValk MA, Robanus-Maandag EC, teRiele HPJ, Berns AJM, Borst P. Disruption of the mouse mdr1a P-glycoprotein gene leads to a deficiency in the blood-brain barrier and to increased sensitivity to drugs. Cell. 1994; 77:491-502. [PubMed: 7910522]

485. Schlosser S, Burgstahler A, Nathanson MH. Isolated rat hepatocytes can signal to other hepatocytes and bile duct cells by release of nucleotides. Proc Natl Acad Sci U S A. 1996; 93:9948-9953. [PubMed: 8790437]

486. Schonhoff CM, Ramasamy U, Anwer MS. Nitric oxide-mediated inhibition of taurocholate uptake involves S-nitrosylation of NTCP. Am J Physiol Gastrointest Liver Physiol. 2011; 300:G364-G370. [PubMed: 21109590]

487. Schonhoff CM, Thankey K, Webster CR, Wakabayashi Y, Wolkoff AW, Anwer MS. Rab4 facilitates cyclic adenosine monophosphate-stimulated bile acid uptake and $\mathrm{Na}^{+}$-taurocholate cotransporting polypeptide translocation. Hepatology. 2008; 48:1665-1670. [PubMed: 18688880]

488. Schonhoff CM, Webster CR, Anwer MS. Cyclic AMP stimulates Mrp2 translocation by activating p38 \{alpha\} MAPK in hepatic cells. Am J Physiol Gastrointest Liver Physiol. 2010; 298:G667-G674. [PubMed: 20203059]

489. Schrenk D, Gant TW, Preisegger K-H, Silverman JA, Marino PA, Thorgeirsson SS. Induction of multidrug resistance gene expression during cholestasis in rats and nonhuman primates. Hepatology. 1993; 17:854-860. [PubMed: 8098315]

490. Schuetz JD, Connelly MC, Sun D, Paibir SG, Flynn PM, Srinivas RV, Kumar A, Fridland A. MRP4: A previously unidentified factor in resistance to nucleoside-based antiviral drugs. Nat Med. 1999; 5:1048-1051. [PubMed: 10470083] 
491. Sellinger M, Weinman SA, Henderson RM, Zweifach A, Boyer JL, Graf J. Anion channels in rat liver canalicular plasma membranes reconstituted into planar lipid bilayers. Am J Physiol. 1992; 262:G1027-G1032. [PubMed: 1377450]

492. Sewell RB, Hoffman NE, Smallwood RA, Cockbain S. Bile acid structure and bile formation: A comparison of hydroxy and keto bile acids. Am J Physiol. 1980; 238:G10-G17. [PubMed: 7356024]

493. Shih DQ, Bussen M, Sehayek E, Ananthanarayanan M, Shneider BL, Suchy FJ, Shefer S, Bollileni JS, Gonzalez FJ, Breslow JL, Stoffel M. Hepatocyte nuclear factor-1alpha is an essential regulator of bile acid and plasma cholesterol metabolism. Nat Genet. 2001; 27:375-382. [PubMed: 11279518]

494. Shimada K, Li X, Xu G, Nowak DE, Showalter LA, Weinman SA. Expression and canalicular localization of two isoforms of the ClC-3 chloride channel from rat hepatocytes. Am J Physiol Gastrointest Liver Physiol. 2000; 279:G268-G276. [PubMed: 10915634]

495. Shin HJ, Anzai N, Enomoto A, He X, Kim do K, Endou H, Kanai Y. Novel liver-specific organic anion transporter OAT7 that operates the exchange of sulfate conjugates for short chain fatty acid butyrate. Hepatology. 2007; 45:1046-1055. [PubMed: 17393504]

496. Shinoda Y, Suematsu M, Wakabayashi Y, Suzuki T, Goda N, Saito S, Yamaguchi T, Ishimura Y. Carbon monoxide as a regulator of bile canalicular contractility in cultured rat hepatocytes. Hepatology. 1998; 28:286-295. [PubMed: 9695989]

497. Shintani T, Iwabuchi T, Soga T, Kato Y, Yamamoto T, Takano N, Hishiki T, Ueno Y, Ikeda S, Sakuragawa T, Ishikawa K, Goda N, Kitagawa Y, Kajimura M, Matsumoto K, Suematsu M. Cystathionine beta-synthase as a carbon monoxide-sensitive regulator of bile excretion. Hepatology. 2009; 49:141-150. [PubMed: 19085910]

498. Shu Y, Sheardown SA, Brown C, Owen RP, Zhang S, Castro RA, Ianculescu AG, Yue L, Lo JC, Burchard EG, Brett CM, Giacomini KM. Effect of genetic variation in the organic cation transporter 1 (OCT1) on metformin action. J Clin Invest. 2007; 117:1422-1431. [PubMed: 17476361]

499. Simon FR, Fortune J, Iwahashi M, Gartung C, Wolkoff A, Sutherland E. Ethinyl estradiol cholestasis involves alterations in expression of liver sinusoidal transporters. Am J Physiol. 1996; 271:G1043-G1052. [PubMed: 8997249]

500. Sinal CJ, Tohkin M, Miyata M, Ward JM, Lambert G, Gonzalez FJ. Targeted disruption of the nuclear receptor FXR/BAR impairs bile acid and lipid homeostasis. Cell. 2000; 102:731-744. [PubMed: 11030617]

501. Singh SK, Mennone A, Gigliozzi A, Fraioli F, Boyer JL. Cl(-)-dependent secretory mechanisms in isolated rat bile duct epithelial units. Am J Physiol Gastrointest Liver Physiol. 2001; 281:G438-G446. [PubMed: 11447024]

502. Sirica AE, Cihla HP. Isolation and partial characterization of oval and hyperplastic bile ductular cell-enriched populations from the livers of carcinogen and noncarcinogen-treated rats. Cancer Res. 1984; 44:3454-3466. [PubMed: 6204745]

503. Slitt AL, Cherrington NJ, Dieter MZ, Aleksunes LM, Scheffer GL, Huang W, Moore DD, Klaassen CD. trans-Stilbene oxide induces expression of genes involved in metabolism and transport in mouse liver via CAR and Nrf2 transcription factors. Mol Pharmacol. 2006; 69:15541563. [PubMed: 16449384]

504. Small DM. Role of ABC transporters in secretion of cholesterol from liver into bile. Proc Natl Acad Sci U S A. 2002; 100:4-6. [PubMed: 12509503]

505. Smit JJ, Schinkel AH, Oude Elferink RP, Groen AK, Wagenaar E, van Deemter L, Mol CA, Ottenhoff R, van der Lugt NM, van Roon MA. Homozygous disruption of the murine mdr2 Pglycoprotein gene leads to a complete absence of phospholipid from bile and to liver disease. Cell. 1993; 75:451-462. [PubMed: 8106172]

506. Smith AJ, van Helvoort A, van Meer G, Szabo K, Welker E, Szakacs G, Varadi A, Sarkadi B, Borst P. MDR3 P-glycoprotein, a phosphatidylcholine translocase, transports several cytotoxic drugs and directly interacts with drugs as judged by interference with nucleotide trapping. J Biol Chem. 2000; 275:23530-23539. [PubMed: 10918072] 
507. Smith Z, Ryerson D, Kemper JK. Epigenomic regulation of bile acid metabolism: Emerging role of transcriptional cofactors. Mol Cell Endocrinol. 2012 May 9. [Epub ahead of print].

508. Sobotka, H. Physiological Chemistry of the Bile. Baltimore: Williams \& Wilkins; 1937.

509. Solari R, Schaerer E, Tallichet C, Braiterman LT, Hubbard AL, Kraehenbuhl J-P. Cellular localization of the cleavage event of the polymeric immunoglobin receptor and fate of its anchoring domain in the rat hepatocyte. Biochem J. 1989; 257:759-768. [PubMed: 2930484]

510. Song X, Kaimal R, Yan B, Deng R. Liver receptor homolog 1 transcriptionally regulates human bile salt export pump expression. J Lipid Res. 2008; 49:973-984. [PubMed: 18270374]

511. Soroka CJ, Lee JM, Azzaroli F, Boyer JL. Cellular localization and up-regulation of multidrug resistance-associated protein 3 in hepatocytes and cholangiocytes during obstructive cholestasis in rat liver. Hepatology. 2001; 33:783-791. [PubMed: 11283840]

512. Soroka CJ, Pate MK, Boyer JL. Canalicular export pumps traffic with polymeric immunoglobulin A receptor on the same microtubule-associated vesicle in rat liver. J Biol Chem. 1999; 274:26416-26424. [PubMed: 10473600]

513. Sperber I. Secretion of organic anions in the formation of urine and bile. Pharmacol Rev. 1959; 11:109-134. [PubMed: 13633440]

514. Sperber, I. Biliary secretion of organic anions and its influence on bile flow. In: Taylor, W., editor. The Biliary System. Oxford: Blackwell; 1965. p. 457-467.

515. Spirli C, Fabris L, Duner E, Fiorotto R, Ballardini G, Roskams T, LaRusso NF, Sonzog A, Okolicsanyi L, Strazzabosco M. Cytokine-stimulated nitric oxide production inhibits adenylyl cyclase and cAMP-dependent secretion in cholangiocytes. Gastroenterology. 2003; 124:737-753. [PubMed: 12612912]

516. Spirli C, Nathanson MH, Fiorotto R, Duner E, Denson LA, Sanz JM, Di Virgilio F, Okolicsanyi L, Casagrande F, Strazzabosco M. Proinflammatory cytokines inhibit secretion in rat bile duct epithelium. Gastroenterology. 2001; 121:156-169. [PubMed: 11438505]

517. Stamler JS, Jaraki O, Osborne J, Simon DI, Keaney J, Vita J, Singel D, Valeri CR, Loscalzo J. Nitric oxide circulates in mammalian plasma primarily as an S-nitroso adduct of serum albumin. Proc Natl Acad Sci U S A. 1992; 89:7674-7677. [PubMed: 1502182]

518. Stapelbroek JM, Peters TA, van Beurden DH, Curfs JH, Joosten A, Beynon AJ, van Leeuwen BM, van der Velden LM, Bull L, Oude Elferink RP, van Zanten BA, Klomp LW, Houwen RH. ATP8B1 is essential for maintaining normal hearing. Proc Natl Acad Sci U S A. 2009; 106:9709-9714. [PubMed: 19478059]

519. Staudinger J, Liu Y, Madan A, Habeebu S, Klaassen CD. Coordinate regulation of xenobiotic and bile acid homeostasis by pregnane X receptor. Drug Metab Dispos. 2001; 29:1467-1472. [PubMed: 11602523]

520. Steinberg SE, Campbell CL, Hillman RS. Kinetics of the normal folate enterohepatic cycle. J Clin Invest. 1979; 64:83-88. [PubMed: 447863]

521. Stieger B. The role of the sodium-taurocholate cotransporting polypeptide (NTCP) and of the bile salt export pump (BSEP) in physiology and pathophysiology of bile formation. Handb Exp Pharmacol. 2011; 201:205-259. [PubMed: 21103971]

522. Stieger B, Fattinger K, Madon J, Kullak-Ublick G-A, Meier PJ. Drugand estrogen-induced cholestasis through inhibition of the hepatocellular bile salt export pump (Bsep) of rat liver. Gastroenterology. 2000; 118:422-430. [PubMed: 10648470]

523. Stieger B, Meier Y, Meier PJ. The bile salt export pump. Pflugers Arch. 2007; 453:611-620. [PubMed: 17051391]

524. Stieger B, O’Neill B, Meier PJ. ATP-dependent bile-salt transport in canalicular rat liver plasmamembrane vesicles. Biochem J. 1992; 284:67-74. [PubMed: 1599411]

525. Stolz A, Hammond L, Lou H, Takikawa H, Ronk M, Shively JE. cDNA cloning and expression of the human hepatic bile acid-binding protein - a member of the monomeric reductase gene family. J Biol Chem. 1993; 268:10448-10457. [PubMed: 8486699]

526. Stolz A, Takikawa H, Ookhtens M, Kaplowitz N. The role of cytoplasmic proteins in hepatic bile acid transport. Annu Rev Physiol. 1989; 51:161-176. [PubMed: 2653179]

527. Strasberg SM, Ilson RG, Paloheimo JE. Bile salt-associated electrolyte secretion and the effect of sodium taurocholate on bile flow. J Lab Clin Med. 1983; 101:317-326. [PubMed: 6822766] 
528. Strautnieks SS, Bull L, Knisely AS, Kocoshis SA, Dahl N, Arnell H, Sokal E, Dahan K, Childs S, Ling V, Tanner MS, Kagalwalla AF. A gene encoding a liver-specific ABC transporter is mutated in progressive familial intrahepatic cholestasis. Nat Genet. 1998; 20:233-238. [PubMed: 9806540]

529. Strautnieks SS, Byrne JA, Pawlikowska L, Cebecauerova D, Rayner A, Dutton L, Meier Y, Antoniou A, Stieger B, Arnell H, Ozcay F, Al Hussaini HF, Bassas AF, Verkade HJ, Fischler B, Nemeth A, Kotalova R, Shneider BL, Cielecka-Kuszyk J, McClean P, Whitington PF, Sokal E, Jirsa M, Wali SH, Jankowska I, Pawlowska J, Mieli-Vergani G, Knisely AS, Bull LN, Thompson RJ. Severe bile salt export pump deficiency: 82 different ABCB11 mutations in 109 families. Gastroenterology. 2008; 134:1203-1214. [PubMed: 18395098]

530. Strazzabosco M, Boyer JL. Regulation of intracellular $\mathrm{pH}$ in the hepatocyte: Mechanisms and physiological implications. J Hepatol. 1996; 24:631-644. [PubMed: 8773922]

531. Strazzabosco M, Joplin R, Zsembery A, Wallace L, Spirli C, Fabris L, Granato A, Rossanese A, Poci C, Neuberger JM, Okolicsanyi L, Crepaldi G. $\mathrm{Na}^{+}$-dependent and -independent $\mathrm{C}^{-} / \mathrm{HCO}_{3}^{-}$ exchange mediate cellular $\mathrm{HCO}_{3}^{-}$transport in cultured human intrahepatic bile duct cells. Hepatology. 1997; 25:976-985. [PubMed: 9096607]

532. Strazzabosco M, Joplin R, Zsembery A, Wallace L, Spirli C, Fabris L, Granato A, Rossanese A, Poci C, Neuberger JM, Okolicsanyi L, Crepaldi G. $\mathrm{Na}^{+}$-dependent and -independent $\mathrm{C}^{-} / \mathrm{HCO}_{3}{ }^{-}$ exchange mediate cellular $\mathrm{HCO}_{3}{ }^{-}$transport in cultured human intrahepatic bile duct cells. Hepatology. 1997; 25:976-985. [PubMed: 9096607]

533. Strazzabosco M, Mennone A, Boyer JL. Intracellular $\mathrm{pH}$ regulation in isolated rat bile duct epithelial cells. J Clin Invest. 1991; 87:1503-1512. [PubMed: 2022723]

534. Strazzabosco M, Sakisaka S, Hayakawa T, Boyer JL. Effect of UDCA on intracellular and biliary pH in isolated rat hepatocyte couplets and perfused livers. Am J Physiol. 1991; 260:G58-G69. [PubMed: 1987808]

535. Strazzabosco M, Spirli C, Okolicsanyi L. Pathophysiology of the intrahepatic biliary epithelium. J Gastroenterol Hepatol. 2000; 15:244-253. [PubMed: 10764023]

536. Suchy FJ, Balistreri WF, Heubi JE, Searcy JE, Levin RS. Physiologic cholestasis: Elevation of the primary serum bile acid concentrations in normal infants. Gastroenterology. 1981; 80:10371041. [PubMed: 7202962]

537. Sudhof TC, Rothman JE. Membrane fusion: Grappling with SNARE and SM proteins. Science. 2009; 323:474-477. [PubMed: 19164740]

538. Sugawara N, Lai Y, Yuasa M, Dhar SK, Arizono K. Biliary excretion of copper, manganese, and horseradish peroxidase in Eisai hyperbilirubinemic mutant rats (EHBRs) with defective biliary excretion of glutathione. Biol Trace Elem Res. 1996; 55:181-189. [PubMed: 8971365]

539. Sugiyama Y, Yamada T, Kaplowitz N. Newly identified bile acid binders in rat liver cytosol Purification and comparison with glutathione S-transferases. J Biol Chem. 1983; 258:3602-3607. [PubMed: 6833218]

540. Svoboda M, Riha J, Wlcek K, Jaeger W, Thalhammer T. Organic anion transporting polypeptides (OATPs): Regulation of expression and function. Curr Drug Metab. 2011; 12:139-153. [PubMed: 21395542]

541. Sztul ES, Biemersderfer D, Caplan MJ, Kashgarian M, Boyer JL. Localization of $\mathrm{Na}^{+}, \mathrm{K}^{+}-$ ATPase a-subunit to the sinusoidal and lateral but not canalicular membranes of rat hepatocytes. J Cell Biol. 1987; 104:1239-1248. [PubMed: 3032985]

542. Takada T, Suzuki H, Sugiyama Y. Characterization of 5'-flanking region of human MRP3. Biochem Biophys Res Comm. 2000; 270:728-732. [PubMed: 10772892]

543. Takahashi I, Nakane PK, Brown WR. Ultrastructure events in the translocation of polymeric IgA by rat hepatocytes. J Immunol. 1982; 128:1181-1187. [PubMed: 7057034]

544. Tanzi RE, Petrukhin K, Chernov I, Pellequer JL, Wasco W, Ross B, Romano DM, Parano E, Pavone L, Brzustowicz LM. The Wilson disease gene is a copper transporting ATPase with homology to the Menkes disease gene. Nat Genet. 1993; 5:344-350. [PubMed: 8298641]

545. Tavoloni N. The intrahepatic biliary epithelium: An area of growing interest in hepatology. Sem Liv Dis. 1987; 7:280-292. 
546. Temel RE, Tang W, Ma Y, Rudel LL, Willingham MC, Ioannou YA, Davies JP, Nilsson LM, Yu L. Hepatic Niemann-Pick C1-like 1 regulates biliary cholesterol concentration and is a target of ezetimibe. J Clin Invest. 2007; 117:1968-1978. [PubMed: 17571164]

547. Thiebaut F, Tsuruo T, Hamada H, Gottesman MM, Pastan I, Willingham MC. Cellular localization of the multidrug-resistance gene product P-glycoprotein in normal human tissues. Proc Natl Acad Sci U S A. 1987; 84:7735-7738. [PubMed: 2444983]

548. Tietz PS, Alpini G, Pham LD, LaRusso NF. Somatostatin inhibits secretin-induced ductal hypercholeresis and exocytosis by cholangiocytes. Am J Physiol. 1995; 32:G110-G118. [PubMed: 7631787]

549. Tirona RG. Molecular mechanisms of drug transporter regulation. Handb Exp Pharmacol. 2011:373-402. [PubMed: 21103976]

550. Toyama K, Yonezawa A, Masuda S, Osawa R, Hosokawa M, Fujimoto S, Inagaki N, Inui K, Katsura T. Loss of multidrug and toxin extrusion 1 (MATE1) is associated with metformininduced lactic acidosis. Br J Pharmacol. 2012; 166:1183-1191. [PubMed: 22242910]

551. Trauner M, Arrese M, Lee HR, Boyer JL, Karpen SJ. Endotoxin-induced down-regulation of the rat liver $\mathrm{Na}^{+}$/taurocholate cotransporter (ntcp) gene is mediated by decreased activity of hepatocyte nuclear factor 1 (HNF 1). Hepatology. 1997; 26:262A. [PubMed: 9252132]

552. Trauner M, Arrese M, Soroka C, Ananthanarayanan M, Koeppel TA, Schlosser SF, Suchy FJ, Keppler D, Boyer JL. The rat canalicular conjugate export pump ( $\mathrm{mrp} 2$ ) is down-regulated in intrahepatic and obstructive cholestasis. Gastroenterology. 1997; 113:255-264. [PubMed: 9207286]

553. Trauner M, Boyer JL. Bile salt transporters: Molecular characterization, function and regulation. Physiol Rev. 2003; 83:633-671. [PubMed: 12663868]

554. Trauner M, Meier PJ, Boyer JL. Molecular pathogenesis of cholestasis. N Eng J Med. 1998; 339:1217-1227.

555. Trauner M, Nathanson MH, Rydberg SA, Koeppel TA, Gartung C, Sessa WC, Boyer JL. Endotoxin impairs biliary glutathione and $\mathrm{HCO}_{3}{ }^{-}$excretion and blocks the choleretic effect of nitric oxide in rat liver. Hepatology. 1997; 25:1184-1191. [PubMed: 9141437]

556. Trauner M, Nathason MH, Mennone A, Rydberg SA, Boyer JL. Nitric oxide donors stimulate bile flow and glutathione disulfide excretion independent of cyclic guanosine $3^{\prime}, 5^{\prime}$-cyclic monophosphate in the isolated perfused rat liver. Hepatology. 1997; 25:263-269. [PubMed: 9021932]

557. Tucker TG, Milne AM, Fournel-Gigleux S, Fenner KS, Coughtrie MW. Absolute immunoquantification of the expression of $\mathrm{ABC}$ transporters P-glycoprotein, breast cancer resistance protein and multidrug resistance-associated protein 2 in human liver and duodenum. Biochem Pharmacol. 2012; 83:279-285. [PubMed: 22062654]

558. Tuma PL, Finnegan CM, Yi JH, Hubbard AL. Evidence for apical endocytosis in polarized hepatic cells: Phosphoinositide 3-kinase inhibitors lead to the lysosomal accumulation of resident apical plasma membrane proteins. J Cell Biol. 1999; 145:1089-1102. [PubMed: 10352024]

559. Tuma, PL.; Hubbard, AL. The Hepatocyte Surface: Dynamic Polarity. In: Arias, IM.; Boyer, JL.; Chisari, FV.; Fausto, N.; Schachter, D., editors. The Liver Biology and Pathbiology. Lippincott Williams \& Wilkins; Philadelphia, PA: 2001. p. 96-117.

560. Tygstrup N, Steig BA, Juijn JA, Bull LN, Houwen RHJ. Recurrent familial intrahepatic cholestasis in the Faeroe Islands phenotypic heterogeneity but genetic homogeneity. Hepatology. 1999; 29:506-508. [PubMed: 9918928]

561. Tzeng SJ, Chang WC, Huang JD. Transcriptional regulation of the rat Mrp3 gene promoter by the specificity protein $(\mathrm{Sp})$ family members and CCAAT/enhancer binding proteins. J Biomed Sci. 2005; 12:741-761. [PubMed: 16132117]

562. Uppal H, Toma D, Saini SP, Ren S, Jones TJ, Xie W. Combined loss of orphan receptors PXR and CAR heightens sensitivity to toxic bile acids in mice. Hepatology. 2005; 41:168-176. [PubMed: 15619241]

563. Van Aubel RA, Smeets PH, van den Heuvel JJ, Russel FG. Human organic anion transporter MRP4 (ABCC4) is an efflux pump for the purine end metabolite urate with multiple allosteric 
substrate binding sites. Am J Physiol Renal Physiol. 2005; 288:F327-F333. [PubMed: 15454390]

564. Van de Steeg E, Stranecky V, Hartmannova H, Noskova L, Hrebicek M, Wagenaar E, van Esch A, de Waart DR, Oude Elferink RP, Kenworthy KE, Sticova E, Al Edreesi M, Knisely AS, Kmoch S, Jirsa M, Schinkel AH. Complete OATP1B1 and OATP1B3 deficiency causes human Rotor syndrome by interrupting conjugated bilirubin reuptake into the liver. J Clin Invest. 2012; 122:519-528. [PubMed: 22232210]

565. Van de Steeg E, Wagenaar E, van der Kruijssen CM, Burggraaff JE, de Waart DR, Elferink RP, Kenworthy KE, Schinkel AH. Organic anion transporting polypeptide 1a/1b-knockout mice provide insights into hepatic handling of bilirubin, bile acids, and drugs. J Clin Invest. 2010; 120:2942-2952. [PubMed: 20644253]

566. van der Velden LM, Stapelbroek JM, Krieger E, van den Berghe PV, Berger R, Verhulst PM, Holthuis JC, Houwen RH, Klomp LW, van de Graaf SF. Folding defects in P-type ATP 8B1 associated with hereditary cholestasis are ameliorated by 4-phenylbutyrate. Hepatology. 2010; 51:286-296. [PubMed: 19918981]

567. Van Dyke RW, Stephens JE, Scharschmidt BF. Effect of ion substitution on bile acid-dependent and bile acid-independent bile formation by the isolated perfused rat liver. J Clin Invest. 1982; 70:505-517. [PubMed: 6286725]

568. van Mil SW, van der Woerd WL, van der BG, Sturm E, Jansen PL, Bull LN, van den Berg IE, Berger R, Houwen RH, Klomp LW. Benign recurrent intrahepatic cholestasis type 2 is caused by mutations in ABCB11. Gastroenterology. 2004; 127:379-384. [PubMed: 15300568]

569. Vavricka SR, Jung D, Fried M, Grutzner U, Meier PJ, Kullak-Ublick GA. The human organic anion transporting polypeptide 8 (SLCO1B3) gene is transcriptionally repressed by hepatocyte nuclear factor 3beta in hepatocellular carcinoma. J Hepatol. 2004; 40:212-218. [PubMed: 14739090]

570. VonDippe P, Amoui M, Alves C, Levy D. $\mathrm{Na}^{+}$-dependent bile acid transport by hepatocytes is mediated by a protein similar to microsomal epoxide hydrolase. Am J Physiol. 1993; 264:G528G534. [PubMed: 8460705]

571. Vrins C, Vink E, Vandenberghe KE, Frijters R, Seppen J, Groen AK. The sterol transporting heterodimer ABCG5/ABCG8 requires bile salts to mediate cholesterol efflux. FEBS. 2007; 581:4616-4620.

572. Wakabayashi Y, Dutt P, Lippincott-Schwartz J, Arias IM. Rab11a and myosin Vb are required for bile canalicular formation in WIF-B9 cells. Proc Natl Acad Sci U S A. 2005; 102:15087-15092. [PubMed: 16214890]

573. Wakabayashi Y, Kipp H, Arias IM. Transporters on demand: Intracellular reservoirs and cycling of bile canalicular ABC transporters. J Biol Chem. 2006; 281:27669-27673. [PubMed: 16737964]

574. Wakabayashi Y, Lippincott-Schwartz J, Arias IM. Intracellular trafficking of bile salt export pump (ABCB11) in polarized hepatic cells: Constitutive cycling between the canalicular membrane and rab11-positive endosomes. Mol Biol Cell. 2004; 15:3485-3496. [PubMed: 15121884]

575. Wang L, Dong H, Soroka CJ, Wei N, Boyer JL, Hochstrasser M. Degradation of the bile salt export pump at endoplasmic reticulum in progressive familial intrahepatic cholestasis type II. Hepatology. 2008; 48:1558-1569. [PubMed: 18798335]

576. Wang L, Soroka CJ, Boyer JL. The role of bile salt export pump mutations in progressive familial intahepatic cholestasis type II. J Clin Invest. 2002; 110:965-972. [PubMed: 12370274]

577. Wang R, Salem M, Yousef IM, Tuchweber B, Lam P, Childs SJ, Helgason CD, Ackerley C, Phillips MJ, Ling V. Targeted inactivation of sister of P-glycoprotein gene (spgp) in mice results in non-progressive but persistent intrahepatic cholestasis. Proc Natl Acad Sci U S A. 2001; 98:2011-2016. [PubMed: 11172067]

578. Wang W, Soroka CJ, Mennone A, Rahner C, Harry K, Pypaert M, Boyer JL. Radixin is required to maintain apical canalicular membrane structure and function in rat hepatocytes. Gastroenterology. 2006; 131:878-884. [PubMed: 16952556] 
579. Watanabe N, Tsukada N, Smith C. Motility of bile canaliculi in the living animal: Implications for bile flow. J Cell Biol. 1991; 113:1069-1080. [PubMed: 2040644]

580. Watanabe S, Smith CR, Phillips MJ. Coordination of the contractile activity of bile canaliculi evidence from calcium microinjection of triplet hepatocytes. Lab Invest. 1985; 53:275-279. [PubMed: 4033067]

581. Webster CR, Anwer MS. Role of the PI3K/PKB signaling pathway in cAMP-mediated translocation of rat liver Ntcp. Am J Physiol. 1999; 277:G1165-G1172. [PubMed: 10600813]

582. Weerachayaphorn J, Cai SY, Soroka CJ, Boyer JL. Nuclear factor erythroid 2-related factor 2 is a positive regulator of human bile salt export pump expression. Hepatology. 2009; 50:1588-1596. [PubMed: 19821532]

583. Weinman SA, Graf J, Boyer JL. Voltage-driven, taurocholate-dependent secretion in isolated hepatocyte couplets. Am J Physiol. 1989; 256:G826-G832. [PubMed: 2719107]

584. Wheeler EL, Ramos OL. Role of bile ducts during secretin choleresis in dogs. Am J Physiol. 1966; 210:1153-1159. [PubMed: 5947262]

585. Wheeler HO. Canalicular bile production in dogs. Am J Physiol. 1968; 214:866-874. [PubMed: 5642950]

586. Wheeler HO. Secretion of bile acids by the liver and their role in the formation of hepatic bile. Arch Intern Med. 1972; 130:533-541. [PubMed: 4562150]

587. Whiting JF, Green RM, Rosenbluth AB, Gollan JL. Tumor necrosis factor-alpha decreases hepatocyte bile salt uptake and mediates endotoxin-induced cholestasis. Hepatology. 1995; 22:1273-1278. [PubMed: 7557881]

588. Wielinga PR, van der Heijden I, Reid G, Beijnen JH, Wijnholds J, Borst P. Characterization of the MRP4- and MRP3-medated transport of cyclic nucleotides from intact cells. J Biol Chem. 2003; 278:17664-17671. [PubMed: 12637526]

589. Wong MH, Oelkers P, Craddock AL, Dawson PA. Expression cloning and characterization of the hamster ileal sodium-dependent bile acid transporter. J Biol Chem. 1994; 269:1340-1347. [PubMed: 8288599]

590. Xia X, Francis H, Glaser S, Alpini G, LeSage G. Bile acid interactions with cholangiocytes. World J Gastroenterol. 2006; 12:3553-3563. [PubMed: 16773712]

591. Xu S, Weerachayaphorn J, Cai SY, Soroka CJ, Boyer JL. Aryl hydrocarbon receptor and NF-E2related factor 2 are key regulators of human MRP4 expression. Am J Physiol Gastrointest Liver Physiol. 2010; 299:G126-G135. [PubMed: 20395535]

592. Yamanashi Y, Takada T, Shoda J, Suzuki H. Novel function of Niemann-Pick C1-like 1 as a negative regulator of Niemann-Pick C2 protein. Hepatology. 2012; 55:953-964. [PubMed: 22095670]

593. Yamanashi Y, Takada T, Suzuki H. Niemann-Pick C1-like 1 overexpression facilitates ezetimibesensitive cholesterol and beta-sitosterol uptake in CaCo-2 cells. J Pharmacol Exp Ther. 2007; 320:559-564. [PubMed: 17135346]

594. Yamanashi Y, Takada T, Yoshikado T, Shoda J, Suzuki H. NPC2 regulates biliary cholesterol secretion via stimulation of ABCG5/G8-mediated cholesterol transport. Gastroenterology. 2011; 140:1664-1674. [PubMed: 21315718]

595. Yang B, Song Y, Zhao D, Verkman AS. Phenotype analysis of aquaporin-8 null mice. Am J Physiol Cell Physiol. 2005; 288:C1161-C1170. [PubMed: 15647389]

596. Yang Q, Onuki R, Nakai C, Sugiyama Y. Ezrin and radixin both regulate the apical membrane localization of ABCC2 (MRP2) in human intestinal epithelial Caco-2 cells. Exp Cell Res. 2007; 313:3517-3525. [PubMed: 17825285]

597. Yegutkin GG. Nucleotide- and nucleoside-converting ectoenzymes: Important modulators of purinergic signalling cascade. Biochim Biophys Acta. 2008; 1783:673-694. [PubMed: 18302942]

598. Yonezawa A, Inui K. Importance of the multidrug and toxin extrusion MATE/SLC47A family to pharmacokinetics, pharmacodynamics/toxicodynamics and pharmacogenomics. Br J Pharmacol. 2011; 164:1817-1825. [PubMed: 21457222]

599. Yoon YB, Hagey LR, Hofmann AF, Gurantz D, Michelotti EL, Steinbach JH. Effect of side-chain shortening on the physiologic properties of bile acids: Hepatic transport and effect on biliary 
secretion of 23-nor-ursodeoxycholate in rodents. Gastroenterology. 1986; 90:837-852. [PubMed: 3949115]

600. Yoshikado T, Takada T, Yamamoto T, Yamaji H, Ito K, Santa T, Yokota H, Yatomi Y, Yoshida H, Goto J, Tsuji S, Suzuki H. Itraconazole-induced cholestasis: Involvement of the inhibition of bile canalicular phospholipid translocator MDR3/ABCB4. Mol Pharmacol. 2011; 79:241-250. [PubMed: 21056966]

601. Yu L, Gupta S, Xu F, Liverman AD, Moschetta A, Mangelsdorf DJ, Repa JJ, Hobbs HH, Cohen JC. Expression of ABCG5 and ABCG8 is required for regulation of biliary cholesterol secretion. J Biol Chem. 2005; 280:8742-8747. [PubMed: 15611112]

602. Yu L, Hammer RE, Li-Hawkins J, von Bergmann K, Lutjohann D, Cohen JC, Hobbs HH. Disruption of Abcg5 and Abcg8 in mice reveals their crucial role in biliary cholesterol secretion. Proc Natl Acad Sci U SA. 2002; 99:16237-16242.

603. Zamek-Gliszczynski MJ, Nezasa K, Tian X, Bridges AS, Lee K, Belinsky MG, Kruh GD, Brouwer KL. Evaluation of the role of multidrug resistance-associated protein (Mrp) 3 and Mrp4 in hepatic basolateral excretion of sulfate and glucuronide metabolites of acetaminophen, 4methylumbelliferone, and harmol in Abcc3-/- and Abcc4-/- mice. J Pharmacol Exp Ther. 2006; 319:1485-1491. [PubMed: 16988054]

604. Zegers MMP, Hoekstra D. Sphingolipid transport to the apical plasma membrane domain in human hepatoma cells is controlled by PKC and PKA activity: A correlation with cell polarity in HepG2 cells. J Cell Biol. 1997; 138:307-321. [PubMed: 9230073]

605. Zeiller K, Loeser R, Parcher G, Hannig K. Free flow electrophoresis II: Analysis of the method with respect to preparative cell separation. Hoppe-Seyler's Z Physiol Chem. 1975; 356:12251244. [PubMed: 1176090]

606. Zelcer N, Reid G, Wielinga P, Kuil A, Van Der Heijden I, Schuetz JD, Borst P. Steriod-and bile acid-conjugates are substrates of human MRP4 (ABCC4). Biochem J. 2003; 371:361-367. [PubMed: 12523936]

607. Zelcer N, van de WK, de Waart R, Scheffer GL, Marschall HU, Wielinga PR, Kuil A, Kunne C, Smith A, van d V, Wijnholds J, Elferink RO, Borst P. Mice lacking Mrp3 (Abcc3) have normal bile salt transport, but altered hepatic transport of endogenous glucuronides. J Hepatol. 2006; 44:768-775. [PubMed: 16225954]

608. Zhou G, Kuo MT. NF-kappaB-mediated induction of mdr1b expression by insulin in rat hepatoma cells. J Biol Chem. 1997; 272:15174-15183. [PubMed: 9182539]

609. Zollner G, Fickert P, Silbert D, Fuchsbichler A, Marschall H-U, Zatloukal K, Denk H, Trauner M. Adaptive changes in hepatobiliary transporter expression in primary biliary cirrhosis. $\mathrm{J}$ Hepatol. 2003; 38:717-727. [PubMed: 12763363]

610. Zollner G, Wagner M, Fickert P, Silbert D, Gumhold J, Zatloukal K, Denk H, Trauner M. Expression of bile acid synthesis and detoxification enzymes and the alternative bile acid efflux pump MRP4 in patients with primary biliary cirrhosis. Liver Int. 2007; 27:920-929. [PubMed: 17696930]

611. Zucker SD, Goessling W, Gollan JL. Kinetics of bilirubin transfer between serum albumin and membrane vesicles - insight into the mechanism of organic anion delivery to the hepatocyte plasma membrane. J Biol Chem. 1995; 270:1074-1081. [PubMed: 7836362]

612. Zucker SD, Goessling W, Hoppin AG. Unconjugated bilirubin exhibits spontaneous diffusion through model lipid bilayers and native hepatocyte membranes. J Biol Chem. 1999; 274(16): 10852-10862. [PubMed: 10196162]

613. Zweers SJ, Booij KA, Komuta M, Roskams T, Gouma DJ, Jansen PL, Schaap FG. The human gallbladder secretes fibroblast growth factor 19 into bile: Towards defining the role of fibroblast growth factor 19 in the enterobiliary tract. Hepatology. 2012; 55:575-583. [PubMed: 21953282] 
(A)

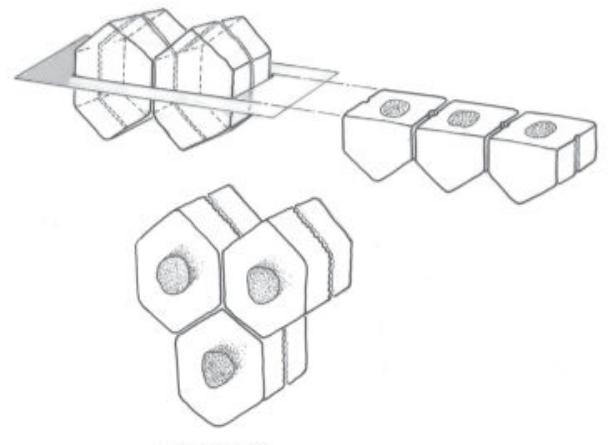

(B)

Sinusoid

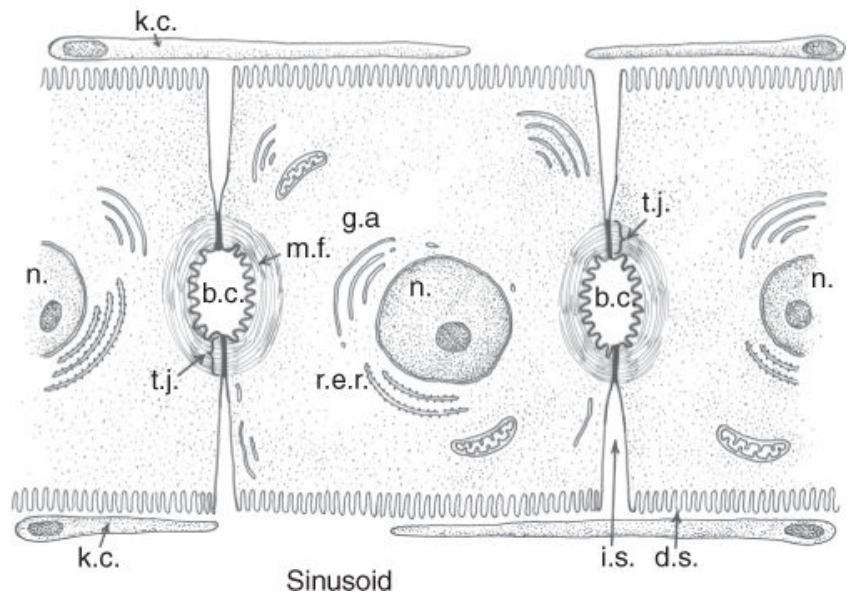

Figure 1.

(A) Three-dimensional projection of arrangement of hexagonal hepatocytes in liver plates illustrating the position of bile canaliculi which form a "chicken wire" mesh of interconnecting conduits of the primary secretion of bile. (B) Adjoining hepatocytes illustrating the location of the bile canaliculus (b.c.), intercellular space (i.c.), Disse's space (d.s.), and fenestrated endothelial lining cells and Kupffer cells (k.c.). Tight junctions seal the lumen of the bile canaliculus (t.j.) whose luminal membrane is surrounded by microfilaments (m.f.) and other cytoskeletal elements that provide a contractile mechanism for canalicular peristalsis. Golgi apparatus (g.a.) and rough endoplasmic reticulum (r.e.r) are also illustrated. Reprinted, with permission, from Ref. (71). 

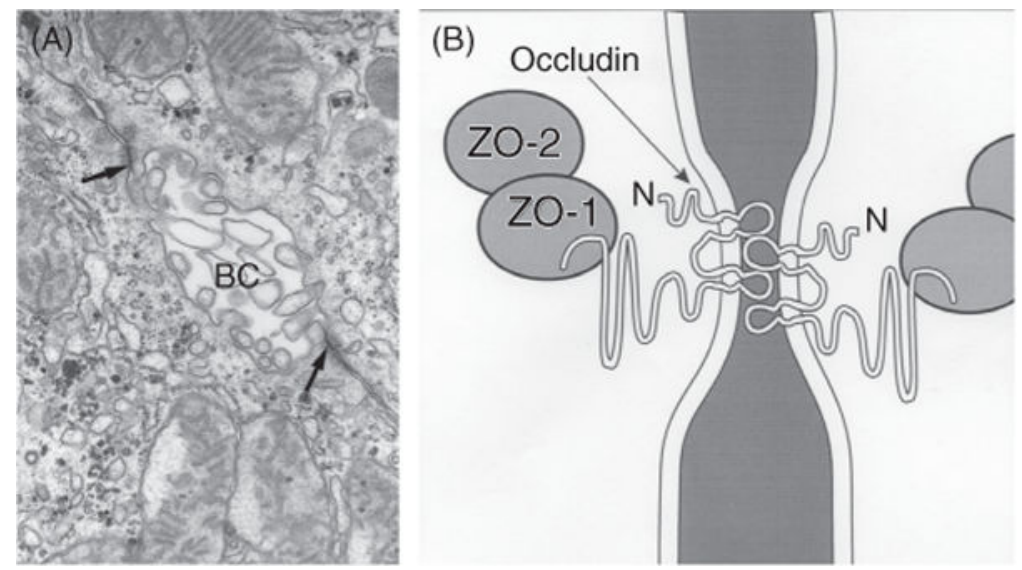

Figure 2.

The hepatocyte tight junction complex. (A) Electron micrograph of the bile canaliculus formed between two adjacent hepatocytes and whose lumen is filled with microvilli and sealed by the tight junctions (arrows). (B) Schematic of the tight junction complex showing that occludins and claudins are transmembrane proteins forming the junction seal, whereas zonula occluden proteins 1 and 2 (ZO1 and Z02) are cytoplasmic proteins that may serve as anchors for occludins. The latter protein forms the interconnecting strands illustrated in the freeze fracture in Figure 3. See Ref. (384) for more details of tight junction anatomy.

Reprinted, with permission, from Ref. (76). 


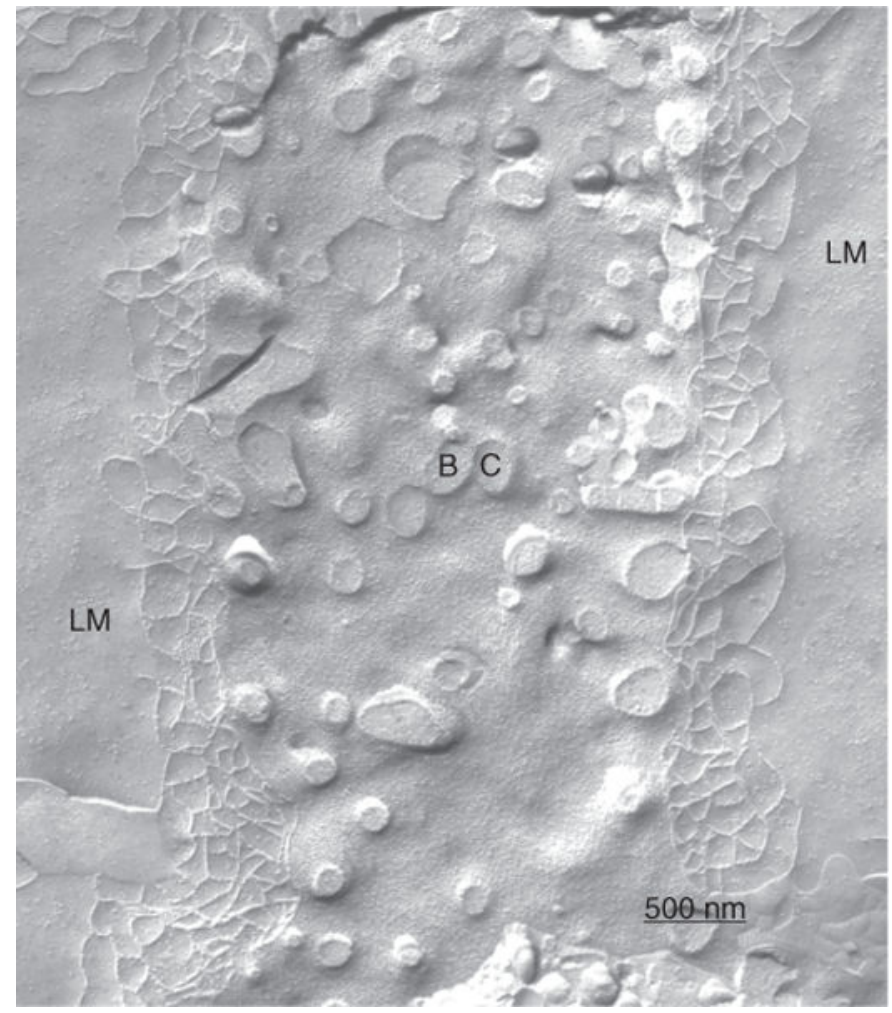

Figure 3.

Freeze fracture replica of the bile canaliculus (BC). The tight junction elements represent the only anatomical barrier between bile and the intercellular space lined by the lateral membrane $(\mathrm{LM})$ of the hepatocyte. Magnifcation $\times 39,186$. Reprinted, with permission, from Ref. (72). 

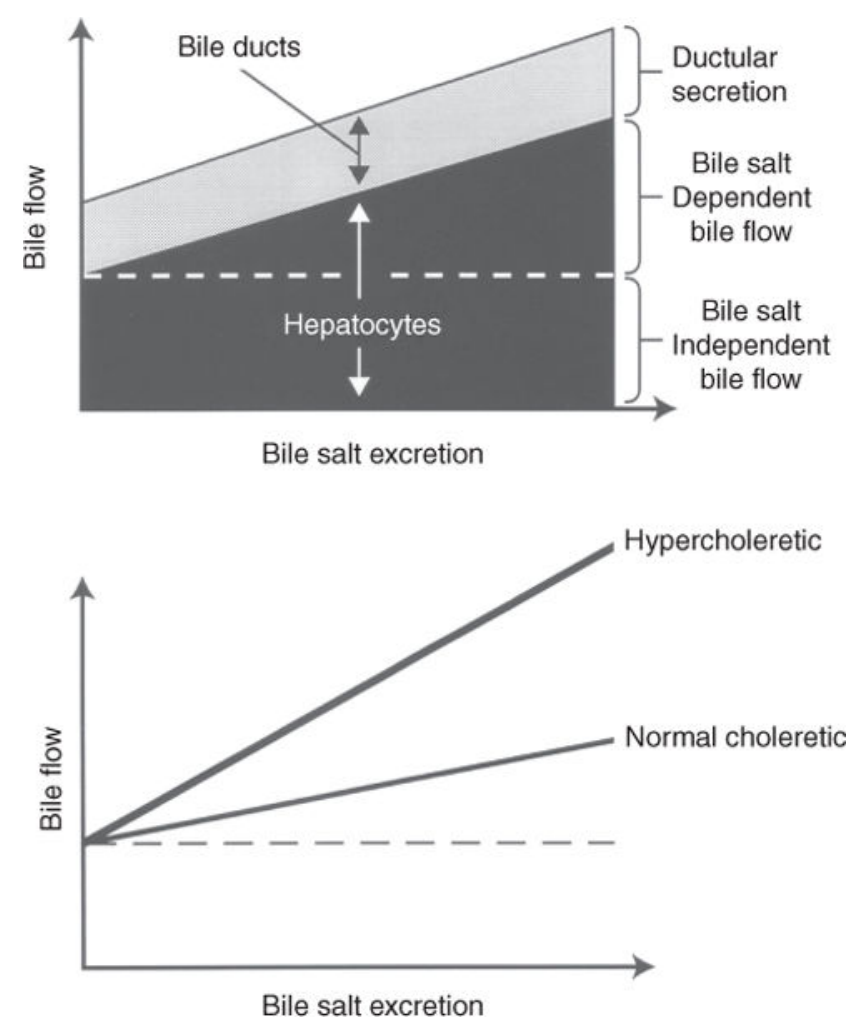

Figure 4.

Graphic representation of determinants of bile flow. Top: canalicular bile flow consists of a bile salt-dependent (BSDF) and a bile salt-independent (BSIF) fraction. The BSDF increases linearly as a function of bile salt excretion. Both canalicular bile flow and secretion from the bile ducts contribute to total bile flow. Bottom: choleretic potential varies among bile salts. Bile flow is linearly related to bile salt excretion, but hypercholeretic bile salts increase bile flow more rapidly than do bile salts with normal choleretic potential. Reprinted, with permission, from Ref. (76). 


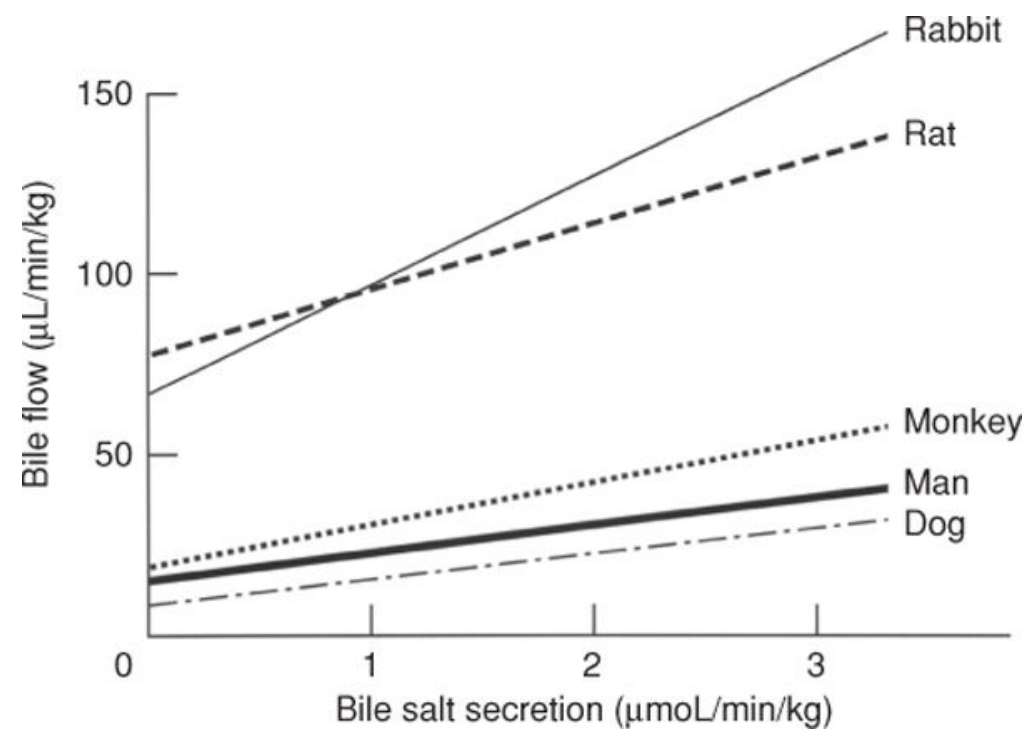

Figure 5.

Relationship between bile salt concentration and bile flow in various animal species. Note that extrapolation to zero bile salt excretion yields a positive intercept for BSIF that is greater in rats and rabbits than in the three other species. Reprinted, with permission, from Ref. (73) 


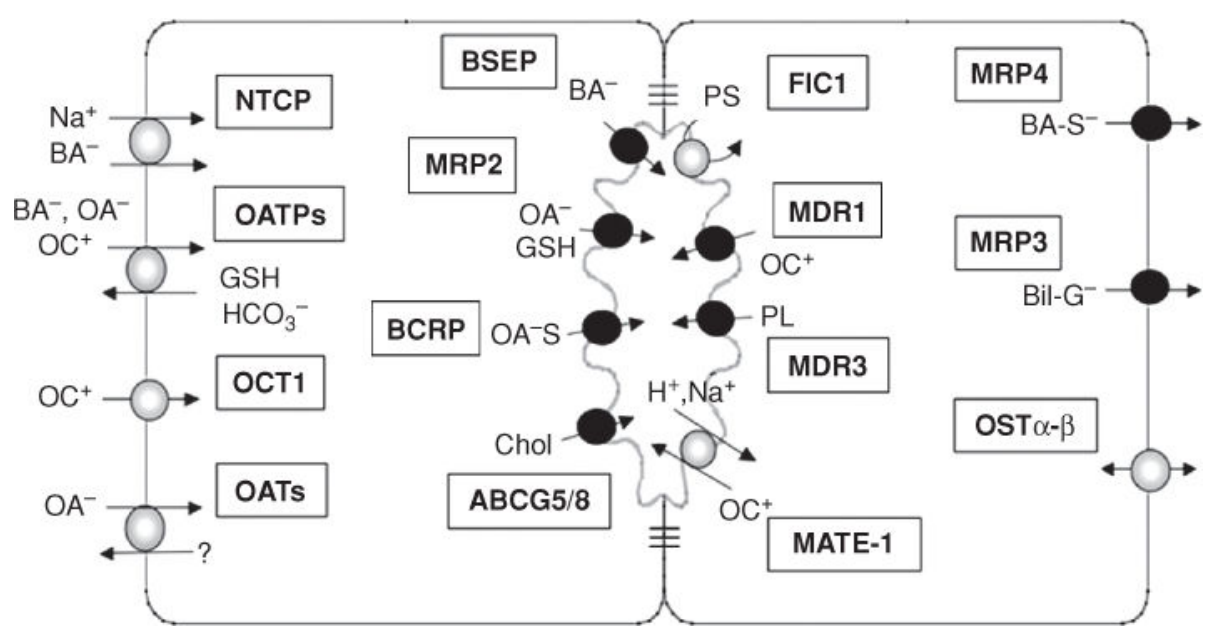

Figure 6.

Membrane transporters that determine the uptake and excretion of bile salts and other organic solutes in hepatocytes. $\left(\mathrm{Na}^{+}\right.$, sodium; $\mathrm{BA}^{-}$, bile salts; $\mathrm{OA}^{-}$, organic anions; $\mathrm{OC}^{+}$, organic cations; $\mathrm{GSH}$, glutathione; $\mathrm{HCO}_{3}{ }^{-}$, bicarbonate; OA-S, sulfated organic anions; Chol, cholesterol; $\mathrm{H}^{+}$, proton; PL, phospholipid; PS, phosphatidyl serine; $\mathrm{BA}_{-} \mathrm{S}^{-}$, sulfated bile salts; Bil-G, bilirubin glucuronide). Also see Table 4 for full terminology and function for these and other transporter determinants of bile secretion. Reprinted, with permission, from Ref. (79). 


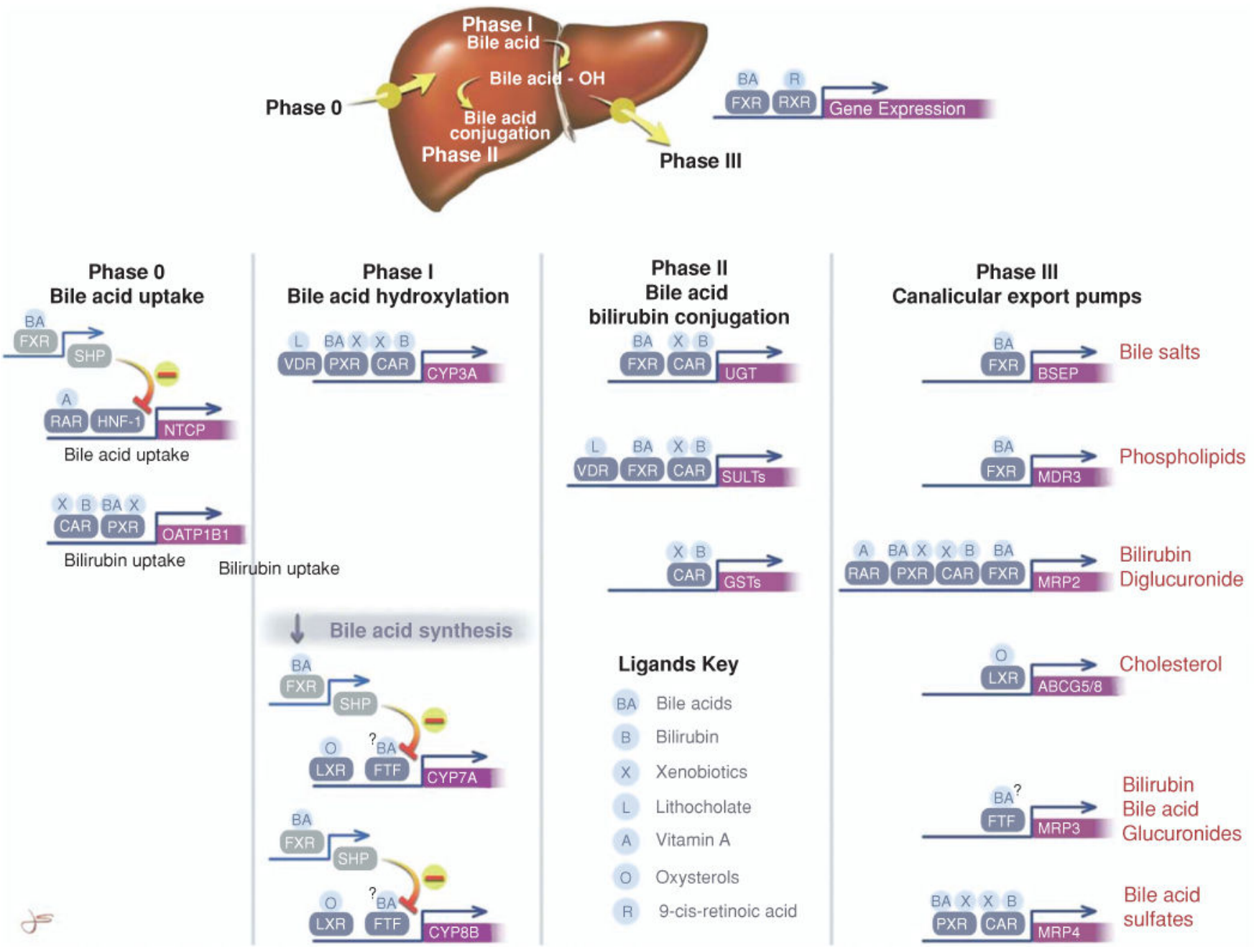

Figure 7.

The hepatic clearance of bile salts and other organic solutes is determined by four steps or phases; Phase 0 , hepatic uptake; Phase I, hydroxylation by cytochrome $3 \mathrm{~A}$ and other CYP450s; Phase II, conjugation reactions with glucuronides, glutathione, sulfates, or acetates; and Phase III, export from the liver by adenosine triphosphate-dependent ATPbinding cassette $(\mathrm{ABC})$ transporters. The figure also shows the coordinated ligand-activated regulation of gene expression that determines the hepatic clearance of bile salts, bilirubin, and xenobiotics. Some of the major nuclear receptors that regulate the expression of these key genes are shown. Unless otherwise indicated by $\downarrow$ or - symbols, these ligands stimulate gene expression. Normally, many of these nuclear receptors form heterodimeric complexes with the retinoid X receptor (RXR). This complex then binds to specific response elements in the gene promoter. Other nuclear receptors such as short heterodimeric protein-1, fetal transcription factor (FTF), and hepatocyte nuclear factor 1 (HNF-1) do not form heterodimers with RXR and do not have specific ligands. Reprinted, with permission, from Ref. (78). 
(A)

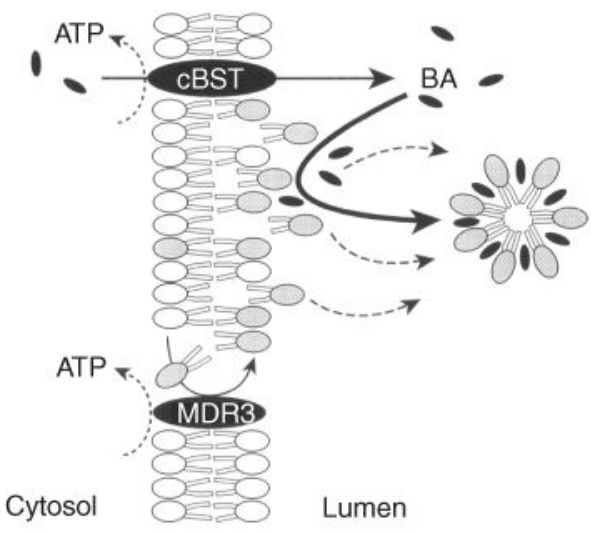

(B)

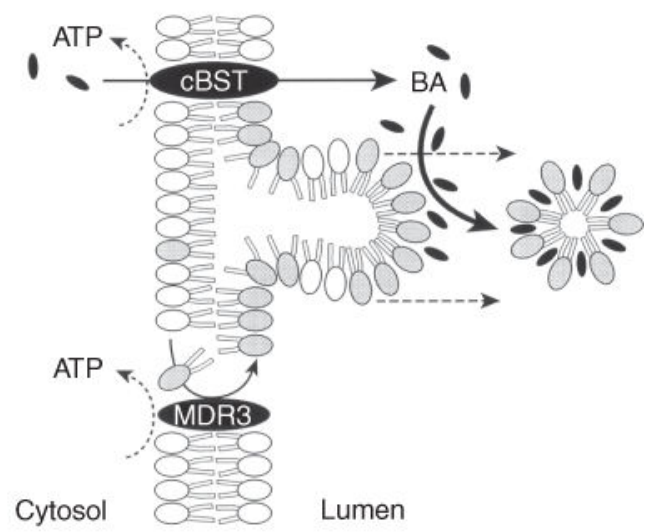

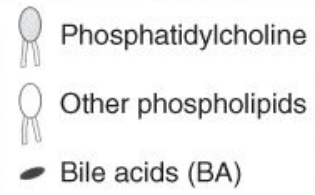

Figure 8.

Two alternative mechanisms for the mechanism of phosphatidylcholine (PC) excretion into bile. (A) Bile salts are transported into the canalicular lumen by the canalicular bile salt transporter (cBST) (now termed BSEP), and PC accumulates on the luminal side of the canalicular membrane by the action of MDR3. Luminal bile salts then extract the phospholipid from the membrane into micelles. (B) MDR3 flops PC to the external domains of the canalicular membrane bilayer which extrude into the bile lumen and are destabilized by bile salts which pinch off the membrane. Reprinted, with permission, from Ref. (76) as modified from Oude Elferink RPJ, Tytgat GNJ, Groen AK. Faseb J, 11: 19, 1997(427). 


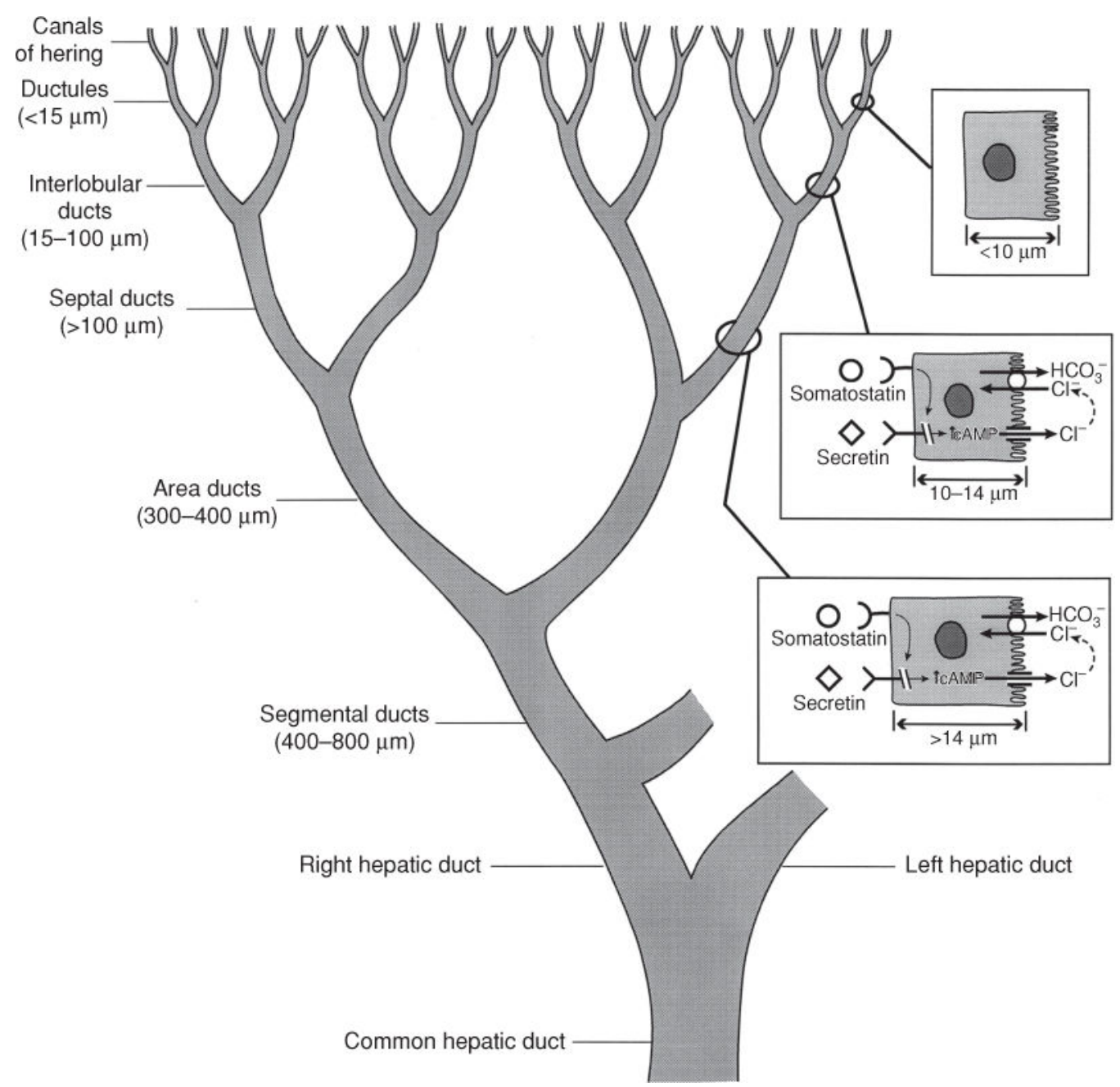

Figure 9.

The figure illustrates the heterogeneity of the structure and function of the biliary tree and bile duct epithelial cells. Canalicular bile secreted by hepatocytes enters the biliary tree by joining upstream with the canals of Hering. As branches of the biliary tree join, the luminal diameter increases (values in parentheses) and the bile duct epithelial cells become larger. The range of receptors and transporters on medium and large bile duct cells is similar although secretin receptor expression and $\mathrm{Cl}^{-} / \mathrm{HCO}_{3}{ }^{-}$exchange activity is greater in the median and large size bile duct cells. Reprinted, with permission, from Ref. (76). 


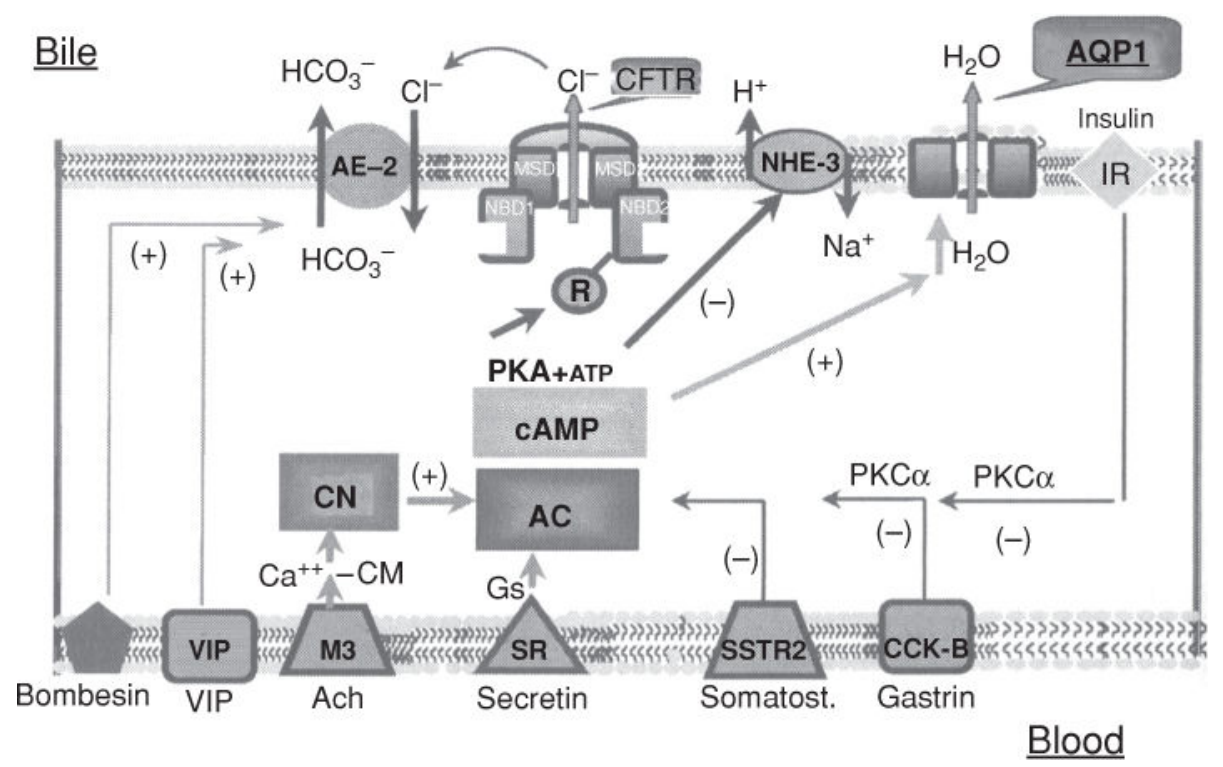

Figure 10.

Hormonal regulation of cholangiocyte $\mathrm{HCO}_{3}{ }^{-}$excretion based on studies in rodents. Secretin induces ductular bicarbonate-rich choleresis by activation of apical $\mathrm{Cl}^{-} / \mathrm{HCO}_{3}{ }^{-}$ exchanger via a cyclic adenosine monophosphate (cAMP) and PKA-dependent pathway; acetylcholine, by activation of calcineurin, induces a "sensitization" of adenylcyclase to secretin leading to a maximal stimulation of the $\mathrm{Cl}^{-} / \mathrm{HCO}_{3}{ }^{-}$exchanger. Vasoactive intestinal peptide (VIP) and bombesin stimulate cholangiocyte bicarbonate secretion via a cAMP and cyclic guanosine monophosphate (cGMP)-independent pathway. Somatostatin, gastrin, and insulin inhibit both basal and hormonal induced bicarbonate cholangiocyte secretion via a PKC-a-dependent pathway. Ach, acetylcholine; M3, muscarinic receptor 3; SR, secretin receptor; $\mathrm{CM}$, calmodulin; $\mathrm{AC}$, adenyl cyclase; PKA, protein kinase A; PKCa, protein kinase c alpha; $\mathrm{AE}-2, \mathrm{Cl}^{-} / \mathrm{HCO}_{3}{ }^{-}$exchanger; CFTR, cystic fibrosis transmembrane conductance regulator; NHE-3, sodium hydrogen exchanger isoform 3; AQP1, aquaporin 1; IR, insulin receptor. Reprinted, with permission, from Ref. (183). 


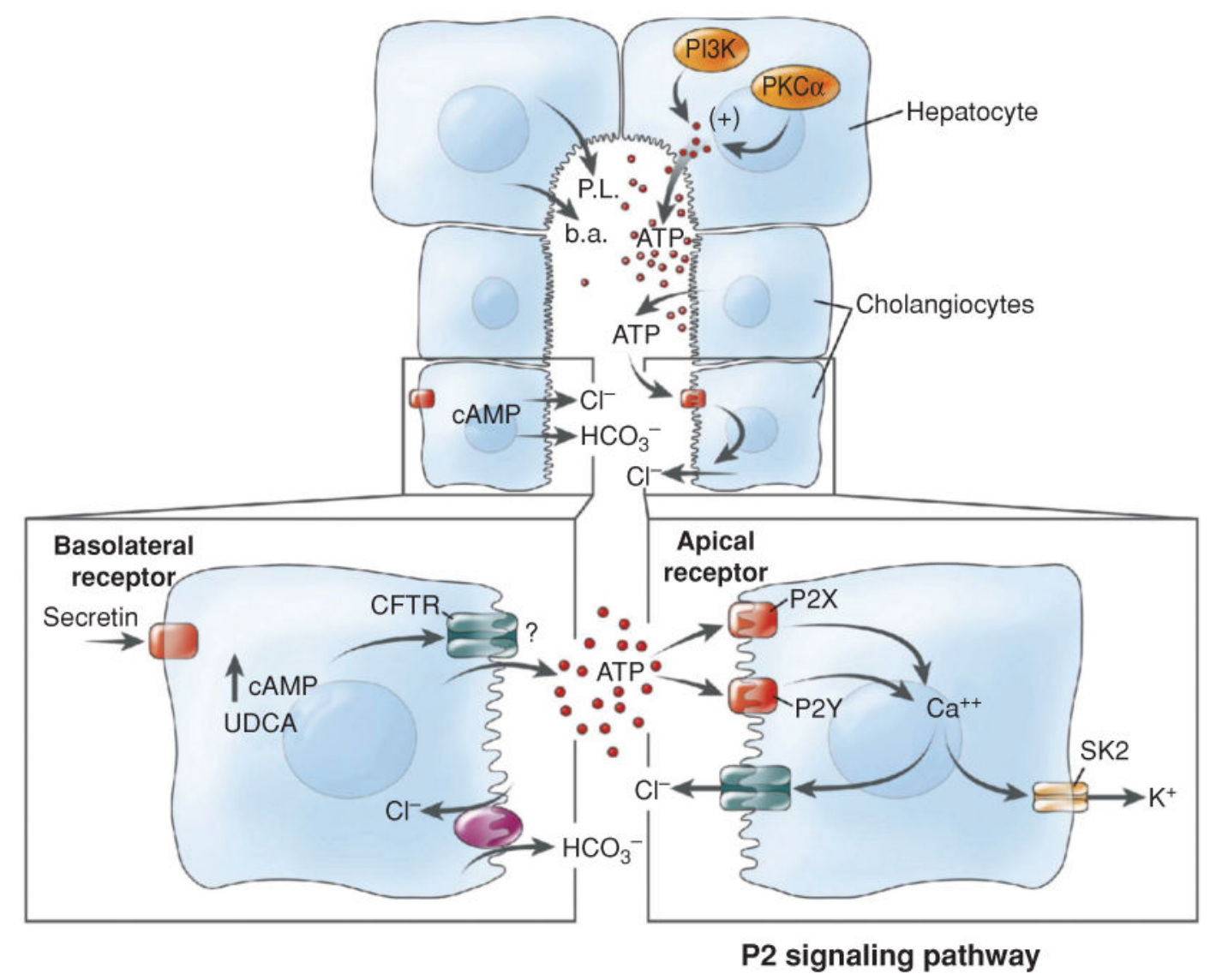

Figure 11.

The role of extracellular adenosine triphosphate (ATP) in bile formation. Proposed model of P2 signaling. Bile formation begins via transport of bile salts, phospholipids, and ATP from the hepatocyte canalicular membrane. Hepatocyte ATP release is positively regulated by phosphatidylinositol 3-kinase (PI3K) and protein kinase C. Secretin stimulates increases in cholangiocyte cyclic adenosine monophosphate (cAMP) levels via stimulation of basolateral receptors resulting in $\mathrm{Cl}^{-}$efflux through $\mathrm{CFTR}$ and an increase in $\mathrm{Cl}^{-} / \mathrm{HCO}_{3}{ }^{-}$exchange. Increases in cAMP, as well as exposure to the bile salt ursodeoxycholate (UDCA), may also increase ATP release through a CFTR-dependent mechanism. BA, bile acids; PL, phospholipids; SK2, $\mathrm{Ca}^{2+}$-activated $\mathrm{K}^{+}$channel; CFTR, cystic fibrosis transmembrane conductance regulator. Reprinted, with permission, from Ref. (159). 


\section{Table 1}

\section{Composition of Bile ${ }^{a}$}

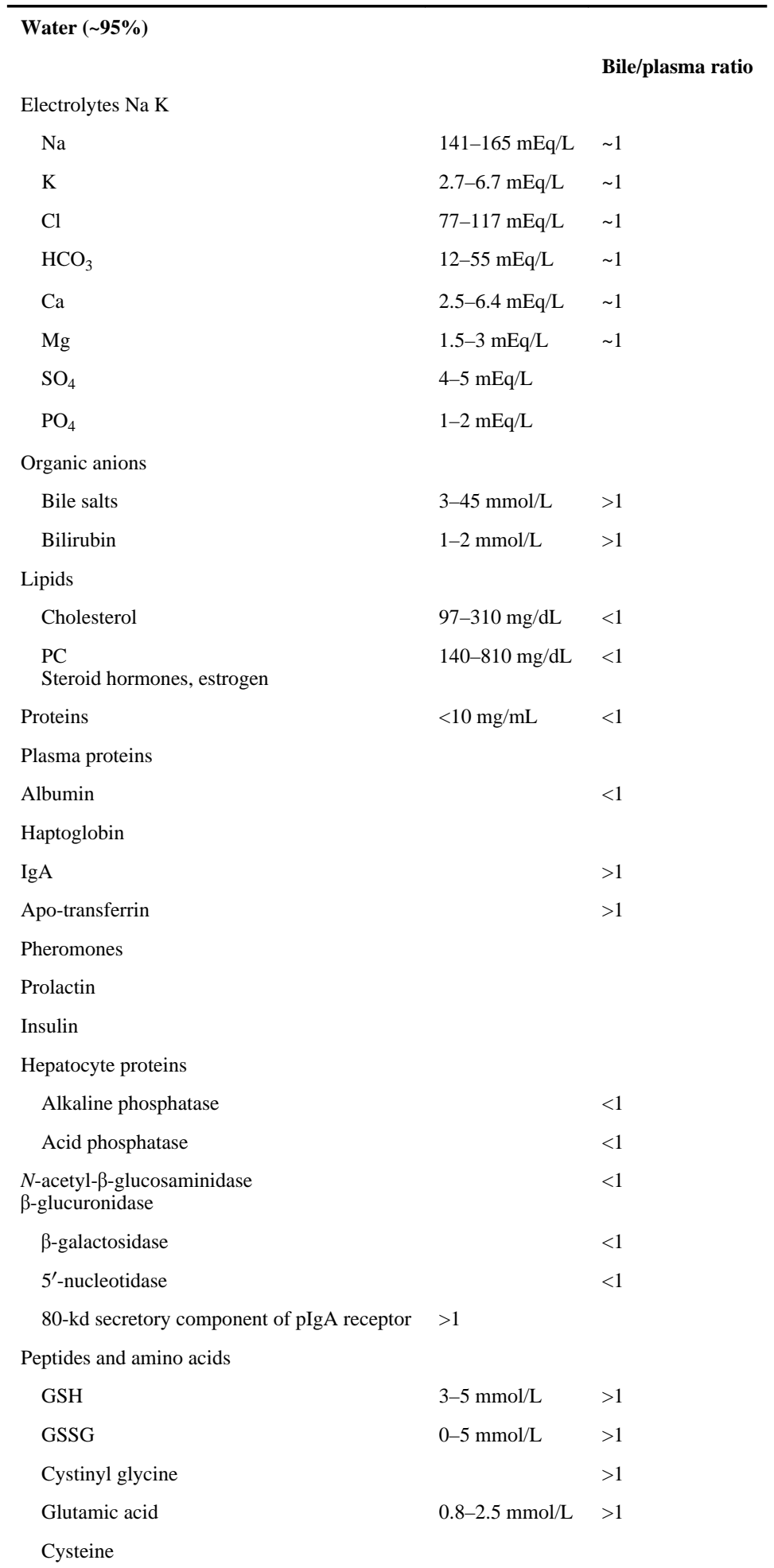




\begin{tabular}{lll}
\hline Water $(\sim 95 \%)$ & & Bile/plasma ratio \\
FGF19 & & $>1$ \\
Aspartic acid & $0.4-1.1 \mathrm{mmol} / \mathrm{L}$ & $>1$ \\
Glycine & $0.6-2.6 \mathrm{mmol} / \mathrm{L}$ & $>1$ \\
Nucleotides & & \\
ATP & $0.1-6 \mu \mathrm{mol} / \mathrm{L}$ & \\
ADP & $0.1-5 \mu \mathrm{mol} / \mathrm{L}$ & \\
AMP & $0.06-5 \mu \mathrm{mol} / \mathrm{L}$ & \\
Heavy metals & & $>1$ \\
Cu & $2.8 \mathrm{mg} / \mathrm{L}$ & $>1$ \\
Mn & $0.2 \mathrm{mg} / \mathrm{L}$ & $>1$ \\
Fe & $<1 \mathrm{mg} / \mathrm{L}$ & $>1$ \\
Zn & $0.2-0.3 \mathrm{mg} / \mathrm{L}$ & \\
Vitamins & & \\
25-OH vitamin D & & \\
Cyanocobalamin & $15-200 \mu \mathrm{g} / \mathrm{L}$ & \\
Riboflavin & $4-60 \mu \mathrm{g} / \mathrm{L}$ & \\
Folate & & \\
\hline
\end{tabular}

${ }^{a}$ Values are from measurements in human or rodent bile.

NOTE: Modified from Ref. (73) with permission. (Boyer JL. Mechanisms of bile secretion and hepatic transport. In: Andreoli TE, Hoffman JF, Fanestil DD, Schultz SG, eds. Physiology of membrane disorders. New York: Plenum Publishing, 1986:609-636, with permission.) 


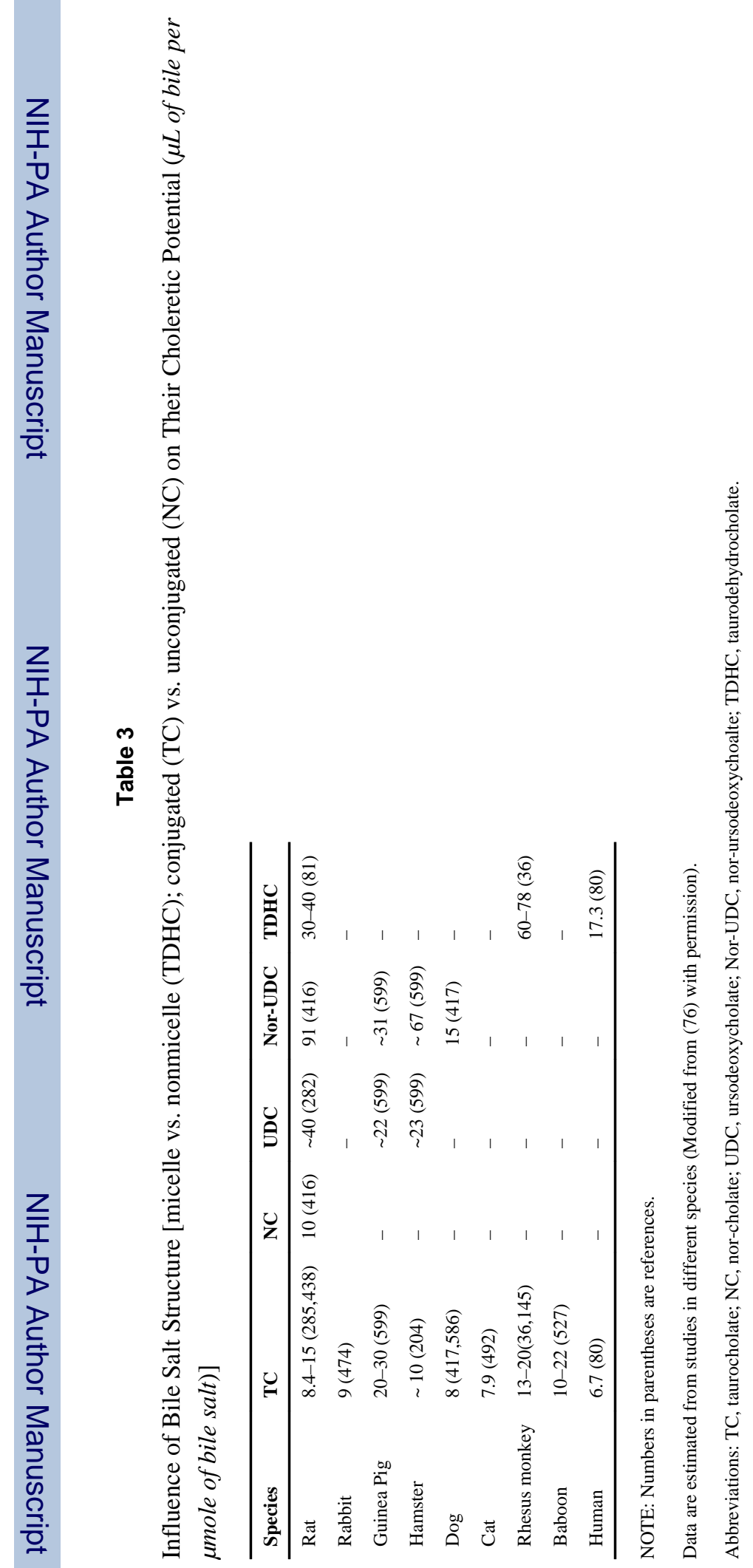

Compr Physiol. Author manuscript; available in PMC 2014 July 10. 
Table 4

Nomenclature, Location, and Function of the Major Hepatocyte and Cholangiocyte Membrane Transporters Involved in Bile Secretion

\begin{tabular}{|c|c|c|c|c|}
\hline Name & Abbreviation (gene) & Phase & Location & Function \\
\hline Sodium-taurocholate cotransporter & NTCP (SLC10A1) & 0 & $\begin{array}{l}\text { Basolateral membrane of } \\
\text { hepatocytes }\end{array}$ & $\begin{array}{l}\text { Primary carrier for } \\
\text { conjugated bile-salt } \\
\text { uptake from portal blood }\end{array}$ \\
\hline Organic-anion-transporting polypeptides & OATPs (SLCO1B1and 1B3) & 0 & $\begin{array}{l}\text { Basolateral membrane of } \\
\text { hepatocytes }\end{array}$ & $\begin{array}{l}\text { Broad substrate carriers } \\
\text { for sodium-independent } \\
\text { uptake of bile salts, } \\
\text { organic anions, and other } \\
\text { amphipathic organic } \\
\text { solutes from portal blood }\end{array}$ \\
\hline Organic solute transporter alpha/beta & $\mathrm{OSTa} / \beta$ & III & $\begin{array}{l}\text { Basolateral membrane of } \\
\text { hepatocytes, } \\
\text { cholangiocytes, ileum, } \\
\text { and proximal tubule of } \\
\text { kidney }\end{array}$ & $\begin{array}{l}\text { Heteromeric solute } \\
\text { carrier for facilitated } \\
\text { transport of bile salts } \\
\text { across basolateral } \\
\text { membrane of ileum. } \\
\text { Expression induced in } \\
\text { liver in cholestasis }\end{array}$ \\
\hline Organic cation transporter-1 & OCT-1 (SLC22A1) & 0 & $\begin{array}{l}\text { Basolateral Membrane of } \\
\text { hepatocytes }\end{array}$ & $\begin{array}{l}\text { Facilitates sodium- } \\
\text { independent hepatic } \\
\text { uptake of small organic } \\
\text { cations }\end{array}$ \\
\hline Organic anion transporter-2 & OAT-2 (SLC22A7) & 0 & $\begin{array}{l}\text { Basolateral membrane of } \\
\text { hepatocytes }\end{array}$ & $\begin{array}{l}\text { Facilitates sodium- } \\
\text { independent hepatic } \\
\text { uptake of drugs and } \\
\text { prostaglandins }\end{array}$ \\
\hline Multidrug-resistance-1 P-glycoprotein ${ }^{*}$ & MDR1 (ABCB1) & III & $\begin{array}{l}\text { Canalicular and } \\
\text { cholangiocyte apical } \\
\text { membrane }\end{array}$ & $\begin{array}{l}\text { ATP-dependent } \\
\text { excretion of various } \\
\text { organic cations, } \\
\text { xenobiotics, and } \\
\text { cytotoxins into bile; } \\
\text { barrier function in } \\
\text { cholangiocytes }\end{array}$ \\
\hline $\begin{array}{l}\text { Multidrug-resistance-3 P-glycoprotein } \\
\text { (phospholipid transporter) }\end{array}$ & MDR3 (ABCB4) & III & Canalicular membrane & $\begin{array}{l}\text { ATP-dependent } \\
\text { translocation of PC from } \\
\text { inner to outer leaflet of } \\
\text { membrane bilayer }\end{array}$ \\
\hline Bile salt export pump $*$ & BSEP (ABCB11) & III & Canalicular membrane & $\begin{array}{l}\text { ATP-dependent bile-salt } \\
\text { transport into bile; } \\
\text { stimulates BSDF }\end{array}$ \\
\hline $\begin{array}{l}\text { Multidrug-resistance-associated protein } 2 \\
\text { (canalicular multispecific organic-anion } \\
\text { transporter) }\end{array}$ & MRP2 (ABCC2) & III & Canalicular membrane & $\begin{array}{l}\text { Mediates ATP- } \\
\text { dependent multispecific } \\
\text { organic-anion transport } \\
\text { (e.g., bilirubin } \\
\text { diglucuronide) into bile; } \\
\text { contributes to bile salt- } \\
\text { independent bile flow by } \\
\text { GSH transport }\end{array}$ \\
\hline Multidrug-resistance-associated protein $3^{*}$ & MRP3 (ABCC3) & III & $\begin{array}{l}\text { Basolateral membrane of } \\
\text { hepatocytes and } \\
\text { cholangiocytes }\end{array}$ & $\begin{array}{l}\text { Expression induced in } \\
\text { cholestasis. Transports } \\
\text { bilirubin and bile acid } \\
\text { glucuronide conjugates }\end{array}$ \\
\hline Mulitdrug-resistance-associated protein $4^{*}$ & MRP4 (ABCC4) & III & $\begin{array}{l}\text { Basolateral membrane of } \\
\text { hepatocyte; apical } \\
\text { membrane of proximal } \\
\text { tubule of kidney }\end{array}$ & $\begin{array}{l}\text { Expression induced in } \\
\text { cholestasis transports } \\
\text { sulfated bile acid } \\
\text { conjugates and cyclic } \\
\text { nucleotides }\end{array}$ \\
\hline Mulitdrug-resistance-associated protein- $6{ }^{*}$ & MRP6 (ABCC6) & III & $\begin{array}{l}\text { Basolateral membrane of } \\
\text { hepatocyte }\end{array}$ & $\begin{array}{l}\text { ATP-dependent transport } \\
\text { of organic anions and } \\
\text { small peptides. } \\
\text { Mutations of MRP6 gene }\end{array}$ \\
\hline
\end{tabular}




\begin{tabular}{|c|c|c|c|c|}
\hline Name & Abbreviation (gene) & Phase & Location & Function \\
\hline & & & & $\begin{array}{l}\text { result in } \\
\text { pseudoxanthoma } \\
\text { elasticum }\end{array}$ \\
\hline Breast cancer resistance protein ${ }^{*}$ & $\mathrm{BCRP}$ (ABCG2) & III & $\begin{array}{l}\text { Canalicular membrane, } \\
\text { proximal tubule of } \\
\text { kidney }\end{array}$ & $\begin{array}{l}\text { ATP-dependent } \\
\text { multispecific drug } \\
\text { transporter, particularly } \\
\text { sulfate cong; } \\
\text { protoporphyrins are } \\
\text { endogenous substrate. } \\
\text { Substrate overlap with } \\
\text { MRP2 }\end{array}$ \\
\hline Sterolin- 1 and $2^{*}$ & $\mathrm{ABCG} / \mathrm{G} 8$ & III & $\begin{array}{l}\text { Canalicular membrane } \\
\text { and apical membrane of } \\
\text { intestine }\end{array}$ & $\begin{array}{l}\text { Heteromeric ATP- } \\
\text { dependent transporter for } \\
\text { cholesterol and plant } \\
\text { sterols (e.g. sitosterol) }\end{array}$ \\
\hline Multidrug and toxin extrusion protein 1 & MATE-1 (SLC47A1) & III & $\begin{array}{l}\text { Canalicular membrane } \\
\text { and brush border of } \\
\text { kidney }\end{array}$ & $\begin{array}{l}\text { Organic cation/H+ } \\
\text { exchanger extrudes } \\
\text { cationic xenobiotics }\end{array}$ \\
\hline
\end{tabular}

These transporters are members of the $\mathrm{ABC}$ superfamily. Table reproduced, with permission, from Ref. (79). 
Table 5

\section{OATP Substrates}

\begin{tabular}{|c|c|c|c|}
\hline OATP1A2 & OATP1B1 & OATP1B3 & OATP1CJ \\
\hline Hormones and conjugates & Hormones and conjugates & Hormones and conjugates & Hormones and conjugates \\
\hline Estradiol-17 P-glucuronide & Estradiol-17 (3-glucuronide) & Estradiol-17 (3-glucuronide) & Estradiol-17 (3-glucuronide) \\
\hline Estrone-3-sulfate & Estrone-3-sulfate & Estrone-3-sulfate & Estrone-3-sulfate \\
\hline DHEA-S & Thyroxine (T4) & DHEA-S & Thyroxine (T4) \\
\hline Reverse triiodothyronine (TT) & Triiodothyronine (T3) & Testosterone & Triiodothyronine (T3) \\
\hline Thyroxine (T4) & DHEA-S & Drags & Reverse triiodothyronine (rT3) \\
\hline Triiodothyronine (T3) & Prostaglandins & Atrasentan, Bosentan & Thyroxine sulfate (T4S) \\
\hline Prostaglandins & Prostaglandin Ei & Cefadroxil, Cefazolin & Others \\
\hline Prostaglandin $£ 2$ & Bile acids & Cephalexin, Digoxin & BSP \\
\hline Bile acids & Cholate & Enalapril, Fexofenadine & \\
\hline Cholate & Taurocholate & Fluvastatin, Gimatecan & \\
\hline Taurocholate & TUDCA & Lopinavir, Methotrexate & \\
\hline Glycocholate & Drugs & Demethylphalloin & \\
\hline TCDCA & Atorvastatin, Olmesartan & Paclitaxel, Docetaxel & \\
\hline TUDCA & Bosentan, Phalloidin & Methotrexate, Imatinib & \\
\hline Others & Caspofungin, Pitavastatin & Olmesartan, Phalloidin & \\
\hline DPDPE & Cefazolin, Pravastatin & Pitavastatin, Telmisartan & \\
\hline Drugs & Cerivastatin, Rapamycin & Rapamycin, Rifampicin & \\
\hline Acebutolol, Rosuvastatin & Darunavir, Rifampicin & Rosuvastatin, Valsartan & \\
\hline Atenolol, Pitavastatin & Enalapril, Rosuvastatin & SN-38 & \\
\hline Sotalol, Ouabain, Labetalol & Ezetimibe, Saquinavir & & \\
\hline Deltorphin n, Nadolol & Flavopiridol, SN-38 & & \\
\hline Ciprofloxacin, Talinolol & Fluvastatin, Temocapril & & \\
\hline Fexofenadine, Saquinavir & Gimatecan, Troglitazone & & \\
\hline Gatifloxacin, Darunavir & Lopinavir, Valsartan & & \\
\hline Levofloxacin & Methotrexate & & \\
\hline \multicolumn{4}{|l|}{ Imatinib, Methotrexate } \\
\hline OATP2A1 & OATP2B1 & OATP3A1 & OATP4A1 \\
\hline Prostaglandins & Hormones and conjugates & Hormones and conjugates & Hormones and conjugates \\
\hline Prostaglandin Ei & Estrone-3-sulfate & Thyroxine (T4) & Estradiol-17 (3-glucuronide) \\
\hline Prostaglandin E2 & DHEA-S & Estrone-3 -sulfate & Estrone-3-sulfate \\
\hline Prostaglandin $\mathrm{Fj}$, & Thyroxine (T4) & Prostaglandins & Thyroxine (T4) \\
\hline Prostaglandin $\mathrm{Hi}$ & Prostaglandins & Prostaglandin Ei & Triiodothyronine (T3) \\
\hline Prostaglandin D2 & Prostaglandin E2 & Prostaglandin E> & Reverse triiodothyronine (rT3 \\
\hline 8-Iso-prostaglandin F2 $<<$ & Drags & Prostaglandin F2a & Bile acids \\
\hline Others & Atorvastatin & Drugs & Taurocholate \\
\hline Thromboxane B2 & Bosentan & Deltorphin BQ-123 & Prostaglandins \\
\hline Drugs & Ezetimibe & Benzyl penicillin & Prostaglandin E > \\
\hline
\end{tabular}




\begin{tabular}{llll}
\hline \multicolumn{3}{c}{ Table 2 substrates transported by the deferent human OATPs } \\
\hline OATP1A2 & OATP1B1 & OATP1B3 & OATP1CJ \\
\hline Latanoprost & Fluvastatin & Others & Drugs \\
& Glibenclamide & Vasopressin & Benzylpenicillin \\
& Pitavastatin & Arachidonic acid & Unoprostone metabolite \\
& Pitavastatin & & \\
& Montelukast & & \\
& Rosuvastatin & & \\
& Talinolol & & \\
\hline
\end{tabular}

Abbreviations: BSP, bromosulfophthalein; DHEA-S, dehydroepiandrosterone sulfate; DPDPE, [D-penicillamine 2,5] enkephalin Reprinted, with permission, from Ref. (418). 